\title{
3 A striatal circuit balances learned fear in the presence and absence of sensory cues
}

4

5

6

$7 \quad$ Michael Kintscher $^{1}$, Olexiy Kochubey ${ }^{1}$, Ralf Schneggenburger ${ }^{1^{*}}$

8

9

10

$11{ }^{1}$ Laboratory for Synaptic Mechanisms, Brain Mind Institute, School of Life Science, Ecole

12 Polytechnique Fédérale de Lausanne (EPFL), Switzerland.

13

$14 *$ Corresponding author; e-mail ralf.schneggenburger@epfl.ch 
bioRxiv preprint doi: https://doi.org/10.1101/2021.12.09.471922; this version posted December $9,2021$. The copyright holder for this preprint (which was not certified by peer review) is the author/funder, who has granted bioRxiv a license to display the preprint in perpetuity. It is made available under aCC-BY-NC-ND 4.0 International license.

\section{Summary}

16 During fear learning, defensive behaviors need to be finely balanced, to allow animals to return to

17 normal behaviors after the termination of threat-indicating sensory cues. Nevertheless, the circuits

18 underlying such balancing are largely unknown. Here, we investigate the role of direct (D1R+) -

19 and indirect (Adora+) pathway neurons of the amygdala-striatal transition zone (AStria) in fear

20 learning. In-vivo $\mathrm{Ca}^{2+}$ imaging revealed that fear learning increased the responses of D1R+ AStria

21 neurons to an auditory CS, given that the animal moved. In Adora + neurons, fear learning also

22 induced a differential activity during freezing and movement, albeit with little influence of the CS.

23 In-vivo optogenetic silencing during the training day showed that plasticity in D1R+ AStria neurons

24 contributes to auditory-cued fear memories, whereas Adora+ neurons suppressed learned freezing

25 when no CS was present. Circuit tracing experiments identified cortical input structures to the

26 AStria, and recording of optogenetically-evoked EPSCs at the corresponding projection revealed

27 different forms of long-term plasticity at synapses onto D1R+ and Adora+ AStria neurons. Taken

28 together, direct- and indirect pathways neurons of the AStria show differential signs of in-vivo and

29 ex-vivo plasticity after fear learning, and balance defensive behaviors in the presence and absence

30 of aversively motivated sensory cues. 


\section{Introduction}

Fear learning is an evolutionary conserved behavior, critically important for animals to detect signs of threats in an ever-changing environment (Phelps and LeDoux, 2005; Janak and Tye, 2015). As such, fear learning is relevant for the survival of animals. Nevertheless, learned defensive behaviors need to be finely balanced, so that animals can return to their normal behaviours after cessation of threat-indicating sensory cues allows (Zanette et al., 2011). Furthermore, a pathological overexpression of defensive behaviours is a hallmark of several anxiety-related disorders in humans (Dunsmoor et al., 2011). Therefore, it is important to understand the neuronal circuits that balance the expression of learned defensive behaviors during and after the presence of threatpredicting sensory cues.

The study of the neuronal mechanisms of fear learning has been strongly facilitated by employing auditory-cued fear learning in model animals like rodents (Davis, 1992; LeDoux, 2000). In fear learning, subjects learn to associate an initially neutral auditory cue, the conditioned stimulus (CS), with an aversive or painful outcome like a footshock (the unconditioned stimulus, US). After associative learning, an animal will develop a defensive behavior when the CS is later presented alone (Fanselow, 2018). The defensive behavior that is mostly studied in the context of fear learning in rodents is behavioral arrest, also called freezing (Fanselow, 1994). Studies spanning several decades have firmly established that the amygdala has an important role in fear learning (see Davis, 1992; LeDoux, 2000; Duvarci and Paré, 2014; Tovote et al., 2015, for reviews). In the lateral (LA)- and basal amygdala (LA and BA respectively), auditory (CS) and somatosensory (US) information are integrated (Romanski et al., 1993; Quirk et al., 1995; Amano et al., 2011; Grewe et al., 2017), while the execution of learned freezing depends on a central amygdala to midbrain (periaqueductal gray) projection (LeDoux et al., 1988; Tovote et al., 2016). Nevertheless, given that freezing is a strong change in the behavioral pattern of an animal, it is likely that further neuronal circuits beyond the BLA - central amygdala - midbrain axis are involved in fear learning. 
The striatum is part of the basal ganglia motor system, a neuronal system with important roles in movement regulation (for reviews, see Hikosaka et al., 2000; Graybiel, 2005; Grillner et al., 2005; striatum are inhibitory projection neurons of two types: First, striato-nigral neurons that project in a direct pathway to output structures like the Substantia nigra pars reticularis (SNR) and others; these neurons selectively express D1-dopamine receptors. Second, striato-pallidal neurons which project in a more indirect pathway towards the basal ganglia output structures; these neurons selectively express D2-dopamine receptors, and also adenosine-2A receptors (Adora) (Gerfen et al., 1990; Schiffmann and Vanderhaeghen, 1993). Different sub-areas of the striatum have different roles in motor control and motor learning. The dorsal striatum is involved in the learning of motor sequences and in the selection of appropriate actions (Nelson and Kreitzer, 2014; Klaus et al., 2019), as well as in habit formation (Redgrave et al., 2010; Burguiere et al., 2015). The ventral striatum is implicated in reward-based learning (Humphries and Prescott, 2010; Cox and Witten, 2019). Recently, based on a systematic study of the cortical inputs to the mouse striatum, a further sub-area of the striatum was identified; a posterior area called tail striatum (Hintiryan et al., 2016; Hunnicutt et al., 2016). Interestingly, early in-vivo recordings in the LA have found US-responsive neurons also in the amygdala - striatal transition zone (AStria; Romanski et al., 1993). The AStria is adjacent to the LA and part of the tail striatum, and is similarly composed of D1R-expressing $(\mathrm{DR} 1+)$ and D2R- and adenosine-2A-receptor expressing (Adora+) neurons (Gangarossa et al., 2019). Nevertheless, a possible role of the AStria in fear learning has not been explored in a systematic fashion.

Here, we use in-vivo miniature microscope $\mathrm{Ca}^{2+}$ imaging, as well as in-vivo and ex-vivo optogenetic approaches and circuit tracing, to investigate the role of the two subtypes of AStria neurons in auditory-cued fear learning. 


\section{Results}

Fear learning causes interdependent coding for tones and movement in D1R+ AStria neurons

The AStria has been known to respond to auditory- and footshock stimulation (Romanski et al., 1993), and the tail striatum, which partially overlaps with the AStria, is innervated by dopamine axons which code for salient sensory stimuli (Menegas et al., 2018). Nevertheless, the in-vivo activity of AStria principal neurons themselves, and a possible role of this structure in fear learning, are unknown. We started by recording the activity of AStria neurons during a three-day fear learning paradigm (Figure 1A). To access the AStria, a brain area deeply nested in the posteriorventral striatum close to the basolateral - and central nuclei of the amygdala, we used miniaturemicroscope $\mathrm{Ca}^{2+}$ imaging (Figure 1B, C; Ghosh et al., 2011). The AStria, similar to other striatal circuits, contains D1-receptor expressing neurons, and D2-receptor, or Adora (adenosine2Areceptor)-expressing neurons (Gerfen et al., 1990; Gangarossa et al., 2019). Therefore, we used either $\mathrm{D} 1 \mathrm{R}^{\mathrm{Cre}}$, or Adora ${ }^{\mathrm{Cre}}$ mice, to unambiguously and separately target the expression of GCamp6m to each subpopulation of AStria neurons, combined with a Cre-dependent AAV vector

(Fig. 1B; Materials and Methods). In a first series of experiments (Figure 1, 2), D1R+ AStria neurons were continuously imaged during each day of the fear learning protocol (day 1 habituation; day 2 - training; day 3 - retrieval).

$\mathrm{D} 1 \mathrm{R}+$ AStria neurons showed, in general, a low frequency of $\mathrm{Ca}^{2+}$ events, especially on the habituation day $(\sim 0.01-0.02 \mathrm{~Hz}$ average frequency across the population; Figure 1D; see also

105 Figure 2T). On the habituation day of the fear learning protocol, 30-s CS stimulation blocks consisting of $7 \mathrm{kHz}$ tone beeps were applied (0.1s duration, repeated 30 times at $1 \mathrm{~Hz}$; see Figure 1 , responded, albeit with a low response fidelity (Figure 1D). During the training day, when each of the six CS blocks was followed by a 1-s footshock, many D1R+ AStria neurons robustly responded 
bioRxiv preprint doi: https://doi.org/10.1101/2021.12.09.471922; this version posted December $9,2021$. The copyright holder for this preprint (which was not certified by peer review) is the author/funder, who has granted bioRxiv a license to display the preprint in perpetuity. It is made available under aCC-BY-NC-ND 4.0 International license.

to the footshocks (Figure 1E, G, H). During the fear memory retrieval day, when the CS was presented alone in a different context, the activity of D1R + AStria neurons seemed to increase during the CS presentation (Figure 1F).

We performed a deconvolution analysis to derive the action potential (AP) activity of AStria neurons, taking into account the timing and amplitude of individual $\mathrm{Ca}^{2+}$ events (Yaksi and Friedrich, 2006). We then constructed peri-stimulus time histograms (PSTHs) and analyzed the significance of the responses with receiver-operated characteristic analysis (ROC; Britten et al., 1992); see Materials and Methods). About one-third of the imaged D1R+ AStria neurons showed a significant footshock response on day 2 (Figure 1G, H; ROC; see horizontal dashed line; 57 out of 167 neurons). Regarding the responses to individual tone beeps, the tone-driven activity of the most active D1R+ AStria neurons was clearly time-locked (see one example neuron in Figure 1I). ROC analysis showed that the number of neurons with a significant response to tones increased on day 2, and further increased on day 3 (Figure 1J, K; $\mathrm{p}=0.0001, \mathrm{Chi}^{2}$ test for trend; 184, 167 and 193 neurons were imaged on days $1,2,3$, respectively; $\mathrm{N}=8 \mathrm{D} 1 \mathrm{R}^{\mathrm{Cre}}$ mice). Averaging the PSTHs over all imaged neurons similarly suggested an increased tone response in the population of D1R+ neurons during fear learning (Figure 1L). Thus, in-vivo $\mathrm{Ca}^{2+}$ imaging showed that a significant fraction of D1R+ neurons in the AStria responds to footshocks, and furthermore, that D1R+ neurons increase their responsiveness to the CS.

During fear learning, rodents acquire a defensive behavior in response to a CS, in the form of freezing (LeDoux, 2000; Fanselow, 2018). In our experiments, freezing bouts of mice typically lasted a few seconds, and were interrupted by movement re-initiation (see e.g. Figure 1 D-F). Interestingly, visual inspection of $\mathrm{Ca}^{2+}$ population data suggested that $\mathrm{D} 1 \mathrm{R}+\mathrm{AStria}$ neurons were preferentially active during the CS blocks, and within these at times when the animal moved (see e.g. Figure 1F). We therefore first asked whether during the CS, transitions from freezing to 
movement would drive activity in D1R+ AStria neurons. PSTHs of the $\mathrm{Ca}^{2+}$ - events using the movement onset for the alignment revealed $\mathrm{Ca}^{2+}$ events in response to movement onset in a subpopulation of D1R+ AStria neurons, as analyzed during the CS epochs (Figure 1M; called "movement-ON" responses). ROC analysis showed that a significant movement-ON response was

140 present in $\sim 5 \%$ of the neurons on the habituation day; the percentage of responding neurons 141 increased to $\sim 20 \%$ on day 2 and 3 of the fear learning protocol (Figure $1 \mathrm{M}, \mathrm{N} ; \mathrm{p}=0.003$; Chi142 square test for trend). The average PSTH for the entire population of imaged D1R+ neurons also 143 indicated a stronger population $\mathrm{Ca}^{2+}$ response during day 2 and day 3 as compared to day 1 (Figure 144 1O). The response fidelity of individual neurons to movement onset showed a highly skewed 145 distribution, with significantly more non-zero values during the training day and the fear memory 146 retrieval day (Figure 1P, $\mathrm{p}<0.0001$, Kruskal-Wallis [KW] test followed by Dunn's multiple 147 comparisons $[\mathrm{MC}]$ test; Hab vs. Train, $\mathrm{p}=0.0002$; Hab vs. Ret, $\mathrm{p}<0.0001$ ). The estimated AP content, derived from the amplitude of the $\mathrm{Ca}^{2+}$ events (see Materials and Methods), was changed less substantially (Figure 1Q, $\mathrm{p}=0.0159, \mathrm{KW}$ test followed by Dunn's MC test; Train vs. Ret, $\mathrm{p}=$ 0.0155). We next analyzed the movement-ON responses in the absence of the CS, and found that these were substantially smaller than during the CS (Figure 1R, and Figure 1, Figure Suppl. 2).

152 Finally, when we aligned the $\mathrm{Ca}^{2+}$ event traces to freezing onset, we found a decreased $\mathrm{Ca}^{2+}$ event frequency (Figure 1, Figure Suppl. 3, 4). These experiments thus show that D1R+ AStria neurons increase their AP firing activity during the onset of movements after a period of immobility. Furthermore, the movement-ON responses were more pronounced during the CS than in the absence of a tone, and fear learning causes an increase in the number of D1R+ AStria neurons which showed movement-ON responses during the CS. sensory events (tones) in the AStria positively influence each other. We therefore next validated 161 whether the tone responses, which we had analyzed above irrespective of movement state (Figure 
1I-L), would depend in their intensity on the latter. This analysis showed that during fear retrieval, the response fidelity to tone beeps was significantly higher during movement than during freezing

the estimated AP content of the $\mathrm{Ca}^{2+}$ events was significantly higher during movement than during freezing (Figure 1S; $\mathrm{p}=0.0012, \mathrm{KW}$ test followed by Dunn's MC test; Train_Frz vs Train_Move, $\mathrm{p}$ $=0.0007)$. Therefore, similarly to the movement-ON responses which were potentiated by the presence of the CS, the response to auditory stimuli during the CS were potentiated during movement as compared to freezing. These results thus reveal an inter-dependency of CS-driven responses, and movement driven responses of D1R + AStria neurons.

173 For a more comprehensive analysis of how the $\mathrm{Ca}^{2+}$-event frequency depends on the movement state of the animal and on the presence or absence of a CS, we analyzed the average $\mathrm{Ca}^{2+}$ event frequency for the four combinations of movement states / tone presentations, for each day of the fear conditioning paradigm (Figure 1T). The data was significantly different across conditions ( $<<$

$1770.0001 ; \mathrm{KW}$ test). Pairwise comparisons showed that during day 1 (habituation), tones did not 178 change the activity of D1R+ during the movement state (Dunn's MC test; Mov_noCS_Hab vs. 179 Mov_CS_Hab, $\mathrm{p}=0.286$ ); we did not statistically compare the data involving the freezing state because of a paucity of freezing events on the habituation day.. On days 2 and days 3 of the fear learning paradigm, this pattern of activity of D1R+ neurons profoundly changed (Figure 1T). Thus,

182 the CS now induced a significant increase of activity in D1R+ neurons given that the animals 183 moved (Dunn's MC test; Mov_noCS_Train vs. Mov_CS_Train, p=0.0008), whereas in the freezing state, the CS induced a decreased activity (Dunn's MC test; Frz_noCS_Train vs. 
bioRxiv preprint doi: https://doi.org/10.1101/2021.12.09.471922; this version posted December $9,2021$. The copyright holder for this preprint (which was not certified by peer review) is the author/funder, who has granted bioRxiv a license to display the preprint in perpetuity. It is made available under aCC-BY-NC-ND 4.0 International license.

unchanged between movement and freezing state in the absence of a CS (Dunn's MC test, Frz_noCS_Train vs Mov_noCS_Train, $\mathrm{p}=0.99)$. This activity pattern was maintained during the fear memory retrieval day (day 3), when again the CS increased the activity of D1R+ neurons given that the mice moved (Dunn's MC test; Mov_noCS_Ret vs. Mov_CS_Ret, p=0.013), and the CS decreased their activity given that the mice froze (Dunn's MC test; Frz_noCS_Ret vs. Frz_CS_Ret; $\mathrm{p}<0.0001)$. Thus, the activity of the D1R + AStria neurons, during and after fear learning, is strongly increased when two conditions are met: Movement, and the presence of an aversivelymotivated sensory cue.

To determine the location of the imaged neurons and to compare them across mice, we semiautomatically aligned the center of the GRIN lens to a mouse brain atlas in each mouse, and generated a common cell map based on the cell coordinates relative to the lens center (Materials and Methods). This revealed a hotspot of footshock- and tone-responding D1R + neurons in the posterior - ventral region of the tail striatum medial to the LA (Figure 2A, B). D1R+ neurons with movement-ON responses (as measured during the retrieval day) were located in roughly the similar area, and were in addition found in more anterior regions $(\sim-1.0 \mathrm{~mm}$ AP; see Figure $2 \mathrm{C})$. An analysis of the overlap of neurons with the various types of responses showed that on the habituation day, neurons with responses to the CS, and to movement did not strongly overlap, and represented only a small proportion of the imaged neurons on this day (Figure 2D). During the training day of the fear learning protocol, the neurons with movement-ON responses increased in numbers and substantially overlapped with a larger sub-population of footshock-responsive neurons. On the retrieval day, the populations of both tone- and movement responders had increased, and their overlap became more substantial as compared to the habituation day (Figure 2D). Taken together, in-vivo $\mathrm{Ca}^{2+}$ imaging with a miniature microscope shows that a subpopulation of D1R+ AStria neurons, located in a posterior - ventral hotspot of the tail striatum, responds to 
bioRxiv preprint doi: https://doi.org/10.1101/2021.12.09.471922; this version posted December $9,2021$. The copyright holder for this preprint (which was not certified by peer review) is the author/funder, who has granted bioRxiv a license to display the preprint in perpetuity. It is made available under aCC-BY-NC-ND 4.0 International license.

213 footshocks. During the course of fear learning, these neurons increasingly code for an aversivelymotivated CS, and for freezing to movement transitions, in a highly inter-dependent fashion.

\section{Coding for footshocks and movement by Adora+ AStria neurons}

The other large population of principal neurons in the AStria are Adora+ neurons which, in analogy to other striatal areas, represent neurons of an "indirect" pathway through the basal ganglia (Gerfen et al., 1990; Gangarossa et al., 2019). We next investigated the in-vivo activity of this population of AStria neurons throughout the three-day fear learning protocol, using an Adora ${ }^{\mathrm{Cre}}$ mouse line to target the expression of GCamp6 to Adora+ neurons (Figure 3A-D; see Materials and Methods). More than half of the Adora+ AStria neurons responded to footshocks on day 2 (148/251 neurons;

223 Figure 3C; 3E-F). A smaller subpopulation $(\sim 10 \%)$ responded to individual tone beeps during the 224 CS (see Figure 3G for an example neuron). However, different from the D1R+ neurons, the percentage of tone (CS) - responsive neurons did not change during fear learning, and the population response to tones was modest throughout the three days of fear learning (Figure $3 \mathrm{H}$,

$227 \mathrm{Chi}^{2}$ test for trend, $\mathrm{p}=$ 0.698) (see also Figure 3I; Figure 3, Figure Suppl. 1). The response fidelity 228 was found to be different between days (Figure 3J, KW test, $\mathrm{p}=0.011$ ), with a slight decrease from 229 the training - to the retrieval day (Figure 3J, Dunn's MC test, $\mathrm{p}=0.012$ ), whereas the estimated AP 230 content of the $\mathrm{Ca}^{2+}$ events showed no change across the fear learning days (Figure $3 \mathrm{~K}, \mathrm{KW}$ test, $\mathrm{p}=$ 231 0.457). Thus, a subpopulation of Adora+ neurons in the AStria responds to footshocks, but the 232 number of Adora+ neurons that responds to tones (CS) is relatively small, and remains largely 233 unchanged during fear learning.

We next analyzed whether the activity of Adora+ AStria neurons was modulated by the movementor freezing state of the mice. We first restricted the analysis to the 30-s intervals of CS stimuli, and 237 found for these times that a sub-population of Adora+ neurons responded to movement onset 238 (Figure 3L). ROC showed that the number of Adora+ neurons with a movement response increased 
239 during day 2 and day 3 of the fear learning protocol (Figure $3 \mathrm{M}, \mathrm{p}=0.0016, \mathrm{Chi}^{2}$ test for trend).

240 The increase in movement-ON responses was also visible in PSTHs over the entire population of

241 imaged Adora+ neurons (Figure 3N). The response fidelity of movement-ON responses was

242 significantly different between the three days of the fear learning protocol, with a significant

243 increase between day 1 and day 2, and between day 2 and 3 (Figure 3O, p $<0.0001$, KW test

244 followed by Dunn's MC test; Hab_RF vs. Train_RF, p $<0.0001$; Hab_RF vs. Ret_RF, p $<0.0001$ ),

245 while the estimated AP content was unchanged (Figure 3P, $\mathrm{p}=0.281, \mathrm{KW}$ test). Corresponding to

246 an increased activity at movement onset, aligning the activity of Adora + AStria neurons to the

247 onset of freezing revealed a decreased activity (Figure 3, Figure Suppl. 2). Finally, an analysis of

248 the movement-ON responses of Adora+ neurons in the absence of a CS revealed only a small

249 response (Figure 3Q). Taken together, these experiments reveal that during the course of fear

250 learning, an increasing percentage of Adora + AStria neurons coded for movement onset.

252 We next analyzed whether vice-versa, the responses to tones might be modulated by the movement 253 state of the mice. Indeed, the response fidelity of Adora + neurons to tone beep stimulation was 254 significantly higher when the mice moved, as compared to when the mice froze, for all three days 255 of the fear learning protocol (Figure 3R, $\mathrm{p}<0.0001 \mathrm{KW}$ test followed by Dunn's MC test; Hab_Frz vs. Hab_Mov, $\mathrm{p}<0.0001$; Train_Frz vs. Train_Mov, $\mathrm{p}<0.0001$; Ret_Frz vs. Ret_Mov, $\mathrm{p}=$ thus show, similar to D1R+ AStria neurons, that the transient movement-ON activity of Adora+ neurons is potentiated in the presence of a CS, and, vice-versa, that tone-driven activity is potentiated by the movement of the mouse.

In order to assess the interaction between movement-state dependent activity, and CS-driven activity in Adora $^{+}$AStria neurons more comprehensively, we next analyzed their average $\mathrm{Ca}^{2+}$ 
event frequencies for the four combinations of movement states / tone representations, separately

266 for each day of the fear memory protocol (Figure 3S). A KW test showed that the $\mathrm{Ca}^{2+}$ event

267 frequencies differed across categories (Figure 3S; $p<0.0001$ ). Given that the mice moved, the

268 activity of Adora+ neurons was unchanged by a CS (Dunn's MC test, Mov_noCS_Hab vs.

269 Mov_CS_Hab, $p=0.99)$; as in the data for the D1R + neurons, the paucity of freezing events on the 270 habituation day did not allow us to make statistical comparisons with data obtained in the freezing

271 state on day 1. During the training day, the average $\mathrm{Ca}^{2+}$ event frequencies were $\sim 2$-fold lower

272 during the freezing state as compared to the movement state, both in the presence- and in the

273 absence of the CS (Figure 3S, Dunn's MC test, Frz_noCS_Train vs. Mov_noCS_Train, p $<0.0001$;

274 Frz_CS_Train vs. Mov_CS_Train, p < 0.0001). On the other hand, for a given movement or

275 freezing state, the presence or absence of the CS did not significantly change the activity of Adora+ 276 neurons, and the same was true for the retrieval day (Dunn's MC test, $\mathrm{p}>0.05$ for all comparisons, 277 see statistics Table for Figure 3 for exact $\mathrm{p}$ values). Furthermore, on the retrieval day, the activity 278 of Adora + neurons was again higher in the movement - than in the freezing state, both in the 279 absence and presence of the CS (Figure 3S, Dunn's MC test, Frz_noCS_Ret vs. Mov_noCS_Ret, p $280<0.0001 ;$ Frz_CS_Ret vs. Mov_CS_Ret, $p<0.0001)$. This analysis revealed that overall, the 281 neuronal representation of movement in Adora + AStria neurons is less influenced by fear learning than in the D1R+ neurons (Figure 1); the learning - induced activity change might consist in a downregulation of the activity of Adora+ neurons in the freezing state. Another difference to the $\mathrm{D} 1 \mathrm{R}+$ neurons is the finding that the CS did not have a primary importance for the activity of 285 Adora+ neurons (Figure 3S).

Taken together, a large population of Adora $^{+}$AStria neurons shows robust responses to footshocks. 
Adora $^{+}$neurons with such a response. The spatial distribution of footshock- and movement-ON

responding Adora+ neurons was broader, and the responding neurons were located more anteriorly

However, only a relatively small population of Adora+ AStria neurons maintained their activity in

Thus, in-vivo $\mathrm{Ca}^{2+}$ imaging reveals similarities, as well as differences in the response types and in the plasticity of responses during fear learning between D1R+ and Adora+ neurons in the AStria.

\section{D1R+ and Adora+ AStria neurons do not instruct freezing or movement}

302 Our in-vivo $\mathrm{Ca}^{2+}$ imaging experiments showed that the two main populations of AStria principal neurons code for footshocks, for the CS (in the case of the D1R+ neurons) and for movements, and

We next wished to investigate whether, and how D1R+ and Adora + AStria neurons might contribute to fear learning. A classical model of basal ganglia function postulate that $\mathrm{D} 1 \mathrm{R}+$ neurons in the direct pathway initiate movement, whereas Adora+ (or D2R+) neurons in the indirect pathway suppress movements (Kravitz et al., 2010; Nelson and Kreitzer, 2014; but see Klaus et al.,

AStria instructs an arrest of movement, or freezing, and vice-versa, that D1R + neurons might instruct movement re-initiation. We wished to test this hypothesis by optogenetic activation of either D1R+ - or Adora+ AStria neurons, at times when the mice are engaged in regular exploratory 
optogenetic stimuli were applied (50 light pulses of $1 \mathrm{~ms}$ length at $25 \mathrm{~Hz}$, repeated six times for each mouse). Optogenetic stimulation did not lead to changes in the movement activity of the

$\mathrm{D} 1 \mathrm{R}^{\mathrm{Cre}}$ mice, nor of the Adora ${ }^{\mathrm{Cre}}$ mice (Figure 4B, $\mathrm{C} ; \mathrm{N}=8$ and 8 mice, respectively; $\mathrm{p}=0.621$ and

Adora $^{+}$neurons is not sufficient to instruct freezing. Similarly, the activity of D1R + AStria neurons was not sufficient to modulate the movement activity of the mice, although we cannot exclude that a role of the $\mathrm{D} 1 \mathrm{R}+$ neurons was masked by ongoing movement.

\section{Plasticity of the D1R+ AStria network contributes to fear learning}

We found above that many D1R + AStria neurons respond to footshocks, and that following fear

learning, a partially overlapping population of $\mathrm{D} 1 \mathrm{R}^{+}$neurons becomes activated during the $\mathrm{CS}$, given that the animal moved at the same time (Figures 1,2). This suggests that fear learning drives plasticity in D1R+ AStria neurons. To investigate the role of this aversively-motived plasticity in fear learning, we next silenced the activity D1R+ AStria neurons during footshock presentation, and observed the effects of this manipulation on freezing behavior during the training day, and one day later during fear memory retrieval. The rationale behind this manipulation is that a strong activity of D1R + AStria neurons during the footshock (Figure 1) is likely a major drive for plasticity at input synapses onto these neurons, and that blocking the footshock-evoked activity likely also blocks plasticity.

For optogenetic silencing, we expressed the light-sensitive proton pump Archaerhodopsin (Arch;

338 Chow et al., 2010) in a Cre-dependent manner bilaterally in the AStria of D1R ${ }^{\text {Cre }}$ mice, and implanted optic fibers over each AStria (Figure 5A, B). Mice in a control group were injected with an AAV vector driving the expression of eGFP (Materials and Methods). Four weeks later, both 341 groups of mice underwent auditory-cued fear learning, and on the training day yellow laser light $342(561 \mathrm{~nm})$ was applied for 3s, starting 1s before each footshock, with the aim to suppress footshock- 
evoked activity in Arch-expressing D1R+ neurons (Figure 5C, D). We found in ex-vivo

experiments that yellow light strongly hyperpolarizes Arch-expressing D1R+ and Adora + AStria neurons, suppresses action potential (AP) firing, and does not evoke rebound APs when the light is switched off (Figure 5, Figure Suppl. 1).

During the habituation day of the fear learning protocol the mice showed little freezing, as expected

(Figure 5E). On the training day, during which mice received a 1s footshock after each tone block,

mice in both groups showed increasing levels of freezing throughout the training period (Figure 5F;

(Figure 5G, left, for the CS epochs; $p=0.386$; Figure 5G right, for the no-CS epochs; $p=0.249$; 2way RM-ANOVA). Thus, optogenetic silencing of the footshock-evoked activity of D1R+ AStria neurons did not change the freezing behavior of mice during the training day.

On the third day, we tested for fear memory retrieval by applying tone stimulation (CS) alone in a different context (see Materials and Methods). The time-resolved freezing analysis revealed a gradual increase of freezing levels when mice entered the conditioning chamber (to $\sim 20 \%$; Figure 5H, arrow). This baseline level of freezing has been observed before (Cummings and Clem, 2020), and likely represents a residual contextual fear memory, despite the change of the context between the training day and the retrieval day (see Materials and Methods). The 30-s CS blocks caused a vigorous increase in freezing in eGFP-expressing control mice, whereas in the Arch - expressing mice, the CS was less efficient in driving freezing (Fig. 5H, black- and green average traces, $\mathrm{N}=9$ eGFP- and $\mathrm{N}=11$ Arch -expressing D1R ${ }^{\mathrm{Cre}}$ mice). Averaging and statistical analysis revealed a significant difference in CS-driven freezing between control - and Arch -expressing D1R ${ }^{\mathrm{Cre}}$ mice (Figure 5I, closed data points; $\mathrm{p}=0.023$, two-way RM- ANOVA). On the other hand, freezing during the no - CS epochs was unchanged between the two groups (Figure 5I, open data points; $\mathrm{p}=$ 
bioRxiv preprint doi: https://doi.org/10.1101/2021.12.09.471922; this version posted December $9,2021$. The copyright holder for this preprint (which was not certified by peer review) is the author/funder, who has granted bioRxiv a license to display the preprint in perpetuity. It is made available under aCC-BY-NC-ND 4.0 International license.

0.541, 2-way RM-ANOVA). Thus, optogenetic inhibition of D1R+ AStria neurons during the aversive footshocks on the training day causes a diminished auditory-cued recall of fear memory one day later. This suggests that D1R+ AStria neurons contribute to auditory-cued fear learning.

\section{The Adora+ AStria network suppresses learned contextual fear}

We next investigated the role of footshock-driven activity in the Adora ${ }^{+}$AStria network for auditory-cued fear learning. For this, we silenced the activity of $\mathrm{Adora}^{+}$AStria neurons during the footshocks on the fear memory training day (Figure 6A-C), in an approach analogous to the one used above for the $\mathrm{D}_{1} \mathrm{R}^{+}$neurons. During the habituation day, we observed low freezing as expected (Figure 6D). On the training day, mice in both the eGFP - expressing control group and in the Arch group showed a gradual increase in freezing with successive CS - US pairings, interrupted by low freezing activity immediately following the footshocks, caused by running and escape behavior (Figure 6E). The analysis of freezing during the CS - and no-CS epochs revealed no difference in the freezing levels between the Arch - and the eGFP groups (Figure 6F; $p=0.375$ and $\mathrm{p}=0.196$ respectively; 2-way RM ANOVA). Thus, similar as for the $\mathrm{D}^{\mathrm{R}} \mathrm{R}^{+}$neurons, footshockdriven activity in Adora $^{+}$AStria neurons is not necessary for freezing behavior that develops during the training day.

On the fear memory recall day, the dynamics of the fear behavior differed between the eGFP and the Arch group (Fig. 6G, H). While the eGFP - expressing control mice displayed an increased freezing during each CS epoch followed by a relaxation to lower freezing levels, mice in the Arch group showed a delayed relaxation of freezing following the CS epochs (Figure 6G; black and red traces respectively). To quantify these effects, we analyzed the average time spent freezing during the CS and during a late no-CS epoch (Figure 6G, blue vertical bar, and grey stripes). This showed that freezing during the no-CS epochs was increased in the Arch group as compared to eGFP controls (Figure 6H, right; $p=0.041$; 2-way RM ANOVA), whereas freezing during the CS epochs 
was unchanged between the Arch - and the control group (Figure 6H, left; $\mathrm{p}=0.548$; 2-way RMANOVA). Thus, surprisingly, footshock - driven plasticity of Adora+ AStria neurons causes a suppression of learned freezing in the absence of the auditory cue during fear memory retrieval. This finding, together with the results obtained from silencing $\mathrm{D} 1 \mathrm{R}^{+}$AStria neurons (see above), establishes separate, but functionally synergistic roles of the direct- and indirect pathway neurons of the AStria in fear learning. In fact, the action of both sub-systems together increases the difference between the strength of a defensive behavior in the presence, and absence of a learned aversive sensory cue.

\section{Brain-wide screening of presynaptic inputs to the AStria}

405 Our in-vivo $\mathrm{Ca}^{2+}$ imaging and optogenetic experiments have revealed a differential role of D1R+ 406 and Adora + AStria neurons in auditory-cued fear learning. To start investigating the role of synaptic afferents to AStria neurons in these plasticity processes, we next used monosynaptic retrograde rabies virus tracing to identify the presynaptic neuron pools that provide input to $\mathrm{D} 1 \mathrm{R}^{+}$ and Adora $^{+}$neurons in the AStria (Fig. 7A; Wickersham et al., 2007; Wall et al., 2013); see Materials and Methods).

412 Mice were injected into the AStria of either $\mathrm{D} 1 \mathrm{R}^{\mathrm{Cre}}$, or Adora ${ }^{\mathrm{Cre}}$ mice with a mix of AAV-helper viruses to render subsets of Cre-expressing neurons competent for EnvA-pseudotyped rabies virus uptake, and to drive eGFP expression (Wickersham et al., 2007); see Materials and Methods for the specific viruses). Three weeks later, a pseudotyped delta-G rabies vector driving the expression of dsRed was injected at the same coordinates. In this way, starter cells at the injection site in the

417 AStria could be identified by GFP- and dsRed co-labelling (red) (Fig. 7B, cells appearing yellow in the overlay); retrogradely-labelled neurons were identified based on their single dsRed expression. The analysis of trans-synaptically labelled neurons was restricted to dsRed positive neurons outside of the striatum. We placed all presynaptic neurons found in $\mathrm{N}=2 \mathrm{D} 1 \mathrm{R}^{\mathrm{Cre}}$ and $\mathrm{N}=2$ Adora ${ }^{\mathrm{Cre}}$ mice 
421 into brain-wide models, with cells from the two mice arbitrarily positioned on different brain sides

422 (Figure 7E, F; red and blue dots, respectively), and analyzed the number and density of back-

423 labelled neurons in each brain area. In both $\mathrm{D} 1 \mathrm{R}^{\mathrm{Cre}}$ and Adora ${ }^{\mathrm{Cre}}$ mice, we found the highest

424 number and density of dsRed-expressing cells in the dorsal (granular and dysgranular) part of the

425 posterior insular cortex ( $\mathrm{pInsCx}$ ), and in the adjacent ventral part of the secondary somatosensory

426 cortex (S2; see also Figure 7 Table Suppl. 1 for a list of all brain structures with detected

427 presynaptic neurons)(Figure 7C, D, G, H). A sizeable number of back-labelled neurons was also

428 found in various areas of the primary somatosensory cortex (S1), in the globus pallidus externa

429 (GPe), and in the thalamic parafascicular nucleus (PF; Figure 7C, D, G, H; Figure 7, Figure Suppl.

430 1). The GPe and the PF stood out by having high densities of presynaptic neurons to both D1R- and

431 Adora-MSNs, even though their absolute numbers were not large (Figure 7G, H; black bars).

432 Although the brain-wide distribution of presynaptic input neurons to $\mathrm{D}^{+} \mathrm{R}^{+}$and $\mathrm{Adora}^{+} \mathrm{AStria}$

433 neurons was overall similar, we detected differences on a finer scale (see Figure 7, Figure Suppl.

434 2). Because $\mathrm{S} 2$ and the pInsCx provided the largest number of input neurons to the AStria, we

435 analyzed the anterior - posterior localization of these neurons. This showed that presynaptic

436 neurons in the $\mathrm{S} 2$ and $\mathrm{pInsCx}$ that provide input to $\mathrm{D}^{+} \mathrm{R}^{+}$AStria neurons have the highest density at

437 bregma levels of $\sim 0$, whereas neurons in $\mathrm{S} 2$ and $\mathrm{pInsCx}$ that provide input to Adora $+\mathrm{AStria}$

438 neurons are located at somewhat more posterior positions (Figure 7I, J). Taken together, rabies-

439 virus mediated circuit tracing shows that the AStria receives its main cortical input from the S2 and

440 the pInsCx, followed by primary somatosensory areas. Thalamic areas like PF and VPM, and basal

441 ganglia like GPe, as well as limbic areas like CeA and BLA for the Adora+ neurons, also contain

442 sizeable numbers of neurons that provide input to the AStria.

444 The posterior insular cortex provides strong excitatory drive to the AStria

445 Retrograde rabies-virus labelling showed that the $\mathrm{pInsCx}$, and the adjacent ventral S2 provide a

446 primary cortical input to the AStria (Figure 7). We next wished to functionally validate the putative 
447

448

449

450

451

452

453

454

455

456

457

458

459

460

461

462

463

464

465

466

467

468

469

470

471

472

connection from the $\mathrm{pInsCx}$ to the AStria, using optogenetically-assisted circuit-mapping (Petreanu et al., 2007; Little and Carter, 2013). For this, we injected a viral vector driving the expression of Chronos (AAV8:hSyn:Chronos-eGFP; Klapoetke et al., 2014) into the pInsCx (Fig. 8A, B). We used D1 $\mathrm{R}^{\mathrm{Cre}} \mathrm{x}$ tdTomato, or Adora ${ }^{\mathrm{Cre}} \mathrm{x}$ tdTomato mice, to target patch clamp recordings to either of the two principle neuron populations in the AStria four weeks later. Blue light pulses (1 ms) at maximal light intensity evoked robust optogenetically-evoked EPSCs of $8.8 \pm 1.6 \mathrm{nA}$ in D1R+ AStria neurons $(n=12$ cells $)$, and of $2.5 \pm 0.5 \mathrm{nA}$ in Adora + AStria neurons $(n=19 ; \mathrm{p}=0.002$, Mann Whitney test; Figure 8C-E). At both connections, gradually increasing the stimulus light intensity led to a smooth increase of the EPSC amplitude, which shows that many axons from pInsCx neurons converge onto each type of AStria neuron (Figure 8C, D). With high light intensities, the optogenetically-evoked EPSC amplitudes saturated, suggesting that a maximal number of input axons was activated (Figure 8C, D). The paired-pulse ratio (PPR) did not differ between the two neuron types, whereas the excitation/inhibition (E/I) ratio was significantly smaller in Adora+ AStria neurons as compared to D1R+ neurons (Figure 8, Figure Suppl. 1; PPR: $\mathrm{p}$ $=0.208$, unpaired t-test; E/I: $\mathrm{p}=0.0054$, Mann Whitney test). Taken together, optogeneticallyassisted circuit mapping shows that both D1R+ and Adora+ neurons of the AStria receive robust excitatory inputs from neurons in the pInsCx. This, together with the monosynaptic rabies tracing (Figure 7), identifies the pInsCx, together with the ventral S2, as main cortical input area to the AStria.

\section{Fear learning causes opposite plasticity at synapses on D1R+ and Adora+ AStria neurons}

The in-vivo imaging data showed that many D1R+ and Adora + AStria neurons robustly respond to footshocks, and that during the course of fear learning, subpopulations of these neurons become responsive to the CS and to movement-ON transitions (Figures 1-3). Furthermore, silencing each AStria neuron population during the footshocks led to characteristic temporal changes in defensive behavior during the fear memory retrieval day (Figures 5,6). These findings suggest that plasticity 
473 might take place at the synapses that drive D1R + and Adora + AStria neurons. We therefore tested

474 whether fear learning induces plasticity at the glutamatergic synapse from the pInsCx to the D1R+ -

475 and Adora+ AStria neurons. Measurements of the AMPA/NMDA ratio can be used as an assay for

476 postsynaptic forms of long-term plasticity following experience-dependent learning (Yin et al.,

477 2009; Shan et al., 2014; Rothwell et al., 2015). Similarly, changes in paired-pulse ratio can be used

478 to test whether presynaptic forms of long-term plasticity have occurred (Lucas et al., 2016). Thus,

479 we used optogenetically-assisted circuit mapping to ask whether fear learning induces signs of

480 plasticity at the synapses from the pInsCx to either D1R+ or Adora+ AStria neurons.

482 We injected $\mathrm{D} 1 \mathrm{R}^{\mathrm{Cre}} \mathrm{x}$ tdTomato mice, and in a separate series of experiments Adora ${ }^{\mathrm{Cre}} \mathrm{x}$ tdTomato 483 mice, with an AAV vector to drive the expression of Chronos in neurons of the pInsCx. Three to 484 four weeks later, the mice were subjected to auditory-cued fear learning (Figure 8F). Following the fear-memory retrieval session on day 3 , which was performed to validate that mice had group; Figure 8F). Optogenetically evoked EPSCs at the pInsCx to $\mathrm{D}^{+} \mathrm{R}^{+}$AStria connection showed a significant increase of the AMPA/NMDA ratio in the CS + US group, as compared to the CS-only group (Figure 8G; $\mathrm{p}=0.001$, unpaired t-test), suggesting that at this connection, a unchanged (Figure 8G; $p=0.974$, unpaired t-test; Figure 8, Figure Suppl. 2). Conversely, at the 493 pInsCx to Adora + AStria connection, the AMPA/NMDA ratio was unchanged (Figure $8 \mathrm{H}, \mathrm{p}=$ 494 0.162, unpaired t-test; see also Figure 8, Figure Suppl. 3), but interestingly, the paired-pulse ratio was increased in the CS+US group as compared to the CS-only group (Figure $8 \mathrm{H} ; \mathrm{p}=0.001$, Mann Whitney test). The latter finding suggests that fear learning might induce a presynaptic form of LTD at the pInsCx to Adora+ AStria synapse. Thus, auditory-cued fear learning drives long-term 498 plasticity with opposite directions at cortical synapses onto $\mathrm{D}^{+} \mathrm{R}^{+}$and $\mathrm{Adora}^{+}$neurons in the AStria. 
499

500

501

502

503

504

505

506

507

508

509

510

511

512

513

514

515

516

517

518

519

520

521

522

523

524

These differential forms of long-term plasticity might contribute to the complementary roles which the two types of AStria neurons play during fear learning.

\section{Discussion}

We describe a role of a posterior striatal circuit, the amygdala-striatal transition zone (AStria) in the formation of auditory-cued fear memories. In-vivo $\mathrm{Ca}^{2+}$-imaging revealed that sub-populations of $\mathrm{D} 1 \mathrm{R}+$ and Adora+ neurons in the AStria respond to tones, footshock stimulation, and the movement state of the animal. During the course of fear learning both neuron populations increasingly code for movement-ON transitions, and D1R+ neurons increased their responsiveness to the CS, showing that neuronal coding in the AStria is changed in a plastic manner after fear learning. In-vivo optogenetic silencing during the footshock presentations revealed a differential role of each subsystem in fear learning. Whereas plasticity in the D1R+ neurons contributes to the retrieval of a cue-dependent fear memory, the Adora+ network acts to suppress freezing in the absence of a sensory cue. We used molecularly defined retrograde tracing approaches and ex-vivo optogenetic circuit mapping to study the role of defined synaptic afferents onto each neuron class of the AStria in fear learning. We found that neurons in the dorsal pInsCx, and in the adjacent ventral S2 provide the main cortical input to AStria neurons. Measurements of optogeneticallyevoked EPSCs at the synapses arising from the pInsCx showed that fear learning induced opposite forms of long-term plasticity at synapses onto D1R+ versus Adora + AStria neurons. Taken together, we find that direct and indirect pathway neurons in the AStria balance the amount of learned fear behavior in the presence, and absence of relevant sensory cues.

\section{Plasticity of in-vivo responses of AStria neurons}

In-vivo $\mathrm{Ca}^{2+}$ imaging with a miniature microscope in freely moving mice showed commonalities and differences in the in-vivo activity of D1R+ and Adora+ neurons of the AStria. In both neuron 
types, footshocks evoked robust responses; the percentage of footshock-activated neurons was higher in Adora + than in D1R+ neurons. Following fear learning, the number of D1R + neurons that coded for the CS as well as for movement-ON transitions increased. Intriguingly, the responses to the sensory stimulus (CS) and to the movement-state change potentiated each other, such that

529 following fear learning, D1R+ neurons responded best when the animals moved in the presence of 530 a CS (Figure 1T). Thus, the activity of D1R+ AStria neurons following fear learning might be seen 531 as a signal of heightened alertness, given that under natural conditions, the decision to move in the 532 presence of an aversive CS might expose the animal to harm. Movement - correlated activity has

533 been observed in striatal neurons (Markowitz et al., 2018), as well as in several types of sensory

534 cortices and also in a more brain-wide fashion (Niell and Stryker, 2010; Keller et al., 2012; Stringer 535 et al., 2019). Regarding the pInsCx, which as we show sends strong afferents to the AStria (Figure $5367,8)$, previous studies have shown somatosensory and auditory processing in this cortical area 537 (Rodgers et al., 2008; Sawatari et al., 2011; Gogolla et al., 2014), as well as state-dependent 538 signaling relating to physiological needs and to the aversive state of the animal (Livneh et al., 2017; 539 Gehrlach et al., 2019), although movement - ON responses have not been reported for the pInsCx.

540 Nevertheless, it is possible that the CS- and movement - state dependent activity of D1R+ neurons 541 is computed in an upstream cortical area like the $\mathrm{pInsCx}$ and/or the ventral S2. Alternatively, movement-ON activity, and auditory (CS) information could be conveyed to D1R+ AStria neurons

543 from largely separate brain areas via different synaptic inputs, and summation of EPSPs would then 544 lead to a positive interdependence between both type of inputs. For example, based on previous 545 anatomical evidence and evidence from in-vivo stimulation experiments, it seems likely that the 546 auditory thalamus provides input to the AStria (Rogan and LeDoux, 1995; Polepalli et al., 2020).

547 Thus, the possibility that D1R + AStria neurons extract information about the movement state and a 548 CS via distinct excitatory inputs which positively interfere with each other, could be investigated in 549 future studies. 
The in-vivo activity of Adora+ AStria neurons and their changes after fear learning were different in several respects from the one of D1R+ neurons. Fear learning did not induce a measurable plasticity of the CS representation in Adora+ neurons (Figure 3). Furthermore, in Adora+ neurons fear learning induced a difference in neuronal activity between the freezing - and the movement state, but this difference was mainly caused by a reduced activity during the freezing state, apparent both during the CS and in the absence of the CS (Figure 3S). This activity pattern was quite

557 different from the one of $\mathrm{D} 1 \mathrm{R}+$ neurons which showed an increased activity given that the animal moved in the presence of a CS (see above). Thus, in-vivo $\mathrm{Ca}^{2+}$ imaging showed that population coding of the CS and of movement states were differentially modulated by fear learning in the 560 direct-, and indirect pathway neurons of the AStria.

\section{Differential roles of direct- and indirect pathway AStria neurons in fear learning}

To investigate the role of the AStria in fear learning, we optogenetically inhibited D1R+ and footshocks on the fear learning training day (Figures 1,3). Therefore, silencing the footshock driven activity of these neurons should reduce an important driving force for aversively motivated plasticity. This manipulation, applied to D1R+ neurons, led to a reduced amount of CS-driven

571 AStria neurons, and their contribution to an auditory-cued fear memory, can be seen as analogous

572 to the role of LA principal neurons in fear learning. Thus, D1R+ neurons integrate US- and CS-

573 information (Figure 1), similar to LA neurons (LeDoux et al., 1990; Romanski et al., 1993).

574 Furthermore, D1R+ AStria neuron develop a sensitivity to the CS which is, in principle, similar to 575 the enhanced CS responses in the LA (Quirk et al., 1995; Amano et al., 2011; Grewe et al., 2017; 576 Zhang and Li, 2018), with the difference that the D1R+ AStria neuronal CS response is coupled to 
577 the movement state of the animal, whereas movement -onset responses were not reported in the

578 above studies in the LA (note that more recent studies in the BA revealed additional coding for

579 behavioral states and behavioral decisions; (Kyriazi et al., 2018; Gründemann et al., 2019). Finally,

$580 \mathrm{D} 1 \mathrm{R}+$ AStria neurons show signs of postsynaptic LTP at a major cortical input after fear learning

581 (Figure 8); signs for postsynaptic LTP have been observed in LA- and/or BA neurons following

582 fear learning, when studying electrically stimulated thalamic - and cortical inputs (McKernan and

583 Shinnick-Gallagher, 1997; Tsvetkov et al., 2002; Rumpel et al., 2005; Namburi et al., 2015). Thus,

$584 \mathrm{D} 1 \mathrm{R}+$ AStria neurons contribute to the formation of an auditory - cue dependent fear memory, in

585 an analogous fashion as LA principal neurons. One difference between both systems are, however,

586 their different output structures: While LA neurons signal to the BA- and to the central amygdala

587 (see Duvarci and Paré, 2014 for a review), our preliminary evidence suggests that D1R+ AStria

588 neurons have a classical basal ganglia output to the Substantia nigra pars reticularis (Figure 8,

589 Figure Suppl. 4). Therefore, future work could investigate how D1R+ AStria neurons influence

590 downstream structures of the basal ganglia (Roseberry and Kreitzer, 2017), and how these are

591 ultimately merged with the amygdala - periaqueductal gray pathway (Tovote et al., 2016), to exert

592 an integrated control of fear behavior.

593

594 Intriguingly, optogenetic silencing experiments revealed a different role for the Adora + AStria 595 neurons in fear learning. Silencing the Adora+ neurons during the footshock led to an increased 596 freezing, given that no CS was present during fear memory retrieval (Figure 6). This suggests that 597 following fear learning, footshock-driven plasticity of the Adora+ AStria neurons normally 598 suppresses freezing when no threat - predicting sensory cues are present. The differential role of 599 the D1R+ - and Adora+ AStria subsystems in fear memory is further apparent by the different types 600 of CS coding in-vivo, and by the different signs of long-term plasticity at the cortical input synapses 601 to each neuronal subsystem. We currently have only little direct evidence how the in-vivo activity 602 of Adora + neurons in the AStria relates to defensive behavior. Nevertheless, our data is consistent 
with the idea that a decreased activity after fear learning, given that the animal freezes (Figure 3S),

604

605

606

607

608

609

610

611

612

613

614

615

616

617

618

619

620

621

622

623

624

625

626

627

signals the absence of danger after the cessation of the learned CS, and might then "liberate" the decision to move. Consistent with a model of a decreased activity of Adora+ neurons is the observation that the $\mathrm{pInsCx}$ to Adora+ AStria synapse shows a presynaptic form of LTD after fear learning (Figure 8). Interestingly, the finding that the AStria Adora+ subsystem signals the absence of danger, and therefore safety, resembles previous work which has correlated the in-vivo activity of AStria neurons with safety learning, albeit without distinguishing between direct- and indirect pathway neurons (Rogan et al., 2005). Taken together, our study shows differential roles for the direct and indirect pathway neurons in the AStria: D1R+ neurons signal danger given that the animal moves during a CS, whereas Adora+ neurons signal safety in the absence of a learned CS.

Subtle, but functionally important differences in the brain areas that project to D1R+ versus Adora+ AStria neurons might determine their different in-vivo responses, and the different role each type of AStria neuron plays during fear learning. In addition, the different responses might also be caused by different effects of dopamine in D1R+ versus Adora+ neurons (Gerfen et al., 1990; Hjorth et al., 2020). Interestingly, recent work has shown that a specific class of midbrain dopamine neurons innervates the posterior tail striatum, and that these dopamine projections are activated by salient, but not by rewarding stimuli (Menegas et al., 2015; Menegas et al., 2018). Although footshock stimuli were not tested in these studies, it is possible that aversive stimuli would similarly cause the release of dopamine in the AStria. Indeed, footshock-driven activity of VTA dopamine neurons that project to the BA was recently shown to contribute to fear learning; furthermore, the same study has obtained anatomical evidence for a projection of VTA DAT + neurons to the AStria (Tang et al., 2020). Therefore, dopamine signaling in the AStria might contribute to the differential plasticity observed here for the two types of AStria neurons, and to their roles in auditory-cued fear learning. 
628 Our optogenetic activation experiments, performed in the naive state of the mice, did not reveal

629 significant effects on the movement - or freezing behavior of mice (Figure 4). Earlier work has

630 shown that bilateral stimulation of D1R + neurons in the dorsomedial striatum causes an increase in

631 movement, whereas activation of D2R+ neurons increases freezing (Kravitz et al., 2010). On the

632 other hand, optogenetic activation of neurons in a more posterior region of the dorsal striatum did

633 not induce movement, but modulated the performance in an auditory learning task (Guo et al.,

634 2018). Our findings in the likewise posteriorly located AStria agree with Guo et al. (2018),

635 showing that neuronal activity in the AStria is not sufficient for driving movement or freezing

636 directly. Rather, the activity of AStria neurons, after plasticity induced by fear learning, seems to

637 play a role during the retrieval of associative, sensory-cue driven fear memories.

\section{Conclusion}

640 In summary, we show a role for the AStria in temporally balancing the expression of learned fear in

641 the presence, and absence of aversive sensory cues, thus balancing cue-specific reaction with a

642 more generalized fear response. Adaptive fear discrimination is critically important for animal

643 survival, but is dys-regulated in anxiety disorders (Sangha et al., 2020). Indeed, it was found that

644 during fear generalization, PTSD patients exhibited stronger responses in the striatum, amygdala

645 and insular cortex amongst other areas (Morey et al., 2020). Because fear expression in the absence

646 of aversive sensory cues is downregulated by Adora+ neurons in the AStria, it is an intriguing

647 possibility to harness the differential pharmacology of direct- and indirect pathway neurons

648 together with in-vivo manipulations of plasticity (Creed et al., 2015), in an attempt to mitigate the 649 effects of fear generalization.

650

651

652

653 
654

655

656

657

658

659

660

661

662

663

664

665

666

667

668

669

670

671

672

673

674

675

676

677

678

679

\section{Methods}

Animals

All experimental procedures with laboratory animals (Mus musculus) were performed under authorizations for animal experimentation by the veterinary office of the Canton of Vaud, Switzerland (authorizations VD3274 and VD3518). The following mouse lines were used: 1) D1R ${ }^{\text {Cre }}$ (B6.129-Tg(Drd1 a-cre)EY217Gsat/Mmucd; see Gong et al., 2007; MMRRC: 030778UCD; 2) Adora ${ }^{\text {Cre }}$ (B6.FVB(Cg)-Tg(Adora2a-cre)KG139Gsat/Mmucd; see Gerfen et al., 2013; MMRRC: 036158-UCD; 3) Cre-dependent tdTomato reporter line/Ai14 (B6.CgGt(ROSA)26Sor<tm9(CAG-tdTomato)Hze>/J; JAX stock \#007909; Madisen et al., 2010). All animals used for experiments were male mice without prior contact to female conspecifics. Animals were group-housed under a 12/12 h light/dark cycle with food and water ad libitum until separated into single cages one day before surgery. For behavioral experiments (Figure 5, 6), mice from 1-2 litters were randomly assigned to control - (GFP - expressing) or effect group (Archexpressing).

\section{Viral vectors and injection coordinates}

For in-vivo $\mathrm{Ca}^{2+}$-imaging experiments (Figures 1 -3), we injected AAV1:hSyn:FLEX:GCaMP6m (200nl; $6.8 \times 10^{12} \mathrm{vg}$ [vector genomes]/ml; cat. 290-1; viral vector facility University of Zürich, Switzerland), into the left AStria of $\mathrm{D} 1 \mathrm{R}^{\mathrm{Cre}}$ or Adora ${ }^{\mathrm{Cre}}$ mice, using the following coordinates: medio-lateral (ML) $3.2 \mathrm{~mm}$; anterior-posterior (AP) -0.8 to -1.0 mm; dorso-ventral (DV) -4.3 mm (from bregma). For the optogenetic activation experiments (Figures 4), we injected AAV1:hSyn:FLEX:Chronos-eGFP (200nl; 2.80x10 $12 \mathrm{vg} / \mathrm{ml}$; University of North Carolina - UNC vector core, Chapel Hill, NC, USA) bi-laterally into the AStria of $\mathrm{D} 1 \mathrm{R}^{\mathrm{Cre}}$ or Adora ${ }^{\mathrm{Cre}}$ mice. For the optogenetic inhibition experiments (Figures 5, 6), we injected AAV1:CAG:FLEX:Arch-eGFP (200nl; $2.05 \times 10^{12} \mathrm{vg} / \mathrm{ml}$; UNC vector core) bi-laterally into the AStria of $\mathrm{D} 1 \mathrm{R}^{\mathrm{Cre}}$ or Adora ${ }^{\mathrm{Cre}}$ mice. In earlier experiments AAV1:CBA:FLEX:Arch-eGFP (200nl;5.48x10 12 vg/ml; AV-1-PV2432; 
680 University of Pennsylvania vector core, Philadelphia, PA, USA) was used; both Arch constructs

681 correspond to the initially described "Arch" (Chow et al., 2010). Mice in the control group received

684 For the ex-vivo optogenetically-assisted circuit-mapping experiments (Figure 8), D1R ${ }^{\mathrm{Cre}} \mathrm{x}$

685 tdTomato mice, or Adora ${ }^{\mathrm{Cre}} \mathrm{x}$ tdTomato mice were injected unilaterally into the posterior insular

686 cortex with AAV8:hSyn:Chronos-eGFP (200nl; $6.5 \times 10^{12} \mathrm{vg} / \mathrm{ml}$; UNC vector core), at the following

687 stereotaxic coordinates: ML $4.2 \mathrm{~mm}$; AP -0.55 mm, DV -3.8 mm (from bregma). In some

688 experiments, D1R ${ }^{\mathrm{Cre}}$ - or Adora ${ }^{\mathrm{Cre}}$ mice were used, and an AAV8:CAG:FLEX:tdTomato (200nl;

$6896.5 \times 1012 \mathrm{vg} / \mathrm{ml}$; UNC vector core) was additionally injected into the AStria (coordinates as above), 690 to visualize $\mathrm{D} 1 \mathrm{R}^{\mathrm{Cre}}$ - or Adora ${ }^{\mathrm{Cre}}$ - positive neurons for subsequent patch-clamp recordings.

691

692

Surgery for virus injection, GRIN lens and optical fiber implantation

693 The surgery for stereotactic injection of all viral vectors and fiber implantation was performed 694 using male mice of the indicated genotype, of 42-56 days of age. The procedures were similar as 695 described in (Tang et al., 2020). In short, a mouse was anesthetized with isoflurane (induction with $6963 \%$, maintained at 1\%) and the head was fixed in a Model 940 stereotactic injection frame (David 697 Kopf Instruments, Tujunga, CA, USA) using non-rupture ear bars (Zygoma Ear cups, Kopf 698 Instruments Model 921). Local anesthesia was applied subcutaneously using a mix (50 $\mu 1)$ of 699 lidocaine $(1 \mathrm{mg} / \mathrm{ml})$, bupivacaine $(1.25 \mathrm{mg} / \mathrm{ml})$ and epinephrine $(0.625 \mu \mathrm{g} / \mathrm{ml})$. After the skull was 700 exposed, small craniotomies were drilled above the indicated coordinates for injection and fiber 701 insertion. For fiber implantation, an additional craniotomy was made close to Lambda to insert an anchoring micro screw. Virus suspension was injected using pulled glass pipettes and an oil hydraulic micromanipulator (MO-10, Narishige, Tokyo, Japan) with an injection speed of $\sim 60$ nl/min. For in-vivo $\mathrm{Ca}^{2+}$-imaging (Figures 1 - 3) or optogenetic experiments (Figures 4 - 6), a GRIN lens $\left(600 \mu \mathrm{m} / 7.3 \mathrm{~mm}\right.$ ProView ${ }^{\mathrm{TM}}$ integrated lenses; cat. 1050-004413; Inscopix Inc, Palo Alto, 
CA, USA) or custom made optical fiber implants, respectively, were implanted $350 \mu \mathrm{m}$ above the virus injection site(s). Prior to GRIN lens implantation, a 25G medical injection needle was slowly inserted and retracted to facilitate the later insertion of the blunt-ended lens. To reduce deformation of brain tissue due to continuous vertical pressure, we lowered the GRIN lens with alternating down $(150 \mu \mathrm{m})$ and up $(50 \mu \mathrm{m})$ movements until the last $200 \mu \mathrm{m}$ before the final position. Optic fiber implants for in-vivo optogenetic experiments were custom-made of a $200 \mu \mathrm{m}$ core / $0.39 \mathrm{NA} /$ $230 \mu \mathrm{m}$ outer diameter optic fiber (FT200EMT; Thorlabs Inc, Newton, NJ, USA) inserted into 1.25 mm outer diameter ceramic ferrules (CFLC230; Thorlabs) as described in (Sparta et al., 2012).

(Kulzer GmbH, Hanau, Germany) and secured in place by blue-light curing dental cement (Tetric

EvoFlow, Ivoclar Vivadent, Schaan, Liechtenstein). The open end of the GRIN lens at the integrated docking platform was sealed using a Kwik-Sil silicone compound (World Precision Instruments, Sarasota, FL, USA). After stitching, the skin was covered with Bepanthen ${ }^{\circledR}$ Plus paracetamol and the animals were monitored for the following 6 days to ensure proper post-

721 surgical recovery.

\section{Behavior}

724 Auditory-cued fear learning was tested three to four weeks after the surgery. Mice were handled by the experimenter and habituated to the procedure of attachment/detachment of the optical patch cords (before optogenetic experiments), or a dummy mini-microscope (Inscopix Inc.) to the GRIN

727 lens platform (before $\mathrm{Ca}^{2+}$-imaging experiments), for 10-15 min on five consecutive days. An 728 auditory-cued fear learning paradigm was performed in a conditioning chamber of a Video Fear 729 Conditioning Optogenetics Package for Mouse (MED-VFC-OPTO-M, Med Associates Inc., 730 Fairfax, VT, USA) under control of VideoFreeze ${ }^{\circledR}$ software (Med Associates Inc). On day 1 731 (habituation), a mouse at a time was connected to the optic fiber patch cords, or a nVista3.0 mini- 
732

733

734

735

736

737

738

739

740

741

742

743

744

745

746

747

microscope (Inscopix Inc.) was attached, and the animal was placed in the conditioning chamber.

The latter was a rectangular chamber with a metal grid floor, cleaned with $70 \%$ ethanol. Six tone blocks (CS), each consisting of 30 tone beeps $(7 \mathrm{kHz}, 80 \mathrm{~dB}, 100 \mathrm{~ms}$ long, repeated at $1 \mathrm{~Hz}$ for 30 s), were applied $90 \mathrm{~s}$ apart. On day 2 (training), the mouse was placed in the same chamber and presented with six CS blocks pseudo-randomly spaced 60-120 s apart, each followed by a 1s foot shock US (0.6 mA, AC) delivered by a stimulator (ENV-414S, Med Associates Inc). On day 3 (retrieval), the mouse was placed in a conditioning chamber within a different context, consisting of a curved wall and a smooth acrylic floor, cleaned with perfumed general-purpose soap. Four CS blocks as on days 1 and 2 were applied for fear memory recall (see Figure 1, Figure Suppl. 1 for the timing of CS - and US stimuli).

For optogenetic silencing experiments with Arch (Figures 5, 6), light was delivered during 3s starting 1s before the footshock via $200 \mu \mathrm{m}$ core / 0.22 NA optic fiber patch cords (Doric Lenses, Canada) from a $561 \mathrm{~nm}$ diode-pumped solid state laser (MGL-FN-561-AOM, $100 \mathrm{~mW}$, Changchun New Industries Optoelectronics Technology, Changchun, China). The laser was equipped with an AOM and an additional mechanical shutter (SHB05T; Thorlabs). For optogenetic activation experiments with Chronos (Figure 4), 1-ms light pulses were delivered at $25 \mathrm{~Hz}, 2$ s duration from a $473 \mathrm{~nm}$ diode-pumped solid-state laser (MBL-FN-473-150mW, Changchun New Industries Optoelectronics Technology). The intensity of each laser was adjusted before the experiment to deliver $10 \mathrm{~mW}$ light power at the fiber tip.

The behaviour of animals was recorded at video rate $(30 \mathrm{~Hz})$ by the VideoFreeze ${ }^{\circledR}$ software (Med Associates Inc). Based on the behavioural videos, a movement trace was generated using ezTrack software (Pennington et al., 2019); see e.g. Figure 1F-H, red trace). The experimenter, and the person analyzing the data were blinded to the assignment of each mouse to the control - or test group. The movement index trace from ezTrack was used to compute a binary freezing trace using 
bioRxiv preprint doi: https://doi.org/10.1101/2021.12.09.471922; this version posted December $9,2021$. The copyright holder for this preprint (which was not certified by peer review) is the author/funder, who has granted bioRxiv a license to display the preprint in perpetuity. It is made available under aCC-BY-NC-ND 4.0 International license.

custom procedures in IgorPro 7 (WaveMetrics Inc, Lake Oswego, OR, USA). The animal was considered to be immobile (freezing state) if the movement index was below a threshold of 40 arbitrary units (without cable attachment) or 120 a.u. (with cable attachment), for a minimum duration of $0.5 \mathrm{~s}$. The binned trace of percent time spent freezing (10s bin size; see e.g. Figures $4 \mathrm{G}$, $\mathrm{J} ; 5 \mathrm{~F}, \mathrm{H} ; 6 \mathrm{E}, \mathrm{G})$ was calculated as a time-average of the freezing state from the binary trace, and then averaged across mice in each group. If mice from any experimental group showed low freezing, they were excluded from the analysis; we used a threshold of $20 \%$ time spent freezing during the fifth and sixth CS-blocks on day 2 (7 out of 59 mice for the behavioral experiments were excluded).

\section{Microendoscopic $\mathrm{Ca}^{2+}$-imaging data acquisition and analysis}

We used the $\mathrm{nVista} 3.0$ system (Inscopix Inc.) for imaging the activity of either $\mathrm{D} 1 \mathrm{R}^{+}$or Adora ${ }^{+}$ neurons in the AStria over the three-day fear conditioning paradigm. Fluorescent images were acquired at $30 \mathrm{~Hz}$ sequentially from three focal planes, resulting in an effective sampling rate of 10 Hz per plane. The intensity of excitation LED in the $n V$ ista3.0 miniature microscope was set to $1-$ $1.5 \mathrm{~mW} / \mathrm{mm}^{2}$, and the camera gain was adjusted to achieve pixel values within the dynamic range of the CCD.

The initial processing of in-vivo $\mathrm{Ca}^{2+}$-imaging data was done using the Inscopix Data Processing Software (IDPS; Inscopix Inc). This included: 1) deinterleaving of the videos into the frames taken at individual focal planes; 2) spatial filtering; 3) motion correction; 4) manual selection of ROIs; 5) removal of duplicates (i.e. cells from the neighboring focal planes if their intensity traces strongly correlated with correlation coefficient $>0.9)$; 6) export of the absolute fluorescence traces for each ROI and of individual timestamps into .csv files. TTL pulses delivered from the behavioral setup (Med Associates) were used to align the $\mathrm{Ca}^{2+}$-traces to CS or US events. The data were then analyzed using custom routines in IgorPro 7 (WaveMetrics) as follows. From the absolute intensity 
784 traces for each i-th cell $\left(F_{i}(t)\right)$, Z-score traces were calculated as $Z_{i}(t)=\frac{F_{i}(t)-\left\langle F_{i}(t)\right\rangle}{\sigma\left(F_{i}(t)\right)}$, where $\left\langle F_{i}(t)\right\rangle$ 785 and $\sigma\left(F_{i}(t)\right)$ are the mean and the standard deviation of the fluorescence intensity, respectively, 786 calculated from the whole trace. $Z_{i}(t)$ traces were denoised with a low-pass finite impulse response 787 filter (101 coefficients; end of the pass and start of the reject bands, 2 and $4 \mathrm{~Hz}$ respectively). To 788 quantitatively analyze cellular responses, filtered Z-score traces $Z_{i}(t)$ were deconvolved using 789 Fourier transform with a kernel function approximating a unitary fluorescence response to a single 790 AP, similar to the approach used in (Yaksi and Friedrich, 2006). For the kernel, a function $z(t)=$ $791\left(1-e^{-t / \tau_{\text {rise }}}\right) \cdot e^{-t / \tau_{\text {decay }}}$ was assumed with the time constants $\tau_{\text {rise }}=0.08 \mathrm{~s}$ and $\tau_{\text {decay }}=0.5 \mathrm{~s}$, 792 respectively, with the peak amplitude set to 2.0. Deconvolution yielded a trace proportional to the 793 AP firing rate $R_{i}(t)=F F T^{-1}\left[F F T\left[\dot{Z}_{i}(t)\right] / F F T[z(t)]\right] / \Delta t$ measured in $[$ a.u. $/ \mathrm{s}]$ where $\Delta \mathrm{t}=0.1 \mathrm{~s}$, 794 sampling interval. The $R_{i}(t)$ traces were smoothed with a 3-points boxcar filter, and the local peaks exceeding a given amplitude threshold (generally set to 2 a.u./s) were detected using a firstderivative method. The time location (limited to $100 \mathrm{~ms}$ by sampling rate) and the amplitude of the peaks thus defined discrete $\mathrm{Ca}^{2+}$ events $E_{i}\left(t_{j}\right)$, which corresponded to the start of the rising phase of the j-th fluorescent transient seen in $F_{i}(t)$ and $Z_{i}(t)$. The amplitudes of the events from deconvolution (referred to as estimated AP content, EAC [a.u./s]) were proportional to the amplitude of the $\mathrm{Ca}^{2+}$-transients (e.g. see Figure 1 - Figure Supplement 1E). With this method, we did not aim to infer exact AP spiking rates of cells (for which we lack temporal resolution), rather we interpret each "event" as a burst of several APs starting at a given timepoint, with the frequency of APs in a burst being proportional to EAC value.

Based on the timing and amplitudes of discrete events $E_{i}\left(t_{j}\right)$, we performed a receiver operating characteristic (ROC) analysis for sorting the cells by their strength of responses to a given sensory input (CS or US), or to a movement state transition (e.g. freeze - movement, or movement - freeze). 
distribution of cellular responses taken as a sum of $E_{i}\left(t_{j}\right)$ amplitudes during test and baseline time windows of the same duration. Baseline was chosen during periods irrelevant for the cell activity. For tone responders, the baseline window was $(-200 ; 0) \mathrm{ms}$ and the test window $(0 ; 200)$ ms relative to tone beep onset at $\mathrm{t}=0$. For move-on transitions, the baseline window was a $600 \mathrm{~ms}$ window

813 close to the middle of a freezing bout outside the CS epoch; the test window was a $(-300 ; 300) \mathrm{ms}$ window centered on movement onset during CS tone blocks. To estimate the significance of the calculated auROC value for each cell for a given stimulus, we compared these values with auROC values obtained by random shuffling $(1000 x)$ of the test and baseline time windows. A neuron was

817 considered negatively or positively discriminative, if its auROC was below or exceeded,

818 respectively, $5 \%$ or $95 \%$ quantile of the shuffled auROCs (Li et al., 2017). For convenience, we converted auROC values into the response strength values defined as $R S=(2 \cdot a u R O C-1)(\mathrm{Li}$ et multiplied with its duration $(100 \mathrm{~ms})$, resulting in [a.u.].

\section{Rabies tracing}

827 For rabies tracing experiments (Fig. 7) $\mathrm{D} 1 \mathrm{R}^{\mathrm{Cre}}$ or Adora ${ }^{\mathrm{Cre}}$ mice were injected into the AStria (see above for coordinates) with a mix of AAVs (AAV8:hSyn:FLEX:TVA-2a-oG and pseudotyped rabies virus uptake (Wickersham et al., 2007; Wall et al., 2013). In later experiments, we used a tricistronic vector; AAV1:hSyn:FLEX:TVA-2a-eGFP-2a-oG $\left(250 \mathrm{nl} ; 5.3 \times 10^{12} \mathrm{vg} / \mathrm{ml}\right.$; cat. 243-1; viral vector facility University of Zürich) to transduce the starter population. Three weeks later, the rabies vector EnvA:deltaG-RV-dsRed $(250 \mathrm{nl}$; viral vector core Salk Institute for 
835

836

837

838

839

840

841

842

843

844

845

846

847

848

849

850

851

852

853

854

855

856

857

858

859

860

sacrificed 7 days later, and a histological analysis was performed on every second $40 \mu \mathrm{m}$ thick coronal section of the entire brain, from the level of the prefrontal cortex up to the end of the cerebellum. The resulting images were analysed in a semi-automatic fashion, i.e. dsRed positive neurons were marked manually, brain sections were registered to the Allen brain atlas and marked neurons were automatically mapped onto the resulting brain regions using Matlab-based software (SHARP-Track; (Shamash et al., 2018). The positioning of all long-range projecting cells was analysed and plotted on a 3D brain model using the python-based Brainrender software (Claudi et al., 2020).

\section{Electrophysiology}

For whole-cell patch-clamp electrophysiology in slices, mice expressing Chronos in the insular cortex (see above) were deeply anesthetized with isoflurane. After decapitation, the brain was quickly removed from the skull and placed in ice-cold slicing buffer containing (in mM): 110 NMDG (N-methyl-D-glutamine), $2.5 \mathrm{KCl}, 1.2 \mathrm{NaH}_{2} \mathrm{PO}_{4}, 20$ HEPES, 25 Glucose, 5 Na- ascorbate, 2 Thiourea, 3 sodium pyruvate, $10 \mathrm{MgCl}_{2}, 0.5 \mathrm{CaCl}_{2}$, saturated with carbogen gas $\left(\mathrm{O}_{2} 95 \% / \mathrm{CO}_{2}\right.$ 5\%), $\mathrm{pH}$ of 7.4 adjusted with $\mathrm{HCl}$. Coronal slices $(300 \mu \mathrm{m})$ containing the ventral tail striatum were cut using a Leica VT1200S slicer (Leica Microsystems, Wetzlar, Germany). Slices were stored for $7 \mathrm{~min}$ at $34^{\circ} \mathrm{C}$ in the slicing buffer and thereafter placed in a chamber containing a storage solution containing (in mM): $92 \mathrm{NaCl}, 2.5 \mathrm{KCl}, 30 \mathrm{NaHCO}_{3}, 1.2 \mathrm{NaH}_{2} \mathrm{PO}_{4}, 20$ HEPES, 25 glucose, 5 sodium ascorbate, 2 Thiourea, $3 \mathrm{Na}$-pyruvate, $2 \mathrm{MgCl}_{2}$ and $2 \mathrm{CaCl}_{2}$, $\mathrm{pH} 7.4$ at room temperature, saturated with carbogen (Ting et al., 2014). Whole-cell patch-clamp recordings were performed with a standard extracellular solution containing (in $\mathrm{mM}$ ): $125 \mathrm{NaCl}, 2.5 \mathrm{KCl}, 25 \mathrm{NaHCO}_{3}, 1.2$ $\mathrm{NaH}_{2} \mathrm{PO}_{4}, 25$ glucose, 0.4 Na-ascorbate, 3 Myo-Inositol, 2 Na-pyruvate, $1 \mathrm{MgCl}_{2}$ and $2 \mathrm{CaCl}_{2}$, pH7.4, saturated with carbogen gas. The set-up was equipped with an EPC10/2 patch-clamp amplifier (HEKA Elektronik GmbH, Reutlingen, Germany), and an upright microscope (BX51WI; Olympus, Tokyo, Japan) with a 60x / 0.9 NA water-immersion objective (LUMPlanFl, Olympus). 
862 Patch-clamp experiments including E/I-ratio and AMPA/NMDA-ratio measurements (Figure 8)

863 were performed using a $\mathrm{Cs}^{+}$-based intracellular solution (in $\mathrm{mM}$ ): $140 \mathrm{Cs}^{+}$-gluconate, $10 \mathrm{HEPES}, 8$

864 TEA-Cl, 5 Na-phosphocreatine, 4 Mg-ATP, 0.3 Na-GTP, 5 EGTA, pH 7.2 adjusted with CsOH.

865 AMPA/NMDA - ratio experiments were done in the presence of $5 \mu \mathrm{M} \mathrm{GABA}_{\mathrm{A}}$ receptor antagonist 866 gabazine (SR-95531; Abcam, Cambridge, UK). Experiments to test the archaerhodopsin (Arch)

867 properties (Figure 5 - Figure Supplement 2) were performed using a $\mathrm{K}^{+}$-based solution with (in

$868 \mathrm{mM}): 8 \mathrm{KCl}, 145 \mathrm{~K}$-gluconate, 10 HEPES, 3 Na-phosphocreatine, 4 Mg ATP, $0.3 \mathrm{Na}-\mathrm{GTP}, 5$

869 EGTA, pH 7.2 adjusted with KOH. All electrophysiological experiments were conducted at near-

870 physiological temperature $\left(34^{\circ} \mathrm{C}\right)$ using an inlet heater SHM-6, a heated recording chamber RC-

871 26GL/PM-1 and a thermostatic control unit TC-344B (all from Warner Instruments, Holliston, MA,

872 USA). All chemicals, unless indicated, were from Sigma-Aldrich (St. Louis, MO, USA).

873

874 For activation of the excitatory and inhibitory opsins in slice experiments, and for visualization of

875 fluorophores in brain slices, high-power LEDs (CREE XP-E2, $480 \mathrm{~nm}$ and $530 \mathrm{~nm}$; Cree Inc.,

876 Durham, NC, USA) were custom-coupled into the epifluorescence port of the microscope.

877 Illumination was controlled by the EPC10 amplifier DAC board connected to the LED driver

878 (BLS-1000-2, Mightex Systems, Toronto, Canada). Irradiance was measured by a photodiode

879 (DET36A/M, Thorlabs) coupled into the illumination light path, whose readings were calibrated by 880 the light power measured under the 60x objective using a power-meter model 1918-R equipped

881 with a 818-UV detector (NewPort, Irvine, CA, USA). Electrophysiological recordings were

882 analyzed in IgorPro (WaveMetrics) using the NeuroMatic plug-in (Rothman and Silver, 2018).

Histology

885 For anatomical analysis of optic fiber - or GRIN lens positions, mice were transcardially perfused 886 with a 4\% paraformaldehyde (PFA) solution. The brains were post-fixed in PFA overnight and then 
transferred to $30 \%$ sucrose in phosphate - buffered solution for dehydration. Coronal brain sections of $40 \mu \mathrm{m}$ thickness were prepared using a HM450 sliding microtome (Thermo Fisher Scientific, objective, or with an upright Leica SP8 confocal microscope. Brain atlas overlays are taken from

893 (Franklin and Paxinos, 2016). The majority of brain structure names and their abbreviations follows 894 (Franklin and Paxinos, 2016); their correspondence to the Allen brain atlas are given in Figure 7, Table Suppl. 1.

\section{Statistical analysis}

898 Statistical analysis was performed in GraphPad Prism 9 (GraphPad, San Diego, CA, USA). Before choosing the main statistical test, the distribution of the data was tested for normality using a Shapiro-Wilk test. When normality was confirmed, we used a paired or unpaired version of the two-tailed Student's t-tests for two-sample datasets, as indicated. For the comparison of relative 902 datasets, we used a one-sample t-test. When the data was not normally distributed, we used two903 tailed non-parametric tests: a Wilcoxon matched-pairs signed-rank test for paired comparisons, or Mann-Whitney U test for unpaired comparisons of two-sample datasets, as indicated.

For datasets with more than two samples (in-vivo $\mathrm{Ca}^{2+}$ imaging data; Figures 1, 3), the data showed

907 skewed distributions which did not pass the normality test, therefore we used a non-parametric 908 version of a one-way ANOVA, a Kruskal-Wallis test (KW test). If the KW test detected significant 909 differences, it was followed by Dunn's post-hoc test for multiple comparisons (called Dunn's MC test). For datasets influenced by two factors such as the optogenetic silencing/control group and the

911 time of the experiment (Figures 5, 6), we used a repeated-measures two-way ANOVA (RM- 
bioRxiv preprint doi: https://doi.org/10.1101/2021.12.09.471922; this version posted December 9,2021 . The copyright holder for this preprint (which was not certified by peer review) is the author/funder, who has granted bioRxiv a license to display the preprint in perpetuity. It is made available under aCC-BY-NC-ND 4.0 International license.

912 ANOVA) separately for the training and fear retrieval days. If RM-ANOVA reported significance,

913 it was followed by Šidák's post-hoc tests for the respective factor.

914

915 The change in number of neurons responding in-vivo to different events across training (Figures

$9161 \mathrm{~K}, 1 \mathrm{~N}, 3 \mathrm{H}, 3 \mathrm{M}$ ) was statistically assessed using a Chi-square test for trend. For the optogenetic

917 silencing experiments, we determined the sample size a priori using a G*Power software (Faul et

918 al., 2007) for an RM-ANOVA test (two groups, 4 replicate measurements for the fear retrieval day)

919 assuming an average change in freezing of $20 \%$ (from 60 to $40 \%$ ) and a standard deviation of $15 \%$

920 (resulting in an effect size of 0.667 ), significance level $\alpha=0.05$, power $1-\beta=0.85$, and the

921 correlation between repeated measures of 0.5 . The resulting total sample size was $\mathrm{N}=16(\mathrm{~N}=8$

922 mice per group), with a critical $\mathrm{F}_{\text {crit }}=4.6$. There was no sample size estimation made for other

923 experiments.

924

925 Each specific statistical test is mentioned in the Results text, and the input data along with

926 statistical test summary (such as p-values, values of test statistics, degrees of freedom, etc.) and the

927 main descriptive statistics are given in the statistics Tables for each relevant figure. The data are

928 expressed as mean \pm SEM. Statistical significance, if applicable, is indicated in the Figures using

929 asterisks as $\mathrm{p} \leq 0.05(*), \mathrm{p} \leq 0.01(* *)$ and $\mathrm{p} \leq 0.001(* * *)$.

930

931 Data availability

932 The essential raw data leading to the conclusions of this paper will be made available at

$93310.5281 /$ zenodo.4003654.

934

935 Acknowledgements

936 We would like to thank Shriya Palchaudhuri and Denys Osypenko for helpful discussions regarding

937 the analysis of freezing behavior. Images were acquired at the bio-optical imaging platform of 
938 EPFL (BiOP). This work was supported by an EMBO fellowship to M.K. (\# ALTF 224-2015), and

939 by grants from the Swiss National Science foundation (SNSF; grant number 31003A_176332 / 1)

940 and from the National Competence Center for Research (NCCR) of the SNSF "Synapsy - The

941 Synaptic Bases of Mental disease", project P28 (both to R.S.).

942

943 


\section{References}

Amano, T., Duvarci, S., Popa, D., and Paré, D. (2011). The fear circuit revisited: contributions of the basal amygdala nuclei to conditioned fear. The Journal of neuroscience : the official journal of the Society for Neuroscience 31, 15481-15489.

Britten, K.H., Shadlen, M.N., Newsome, W.T., and Movshon, J.A. (1992). The analysis of visual motion: a comparison of neuronal and psychophysical performance. The Journal of neuroscience : the official journal of the Society for Neuroscience 12, 4745-4765.

Burguiere, E., Monteiro, P., Mallet, L., Feng, G., and Graybiel, A.M. (2015). Striatal circuits,

953 habits, and implications for obsessive-compulsive disorder. Current opinion in neurobiology 30,

\section{$954 \quad 59-65$.}

955 Chow, B.Y., Han, X., Dobry, A.S., Qian, X., Chuong, A.S., Li, M., Henninger, M.A., Belfort, 956 G.M., Lin, Y., Monahan, P.E., and Boyden, E.S. (2010). High-performance genetically targetable 957 optical neural silencing by light-driven proton pumps. Nature 463, 98-102.

958 Claudi, F., Tyson, L.A., and Branco, T. (2020). Brainrender. A python based software for 959 visualisation of neuroanatomical and morphological data. bioRxiv https://doi.org/10.1101/2020.02.23.961748.

961 Cox, J., and Witten, I.B. (2019). Striatal circuits for reward learning and decision-making. Nature reviews. Neuroscience 20, 482-494.

963 Creed, M., Pascoli, V.J., and Lüscher, C. (2015). Addiction therapy. Refining deep brain

964 stimulation to emulate optogenetic treatment of synaptic pathology. Science 347, 659-664.

965 Cummings, K.A., and Clem, R.L. (2020). Prefrontal somatostatin interneurons encode fear memory. Nature neuroscience 23, 61-74.

Davis, M. (1992). The role of the amygdala in fear and anxiety. Annual review of neuroscience 15, $353-375$.

972 Dunsmoor, J.E., Prince, S.E., Murty, V.P., Kragel, P.A., and LaBar, K.S. (2011). Neurobehavioral 973 mechanisms of human fear generalization. NeuroImage 55, 1878-1888.

974 Duvarci, S., and Paré, D. (2014). Amygdala microcircuits controlling learned fear. Neuron 82, 966975980. 
976 Faul, F., Erdfelder, E., Lang, A.G., and Buchner, A. (2007). G*Power 3: a flexible statistical power 977 analysis program for the social, behavioral, and biomedical sciences. Behav Res Methods 39, $175-$ 978191.

979 Fanselow, M.S. (1994). Neural organization of the defensive behavior system responsible for fear. Psychonomic bulletin \& review 1, 429-438.

981 Fanselow, M.S. (2018). The Role of Learning in Threat Imminence and Defensive Behaviors. Curr Opin Behav Sci 24, 44-49.

983 Franklin, K.B.J., and Paxinos, G. (2016). The Mouse Brain in stereotaxic coordinates. Elsevier / Academic Press 4th edition.

985

986

987

988

989

990

991

992

993

994

995

996

997

998

999

1000

1001

1002

1003

1004

1005

1006

Gangarossa, G., Castell, L., Castro, L., Tarot, P., Veyrunes, F., Vincent, P., Bertaso, F., and Valjent, E. (2019). Contrasting patterns of ERK activation in the tail of the striatum in response to aversive and rewarding signals. J Neurochem 151, 204-226.

Gehrlach, D.A., Dolensek, N., Klein, A.S., Roy Chowdhury, R., Matthys, A., Junghänel, M., Gaitanos, T.N., Podgornik, A., Black, T.D., Reddy Vaka, N., et al. (2019). Aversive state processing in the posterior insular cortex. Nature neuroscience 22, 1424-1437.

Gerfen, C.R., Engber, T.M., Mahan, L.C., Susel, Z., Chase, T.N., Monsma, F.J., Jr., and Sibley, D.R. (1990). D1 and D2 dopamine receptor-regulated gene expression of striatonigral and striatopallidal neurons. Science 250, 1429-1432.

Gerfen, C.R., Paletzki, R., and Heintz, N. (2013). GENSAT BAC cre-recombinase driver lines to study the functional organization of cerebral cortical and basal ganglia circuits. Neuron 80,1368 1383.

Ghosh, K.K., Burns, L.D., Cocker, E.D., Nimmerjahn, A., Ziv, Y., Gamal, A.E., and Schnitzer, M.J. (2011). Miniaturized integration of a fluorescence microscope. Nat Methods 8, 871-878.

Gogolla, N., Takesian, A.E., Feng, G., Fagiolini, M., and Hensch, T.K. (2014). Sensory integration in mouse insular cortex reflects GABA circuit maturation. Neuron 83, 894-905.

Gong, S., Doughty, M., Harbaugh, C.R., Cummins, A., Hatten, M.E., Heintz, N., and Gerfen, C.R. (2007). Targeting Cre recombinase to specific neuron populations with bacterial artificial chromosome constructs. The Journal of neuroscience : the official journal of the Society for Neuroscience 27, 9817-9823.

Graybiel, A.M. (2005). The basal ganglia: learning new tricks and loving it. Current opinion in neurobiology $15,638-644$. 
1007 Grewe, B.F., Gründemann, J., Kitch, L.J., Lecoq, J.A., Parker, J.G., Marshall, J.D., Larkin, M.C., 1008 Jercog, P.E., Grenier, F., Li, J.Z., et al. (2017). Neural ensemble dynamics underlying a long-term associative memory. Nature 543, 670-675.

1010 Grillner, S., Hellgren, J., Menard, A., Saitoh, K., and Wikstrom, M.A. (2005). Mechanisms for selection of basic motor programs - roles for the striatum and pallidum. Trends in neurosciences 28 , 364-370.

1013 Gründemann, J., Bitterman, Y., Lu, T., Krabbe, S., Grewe, B.F., Schnitzer, M.J., and Lüthi, A. 1014 (2019). Amygdala ensembles encode behavioral states. Science 364.

1015 Guo, L., Walker, W.I., Ponvert, N.D., Penix, P.L., and Jaramillo, S. (2018). Stable representation of sounds in the posterior striatum during flexible auditory decisions. Nature communications 9,1534 .

1017 Hikosaka, O., Takikawa, Y., and Kawagoe, R. (2000). Role of the basal ganglia in the control of 1018 purposive saccadic eye movements. Physiological reviews 80, 953-978.

1019 Hintiryan, H., Foster, N.N., Bowman, I., Bay, M., Song, M.Y., Gou, L., Yamashita, S., 1020 Bienkowski, M.S., Zingg, B., Zhu, M., et al. (2016). The mouse cortico-striatal projectome. Nature 1021 neuroscience 19, 1100-1114.

1022 Hjorth, J.J.J., Kozlov, A., Carannante, I., Frost Nylen, J., Lindroos, R., Johansson, Y., Tokarska, 1023 A., Dorst, M.C., Suryanarayana, S.M., Silberberg, G., et al. (2020). The microcircuits of striatum in 1024 silico. Proceedings of the National Academy of Sciences of the United States of America 117, 1025 9554-9565.

1026 Humphries, M.D., and Prescott, T.J. (2010). The ventral basal ganglia, a selection mechanism at the 1027 crossroads of space, strategy, and reward. Progress in neurobiology 90, 385-417.

1028 Hunnicutt, B.J., Jongbloets, B.C., Birdsong, W.T., Gertz, K.J., Zhong, H., and Mao, T. (2016). A 1029 comprehensive excitatory input map of the striatum reveals novel functional organization. eLife 5. 1030 Janak, P.H., and Tye, K.M. (2015). From circuits to behaviour in the amygdala. Nature 517, 2841031292.

1032 Keller, G.B., Bonhoeffer, T., and Hubener, M. (2012). Sensorimotor mismatch signals in primary 1033 visual cortex of the behaving mouse. Neuron 74, 809-815.

1034 Klapoetke, N.C., Murata, Y., Kim, S.S., Pulver, S.R., Birdsey-Benson, A., Cho, Y.K., Morimoto, 1035 T.K., Chuong, A.S., Carpenter, E.J., Tian, Z., et al. (2014). Independent optical excitation of 1036 distinct neural populations. Nat Methods 11,338-346.

1037 Klaus, A., Alves da Silva, J., and Costa, R.M. (2019). What, if, and when to move: Basal ganglia circuits and self-paced action initiation. Annual review of neuroscience 42, 459-483. 
1039 Kravitz, A.V., Freeze, B.S., Parker, P.R., Kay, K., Thwin, M.T., Deisseroth, K., and Kreitzer, A.C. 1040 (2010). Regulation of parkinsonian motor behaviours by optogenetic control of basal ganglia circuitry. Nature 466, 622-626.

1042 Kyriazi, P., Headley, D.B., and Pare, D. (2018). Multi-dimensional Coding by Basolateral Amygdala Neurons. Neuron 99, 1315-1328 e1315.

LeDoux, J.E. (2000). Emotion circuits in the brain. Annual review of neuroscience 23, 155-184.

1045 LeDoux, J.E., Farb, C., and Ruggiero, D.A. (1990). Topographic organization of neurons in the acoustic thalamus that project to the amygdala. The Journal of neuroscience : the official journal of the Society for Neuroscience 10, 1043-1054.

LeDoux, J.E., Iwata, J., Cicchetti, P., and Reis, D.J. (1988). Different projections of the central amygdaloid nucleus mediate autonomic and behavioral correlates of conditioned fear. The Journal of neuroscience : the official journal of the Society for Neuroscience 8, 2517-2529. Awake Behaving Mice. Cell 171, 1176-1190 e1117. connectivity between the medial prefrontal cortex and basolateral amygdala. The Journal of neuroscience : the official journal of the Society for Neuroscience 33, 15333-15342.

1057 Livneh, Y., Ramesh, R.N., Burgess, C.R., Levandowski, K.M., Madara, J.C., Fenselau, H., Goldey, 1058 G.J., Diaz, V.E., Jikomes, N., Resch, J.M., et al. (2017). Homeostatic circuits selectively gate food 1059 cue responses in insular cortex. Nature 546, 611-616.

1060 Lucas, E.K., Jegarl, A.M., Morishita, H., and Clem, R.L. (2016). Multimodal and site-specific 1061 plasticity of amygdala parvalbumin interneurons after fear learning. Neuron 91, 629-643.

1062 Madisen, L., Zwingman, T.A., Sunkin, S.M., Oh, S.W., Zariwala, H.A., Gu, H., Ng, L.L., Palmiter, 1063 R.D., Hawrylycz, M.J., Jones, A.R., et al. (2010). A robust and high-throughput Cre reporting and characterization system for the whole mouse brain. Nature neuroscience 13, 133-140.

1065 Markowitz, J.E., Gillis, W.F., Beron, C.C., Neufeld, S.Q., Robertson, K., Bhagat, N.D., Peterson, R.E., Peterson, E., Hyun, M., Linderman, S.W., et al. (2018). The Striatum Organizes 3D Behavior via Moment-to-Moment Action Selection. Cell 174, 44-58 e17. 
1070

1071

1072

1073

1074

1075

1076

1077

1078

1079

1080

1081

1082

1083

1084

1085

1086

1087

1088

1089

1090

1091

1092

1093

1094

1095

1096

1097

1098

1099

1100

Menegas, W., Akiti, K., Amo, R., Uchida, N., and Watabe-Uchida, M. (2018). Dopamine neurons projecting to the posterior striatum reinforce avoidance of threatening stimuli. Nature neuroscience $21,1421-1430$.

Menegas, W., Bergan, J.F., Ogawa, S.K., Isogai, Y., Umadevi Venkataraju, K., Osten, P., Uchida, N., and Watabe-Uchida, M. (2015). Dopamine neurons projecting to the posterior striatum form an anatomically distinct subclass. eLife 4, e10032.

Morey, R.A., Haswell, C.C., Stjepanovic, D., Mid-Atlantic, M.W., Dunsmoor, J.E., and LaBar, K.S. (2020). Neural correlates of conceptual-level fear generalization in posttraumatic stress disorder. Neuropsychopharmacology 45, 1380-1389.

Namburi, P., Beyeler, A., Yorozu, S., Calhoon, G.G., Halbert, S.A., Wichmann, R., Holden, S.S., Mertens, K.L., Anahtar, M., Felix-Ortiz, A.C., et al. (2015). A circuit mechanism for differentiating positive and negative associations. Nature 520,675-678.

Nelson, A.B., and Kreitzer, A.C. (2014). Reassessing models of basal ganglia function and dysfunction. Annual review of neuroscience 37, 117-135.

Niell, C.M., and Stryker, M.P. (2010). Modulation of visual responses by behavioral state in mouse visual cortex. Neuron 65, 472-479.

Pennington, Z.T., Dong, Z., Feng, Y., Vetere, L.M., Page-Harley, L., Shuman, T., and Cai, D.J. (2019). ezTrack: An open-source video analysis pipeline for the investigation of animal behavior. Sci Rep 9, 19979.

Petreanu, L., Huber, D., Sobczyk, A., and Svoboda, K. (2007). Channelrhodopsin-2-assisted circuit mapping of long-range callosal projections. Nature neuroscience 10, 663-668.

Phelps, E.A., and LeDoux, J.E. (2005). Contributions of the amygdala to emotion processing: from animal models to human behavior. Neuron 48, 175-187.

Polepalli, J.S., Gooch, H., and Sah, P. (2020). Diversity of interneurons in the lateral and basal amygdala. NPJ Sci Learn 5, 10.

Quirk, G.J., Repa, C., and LeDoux, J.E. (1995). Fear conditioning enhances short-latency auditory responses of lateral amygdala neurons: parallel recordings in the freely behaving rat. Neuron 15 , 1029-1039.

Redgrave, P., Rodriguez, M., Smith, Y., Rodriguez-Oroz, M.C., Lehericy, S., Bergman, H., Agid, Y., DeLong, M.R., and Obeso, J.A. (2010). Goal-directed and habitual control in the basal ganglia: implications for Parkinson's disease. Nature reviews. Neuroscience 11, 760-772. 
1101 Rodgers, K.M., Benison, A.M., Klein, A., and Barth, D.S. (2008). Auditory, somatosensory, and multisensory insular cortex in the rat. Cerebral cortex 18, 2941-2951.

1103 Rogan, M.T., and LeDoux, J.E. (1995). LTP is accompanied by commensurate enhancement of auditory-evoked responses in a fear conditioning circuit. Neuron 15, 127-136.

1105 Rogan, M.T., Leon, K.S., Perez, D.L., and Kandel, E.R. (2005). Distinct neural signatures for safety and danger in the amygdala and striatum of the mouse. Neuron 46, 309-320.

1107 Romanski, L.M., Clugnet, M.C., Bordi, F., and LeDoux, J.E. (1993). Somatosensory and auditory convergence in the lateral nucleus of the amygdala. Behavioral neuroscience 107, 444-450.

1109 Roseberry, T., and Kreitzer, A. (2017). Neural circuitry for behavioural arrest. Philos Trans R Soc Lond B Biol Sci 372.

1111 Rothman, J.S., and Silver, R.A. (2018). NeuroMatic: An integrated open-source software toolkit for acquisition, analysis and simulation of electrophysiological data. Frontiers in neuroinformatics 12, 14.

Rothwell, P.E., Hayton, S.J., Sun, G.L., Fuccillo, M.V., Lim, B.K., and Malenka, R.C. (2015). Input- and output-specific regulation of serial order performance by corticostriatal circuits. Neuron 88, 345-356.

1117 Rumpel, S., LeDoux, J., Zador, A., and Malinow, R. (2005). Postsynaptic receptor trafficking underlying a form of associative learning. Science 308, 83-88.

1119 Sacco, T., and Sacchetti, B. (2010). Role of secondary sensory cortices in emotional memory 1120 storage and retrieval in rats. Science 329, 649-656.

1121 Sangha, S., Diehl, M.M., Bergstrom, H.C., and Drew, M.R. (2020). Know safety, no fear.

1122 Neuroscience and biobehavioral reviews 108, 218-230.

1123 Sawatari, H., Tanaka, Y., Takemoto, M., Nishimura, M., Hasegawa, K., Saitoh, K., and Song, W.J.

1124 (2011). Identification and characterization of an insular auditory field in mice. The European 1125 journal of neuroscience $34,1944-1952$.

1126 Schiffmann, S.N., and Vanderhaeghen, J.J. (1993). Adenosine A2 receptors regulate the gene 1127 expression of striatopallidal and striatonigral neurons. The Journal of neuroscience : the official 1128 journal of the Society for Neuroscience 13, 1080-1087.

1129 Shamash, P., Carandini, M., Harris, K., and Steinmetz, N. (2018). A tool for analyzing electrode 1130 tracks from slice histology. bioRxiv http://dx.doi.org/10.1101/447995. 
1131

1132

1133

1134

1135

1136

1137

1138

1139

1140

1141

1142

1143

1144

1145

1146

1147

1148

1149

1150

1151

1152

1153

1154

1155

1156

1157

1158

1159

1160

1161

1162

Shan, Q., Ge, M., Christie, M.J., and Balleine, B.W. (2014). The acquisition of goal-directed actions generates opposing plasticity in direct and indirect pathways in dorsomedial striatum. The Journal of neuroscience : the official journal of the Society for Neuroscience 34, 9196-9201.

Sparta, D.R., Stamatakis, A.M., Phillips, J.L., Hovelso, N., van Zessen, R., and Stuber, G.D. (2012). Construction of implantable optical fibers for long-term optogenetic manipulation of neural circuits. Nat Protoc 7, 12-23.

Stringer, C., Pachitariu, M., Steinmetz, N., Reddy, C.B., Carandini, M., and Harris, K.D. (2019). Spontaneous behaviors drive multidimensional, brainwide activity. Science 364, 255.

Tang, W., Kochubey, O., Kintscher, M., and Schneggenburger, R. (2020). A VTA to basal amygdala dopamine projection contributes to signal salient somatosensory events during fear learning. The Journal of neuroscience : the official journal of the Society for Neuroscience 40, 3969-3980.

Ting, J.T., Daigle, T.L., Chen, Q., and Feng, G. (2014). Acute brain slice methods for adult and aging animals: application of targeted patch clamp analysis and optogenetics. Methods in molecular biology 1183, 221-242.

Tovote, P., Esposito, M.S., Botta, P., Chaudun, F., Fadok, J.P., Markovic, M., Wolff, S.B., Ramakrishnan, C., Fenno, L., Deisseroth, K., et al. (2016). Midbrain circuits for defensive behaviour. Nature 534, 206-212.

Tovote, P., Fadok, J.P., and Lüthi, A. (2015). Neuronal circuits for fear and anxiety. Nature reviews. Neuroscience 16,317-331.

Tsvetkov, E., Carlezon, W.A., Benes, F.M., Kandel, E.R., and Bolshakov, V.Y. (2002). Fear conditioning occludes LTP-induced presynaptic enhancement of synaptic transmission in the cortical pathway to the lateral amygdala. Neuron 34, 289-300.

Wall, N.R., De La Parra, M., Callaway, E.M., and Kreitzer, A.C. (2013). Differential innervation of direct- and indirect-pathway striatal projection neurons. Neuron 79, 347-360.

Weinberger, N.M. (2007). Auditory associative memory and representational plasticity in the primary auditory cortex. Hearing research $229,54-68$.

Wickersham, I.R., Lyon, D.C., Barnard, R.J., Mori, T., Finke, S., Conzelmann, K.K., Young, J.A., and Callaway, E.M. (2007). Monosynaptic restriction of transsynaptic tracing from single, genetically targeted neurons. Neuron 53, 639-647.

Yaksi, E., and Friedrich, R.W. (2006). Reconstruction of firing rate changes across neuronal populations by temporally deconvolved $\mathrm{Ca}^{2+}$ imaging. Nat Methods 3, 377-383. 
1163 Yin, H.H., Mulcare, S.P., Hilario, M.R., Clouse, E., Holloway, T., Davis, M.I., Hansson, A.C., 1164 Lovinger, D.M., and Costa, R.M. (2009). Dynamic reorganization of striatal circuits during the 1165 acquisition and consolidation of a skill. Nature neuroscience 12, 333-341.

1166 Zanette, L.Y., White, A.F., Allen, M.C., and Clinchy, M. (2011). Perceived predation risk reduces 1167 the number of offspring songbirds produce per year. Science 334, 1398-1401.

1168 Zhang, X., and Li, B. (2018). Population coding of valence in the basolateral amygdala. Nature 1169 communications 9, 5195.

1170

1171

1172 


\section{Figure Legends}

1174 Figure 1. Miniature Microscope $\mathrm{Ca}^{2+}$-imaging of $\mathrm{D} 1 \mathrm{R}+$ neurons in the AStria reveals

\section{5 interdependent coding for tones and movement during fear learning.}

1176 (A) Outline of the 3-day fear conditioning protocol. On the training day, after the tone a $1 \mathrm{~s}, 0.6 \mathrm{~mA}$

1177 footshock was applied (see inset on the right). (B) Experimental scheme of the injection of an AAV

1178 vector and placement of the GRIN lens in the Astria of D1R ${ }^{\mathrm{Cre}}$ mice. (C) Posthoc fluorescence

1179 microscopy image from an injected D1R ${ }^{\mathrm{Cre}}$ mouse expressing GCaMP6m (green). The black region

1180 indicates the position of the GRIN lens. The putative imaging area is depicted with a red rectangle.

1181 Scalebar, $500 \mu \mathrm{m}$. (D-F) Z-scored $\mathrm{Ca}^{2+}$ traces for three example neurons (black traces); movement

1182 traces of the mouse (red traces); freezing-state trace of the mouse (blue); and the color-coded z-

1183 scored $\mathrm{Ca}^{2+}$ traces for all neurons in one example mouse (bottom). Data are from the second CS

1184 presentation of day 1 (D), the fourth CS-US presentation of day 2 (E), and the second CS

1185 presentation on day $3(\mathrm{~F})$. (G) Six consecutive footshock responses of an example neuron (black)

1186 and the average trace (red). (H) PSTH of the footshock responses of all neurons $(\mathrm{n}=167)$ imaged

1187 on day 2 in all $\mathrm{D} 1 \mathrm{R}^{\mathrm{Cre}}$ mice $(\mathrm{N}=8)$. The fraction of ROC - identified responders is depicted by the

1188 horizontal dashed line $(\mathrm{n}=57)$. (I) $\mathrm{Ca}^{2+}$-traces of an example neuron in response to all 120 tone

1189 beeps applied on day 3 (grey and black lines), and the average response (red). (J) PSTHs of tone

1190 responses of all cells on the training days, sorted by response strength. A significant response as

1191 determined by ROC was found in the neurons above the horizontal dashed line. (K) Percentage of

1192 neurons with a significant response, as determined by ROC, to tone stimulation for each day. (L)

1193 The PSTH of the tone beep response, averaged over the entire population of imaged neurons for

1194 each day. Note the increased tone responsiveness especially on the fear memory retrieval day (red

1195 trace). Blue and green traces depict data from the habituation- and training days, respectively. (M)

1196 PSTHs of the movement-onset responses in a similar display as above for tone responses (J),

1197 analyzed for times within CS presentations. (N) Percentage of neurons with a significant response

1198 to movement onset after freezing. (O) The PSTH of the movement onset response, averaged over 
1199 the entire population of imaged neurons for each day. Color code is as in (L). (P, Q) Response

1200 fidelities (P), and estimated AP content of the $\mathrm{Ca}^{2+}$ events (Q) (see Materials and Methods) in

1201 response to movement onset, for the entire population of imaged neurons on day 1, 2 and 3 (blue,

1202 green, and red data, respectively). (R) The population PSTH of the movement onset response for

1203 each day, now analyzed in the absence of the CS ("no CS"). Note the smaller responses as

1204 compared to the movement - onset response in the presence of the CS (O, same y-scale). (S)

1205 Response fidelities and estimated AP content of the $\mathrm{Ca}^{2+}$ events for the tone responses, analyzed

1206 both during the freezing state of the mouse ("freeze") and when mice moved ("move"). Note the

1207 significantly higher response fidelity on day 3, and the significantly higher estimated AP-content

1208 on day 2 when mice moved as compared to the freezing state (see Results for statistical

1209 significance). (T) The frequency of $\mathrm{Ca}^{2+}$ events was analyzed separately for each of the four

1210 combinations of CS/no CS, and movement/Freezing states of the mice, for habituation day ("Hab"),

1211 training day ("train"), and fear memory retrieval day ("Ret"). The presence of a CS is indicated by

1212 the blue bars. The $\mathrm{p}$ - values for statistical significance are reported in the Results text, and can

1213 additionally be found the statistic Table for Figure 3. 
bioRxiv preprint doi: https://doi.org/10.1101/2021.12.09.471922; this version posted December 9,2021 . The copyright holder for this preprint (which was not certified by peer review) is the author/funder, who has granted bioRxiv a license to display the preprint in perpetuity. It is made available under aCC-BY-NC-ND 4.0 International license.

1217 Figure 2. Spatial localization of the imaged D1R+ AStria neurons, and overlap of neurons coding for sensory events and movement state.

1219 (A-C) Maps with the position of all imaged D1R + AStria neurons, plotted as horizontal projection.

1220 Shown are the footshock-responses (A), the tone (CS) responses as imaged on day3 (B), and the

1221 movement - onset responses imaged on day $3(\mathrm{C})$. Neurons are color - coded based on their

1222 respective ROC classification (red, responders, blue, non-responders) and size - coded based on

1223 their response amplitudes. For a coarse orientation, outlines of the amygdalar nuclei (basolateral

1224 amygdala; "BLA" and central amygdala, "CeA") and cortex ("Ctx") are shown. (D) Venn diagrams

1225 showing the overlap of neuronal populations within the D1R+ AStria neurons that respond to tones

1226 (green), to movement - onset transitions (blue), and to footshock stimulation on day 2 (red). Note

1227 the increased number of neurons responding to tones and movement - onset during fear memory

1228 retrieval, and the overlap of these sub-populations (right panel).

1229

1230

1231 
Figure 3. Adora+ AStria neurons code for footshocks and movement onset, but CS coding is less relevant than in D1R+ AStria neurons.

1234

1235

1236

1237

1238

1239

1240

1241

1242

1243

1244

1245

1246

1247

(A) Experimental scheme of the injection of an AAV vector and placement of the GRIN lens in Adora ${ }^{\mathrm{Cre}}$ mice. (B-D) $\mathrm{Ca}^{2+}$-traces for three example neurons (black); movement trace (red); freezing - state trace of the mouse (blue); and the color-coded $\mathrm{Ca}^{2+}$ traces for all neurons in this example mouse. Data are from the second CS presentation of day 1 (D), the fourth CS-US presentation of day 2 (E), and the second CS presentation on day $3(\mathrm{~F})$. (E) Six footshock responses of an example neuron (black) and the average trace (red). (F) PSTH of the footshock responses of all neurons $(\mathrm{n}=251)$ imaged on day 2 in the $\mathrm{D} 1 \mathrm{R}^{\mathrm{Cre}}$ mice $(\mathrm{N}=8)$. $(\mathbf{G}) \mathrm{Ca}^{2+}$-traces of an example neuron in response to all 120 tone beeps applied on day 3 (grey and black lines), and the average response (red). (H). Percentage of neurons with a significant response to tone stimulation for each day. (I) The population PSTH to tone beep stimulation, for habituation day (blue), training day (green), and fear memory retrieval day (red). (J, K). Response fidelities (J), and estimated AP content of the $\mathrm{Ca}^{2+}$ events $(\mathrm{K})$ in response to tone stimulation for all neurons on day 1,2 and 3 (blue, green, and red data, respectively). (L) PSTHs of the movement-onset responses of all imaged neurons, analyzed for times within CS presentations. (M) Percentage of neurons with a significant response to movement onset after freezing. (N) The population PSTH of the movement onset response in the presence of the CS. Colour code is as in (I). (O, P) Response fidelities (O), and estimated AP content of the $\mathrm{Ca}^{2+}$ events $(\mathrm{P})$ in response to movement onset for days 1,2 and 3 (color code as in J, K). (Q) The population PSTH of the movement onset response in the absence of the CS. (R) Response fidelities and estimated AP content of the $\mathrm{Ca}^{2+}$ events for the tone responses, analyzed both during the freezing state of the mouse ("freeze") and when mice moved ("move").

Note the significantly higher response fidelities on all three days when the mice moved, as compared to the freezing state (see Results for statistical significance). (S) The frequency of $\mathrm{Ca}^{2+}$ events, analyzed separately for the four combinations of CS/no CS, and movement/Freezing states of the mice, for habituation day ("Hab"), training day ("train"), and fear memory retrieval day 
1258 ("Ret"). The presence of a CS is indicated by the blue bars. The p-values for the indicated statistical

1259 comparisons are reported in the Results text. (T, U) Maps with the position of all imaged Adora+

1260 AStria neurons from $\mathrm{N}=8$ mice, plotted in the same way as in Figure 2A-C for the D1R+ neurons.

1261 Shown are the footshock-responses (T), and the movement responses imaged on day3 (U). (V)

1262 Venn diagrams showing the overlap of neuronal populations within the Adora + AStria neurons that

1263 respond to tones (green), to movement - onset transitions (blue), and to footshock stimulation on

1264 day 2 (red).

1265

1266

1267

1268

1269

1270

1271 
1272 Figure 4. Optogenetic stimulation of D1R+ and Adora+ AStria neurons has no direct effect

1273 on movement.

1274 (A) Scheme showing the bilateral placement of optic fibers over each AStria, and the injection of

1275 an AAV vector driving the Cre-dependent expression of Chronos. (B) Adora ${ }^{\text {Cre }}$ mice were allowed

1276 to explore the fear conditioning chamber, and trains of blue light stimuli (50 pulses of 1 ms length,

$127725 \mathrm{~Hz}$, duration of 2s) were applied. The average movement indices for $\mathrm{N}=8$ mice are shown,

1278 either centered around the time of light stimulation (red trace), or taken from a control time when

1279 no light was applied ("ctrl TP"). (C) Analogous experiment to the one in (B), now performed for

$1280 \mathrm{D} 1 \mathrm{R}^{\mathrm{Cre}}$ mice $(\mathrm{N}=7)$. Note that optogenetic stimulation of neither Adora + neurons $(\mathrm{B})$, nor of $\mathrm{D} 1 \mathrm{R}+$

1281 neurons led to notable changes in the movement of mice.

1282

1283

1284

1285

1286

1287

1288 
bioRxiv preprint doi: https://doi.org/10.1101/2021.12.09.471922; this version posted December $9,2021$. The copyright holder for this preprint (which was not certified by peer review) is the author/funder, who has granted bioRxiv a license to display the preprint in perpetuity. It is made available under aCC-BY-NC-ND 4.0 International license.

Figure 5. Optogenetic inhibition of D1R+ AStria neurons during footshock reduces auditorycued fear memory retrieval one day later.

(A) Scheme showing the bi-lateral injections in $\mathrm{D} 1 \mathrm{R}^{\mathrm{Cre}}$ mice of an AAV vector driving the expression of either Arch or eGFP (for controls), and the placement of optic fibers over each AStria. (B) Image of a coronal brain section at the indicated Bregma levels, illustrating the fiber placement (black arrows at fiber tip) and Arch expression (green). (C) Behavioral paradigm outlining the 3-day fear-learning protocol. (D) Scheme of the tone - footshock pairing, ending with a $1 \mathrm{~s}$ footshock. The time of the $3 \mathrm{~s}$ yellow light application is indicated (yellow bar; a $3 \mathrm{~s}$ constant light pulse of $561 \mathrm{~nm}$ and $10 \mathrm{~mW}$ at the fiber tip). (E) Freezing levels during 30s CS presentations on the habituation day for the control mice (expressing eGFP; black circles), and for Arch expressing mice (green circles). (F) Time - binned average percent freezing traces for control mice (black data) and Arch - expressing mice (green data; bin width is $10 \mathrm{~s}$ in both cases). Light blue boxes indicate the 30s CS presentation periods. Grey bars indicate epochs of "no CS" analysis. Vertical orange lines indicate the times of footshock presentation. (G) Quantification of freezing during the training day for the control mice and Arch - expressing mice (black and green data, 1304 respectively). Freezing was averaged during the 30s CS presentations (filled circles, left) and for the no CS epochs (open circles, right). (H) Time-resolved freezing during the cued retrieval on day 3. Note the phasic increases in freezing caused by each CS presentation (blue) in control mice (black trace, average of $\mathrm{N}=9$ eGFP expressing mice), which were smaller in amplitude in Arch expressing mice ( $\mathrm{N}=11$, green trace). (I) Quantification of freezing during the 30s CS presentation 1309 (left) and during the no CS epochs (right). Note the significant reduction of freezing during the CS in the Arch group (see Results for statistical significance). 
bioRxiv preprint doi: https://doi.org/10.1101/2021.12.09.471922; this version posted December 9,2021 . The copyright holder for this preprint (which was not certified by peer review) is the author/funder, who has granted bioRxiv a license to display the preprint in perpetuity. It is made available under aCC-BY-NC-ND 4.0 International license.

\section{Figure 6. Optogenetic inhibition reveals a role of Adora+ AStria neurons in suppressing}

1314 learned freezing in the absence of a learned CS.

1315 (A) Scheme of the experimental approach. (B) Example of a post-hoc validation of Arch expression 1316 (green) and the fiber placement (red dashed line) in the AStria of an Adora ${ }^{\text {Cre }}$ mouse. (C) Scheme 1317 of the tone - footshock pairing on the training day (left), and of the time of yellow light application.

1318 (D) Freezing levels during CS presentations on the habituation day for controls mice (expressing 1319 eGFP; black data) and Arch - expressing mice (red filled circles). (E) Time-resolved freezing 1320 analysis for control mice (black trace, average of $\mathrm{N}=8$ mice) and Arch - expressing mice (red 1321 trace, $\mathrm{N}=10$ ), displayed for $10 \mathrm{~s}$ bins. Bars and boxes have the same meaning as in Figure 5F. (F)

1322 Quantification of freezing during the 30s CS presentations (left), and during the 30s "no CS"

1323 epochs (right), both for control mice (black) and Arch - expressing mice (red). (G) Time-resolved 1324 freezing during the fear memory retrieval day. Color codes are as in $(\mathrm{E})$. (H) Average percent of 1325 time spent freezing, analyzed during the 30s CS presentations (left), and during the no CS epochs 1326 (right) of the fear memory retrieval day, for both groups of mice. Note the significantly enhanced 1327 freezing in the Arch group at times when no CS was present (right; for statistical significance see 1328 Results). 
bioRxiv preprint doi: https://doi.org/10.1101/2021.12.09.471922; this version posted December $9,2021$. The copyright holder for this preprint (which was not certified by peer review) is the author/funder, who has granted bioRxiv a license to display the preprint in perpetuity. It is made available under aCC-BY-NC-ND 4.0 International license.

Figure 7. Retrograde transsynaptic tracing of brain-wide inputs to both D1R+ and Adora+

1331

1332

1333

1334

1335

1336

1337

1338

1339

1340

1341

1342

1343

1344 and Paxinos, 2016).

\section{AStria neurons.}

(A) Scheme of the experimental protocol for rabies-virus mediated transsynaptic tracing. (B) Left, Example confocal images of the injection site in a $\mathrm{D} 1 \mathrm{R}^{\mathrm{Cre}}$ mouse, Right, confocal images at a higher magnification taken from the boxed area of the left image. Green, red and blue channels are eGFP-labelled cells expressing the helper viruses (green), rabies-virus expressing cells (red) and DAPI labelling (blue, only shown in the overlay images). Scale bars, $200 \mu \mathrm{m}$ (left) and $50 \mu \mathrm{m}$ $(r i g h t) .(\mathbf{C}, \mathbf{D})$ Example widefield epifluorescence images of rabies virus - labelled presynaptic neurons in coronal sections, from a D1R ${ }^{\text {Cre }}$ mouse (C) and an Adora ${ }^{\text {Cre }}$ mouse (D). The abbreviations of brain areas are shown in Figure 7, Suppl. Table 1. Scalebars, $250 \mu \mathrm{m}$. (E, F) Localizations of presynaptic neurons plotted in a 3D brain model, both for $\mathrm{D} 1 \mathrm{R}^{\mathrm{Cre}}(\mathrm{E})$ and $\mathrm{Adora}{ }^{\mathrm{Cre}}$ (F) mice. Each brain shows the results of two animals (blue and red dots) with one dataset being artificially mirrored on the other hemisphere for each genotype. For orientation, some brain areas are highlighted (S2 - green, InsCtx - yellow, PF - red, BLA - pink). (G, H) Quantification of labelled neurons for each brain area. Upwards and downward data signify cell density and absolute number of cells, quantified for $\mathrm{N}=2$ mice of each genotype. Data from single animals are plotted as filled grey circles and triangles (I, J) Distribution of presynaptic neurons along the anterior posterior axis in the insular cortex (I), and in the secondary somatosensory cortex $(\mathrm{J})$. The dashed line indicates the border between the anterior and posterior insular cortex according to (Franklin 
bioRxiv preprint doi: https://doi.org/10.1101/2021.12.09.471922; this version posted December $9,2021$. The copyright holder for this preprint (which was not certified by peer review) is the author/funder, who has granted bioRxiv a license to display the preprint in perpetuity. It is made available under aCC-BY-NC-ND 4.0 International license.

1351

1352

1353

1354

1355

1356

1357

1358

1359

1360

1361

1362

1363

1364

1365

1366

1367

1368

1369

1370

1371

1372

1373

1374

Figure 8. pInsCx provides strong excitatory inputs onto D1R+ - and Adora+ AStria neurons which show differential plasticity after fear learning.

(A) Experimental scheme of injection of an AAV vector driving the expression of Chronos into the pInsCx, and subsequent slice electrophysiology in the AStria. (B) Left, example fluorescence images of the injection site in the cortex expressing Chonos-eGFP (scalebar, $500 \mu \mathrm{m}$ ); middle, overview brightfield image with the position of the patch pipette (black dotted lines) in the AStria; right, higher magnification images examples of a recorded example cell (brightfield, top; and tdTomato fluorescence, bottom). (C, D) Left, EPSCs recorded by stimulating with $1 \mathrm{~ms}$ light pulses of increasing intensities (blue, photodiode-recorded trace), and right, the resulting input-output curve of EPSC amplitude versus light intensity, with data from all recorded cells overlaid. The example cell shown on the left is highlighted in black in the right panel. Data is shown for D1R+ AStria neurons $(\mathrm{C}, \mathrm{n}=12$ recordings $)$ and Adora + AStria neurons $(\mathrm{D}, \mathrm{n}=19$ recordings $)$. Quantification of the maximal amplitude of EPSCs (left), and of the EPSC delay (right) measured in D1R+ - and Adora+ AStria neurons ( $\mathrm{n}=12$ and $\mathrm{n}=19$, respectively). (F) Timeline of the exvivo patch-clamp plasticity experiments. See Results for details. (G) Example traces for NMDAEPSCs recorded at $+50 \mathrm{mV}$ (top traces), and for AMPA-EPSCs at $-70 \mathrm{mV}$ (bottom traces), recorded in $\mathrm{D} 1 \mathrm{R}+$ neurons in each experimental group (left). The right panel shows the quantification of AMPA/NMDA ratios and paired-pulse ratios (50 ms inter-stimulus interval) recorded in each group of D1R $\mathrm{R}^{\mathrm{Cre}}$ mice ("CS only", $\mathrm{n}=11$ recordings; "CS+US", $\mathrm{n}=12$ ).

Example AMPA-EPSC traces for the measurement of paired-pulse ratio (50 ms inter-stimulus interval) recorded in Adora+ neurons in each experimental group, as indicated. Right, quantification of AMPA/NMDA ratios, and paired-pulse ratios recorded in each group of Adora ${ }^{\mathrm{Cre}}$ mice ("CS only", $\mathrm{n}=12$ recordings; "CS+US", $\mathrm{n}=12$ ). 


\section{Figure Legends for Figure Supplements}

\section{Figure 1, Figure Suppl. 1.}

1377 Exact timing of tone blocks (CS) and footshocks on each day of the fear learning protocol. Each tone block (CS presentation) consisted of $\mathrm{n}=30$ tone beeps $(7 \mathrm{kHz}, 80 \mathrm{~dB})$ of $100 \mathrm{~ms}$ length,

1379 repeated at $1 \mathrm{~Hz}$. On the training day, each CS was terminated by a $1 \mathrm{~s}$ footshock $(0.6 \mathrm{~mA})$. For 1380 further details of the fear learning protocol, see Materials and Methods.

Figure 1, Figure Suppl. 2.

1383 (A) PSTH of movement - onset responses of all imaged D1R+ AStria neurons, in the absence of a 1384 CS.

(B) Corresponding PSTH of the movement - onset responses, averaged over the entire population of imaged neurons. Note the only small population response to movement onset in the absence of a CS (compared with Figure 1L, during the CS).

\section{Figure 1, Figure Suppl. 3.}

1390 (A, B) PSTHs of $\mathrm{Ca}^{2+}$ event frequency for individual D1R+ neurons (A), and the population PSTH 1391 (B), aligned to freezing onset, for events that had occurred during the CS. Note the decreased $\mathrm{Ca}^{2+}$ event frequency at the onset of freezing on the training day and on the fear memory retrieval day (B, green and red traces).

(C) A plot of the averaged event frequency, normalized to pre-freezing baseline, revealed a statistically significant reduction in $\mathrm{Ca}^{2+}$ event frequency during day 2 and day 3 (p $<0.001$ for both; one-sample t-test).

Figure 1, Figure Suppl. 4.

(A, B) PSTHs of $\mathrm{Ca}^{2+}$ event frequency for individual neurons (A), and the population PSTH (B), 1400 aligned to freezing onset in the absence of the CS. 


\section{Figure 3, Figure Suppl. 1.}

1402 PSTH of $\mathrm{Ca}^{2+}$ event frequency for individual Adora+ neurons, aligned to tone onset, irrespective

1403 whether the mouse moved, or froze. See Figure 3I for the corresponding population PSTH.

1404

1405 Figure 3, Figure Suppl. 2.

1406 (A, B) PSTH of $\mathrm{Ca}^{2+}$ event frequency for individual Adora + neurons (A), and the corresponding 1407 population PSTH (B), aligned to the onset of freezing, for events that had occurred during the CS.

1408 (C) A plot of the averaged event frequency, normalized to pre-freezing baseline, revealed a

1409 significant reduction in event frequency during the fear memory retrieval day $(\mathrm{p}<0.001$; one-

1410 sample t-test). 
bioRxiv preprint doi: https://doi.org/10.1101/2021.12.09.471922; this version posted December $9,2021$. The copyright holder for this preprint (which was not certified by peer review) is the author/funder, who has granted bioRxiv a license to display the preprint in perpetuity. It is made available under aCC-BY-NC-ND 4.0 International license.

\section{Figure 5, Figure Suppl. 1.}

1417 Properties of light-activated archaerhodopsin, as measured in D1R+ - and Adora + AStria neurons 1418 in slice electrophysiology at $34^{\circ} \mathrm{C}$.

1419 (A) An Adora ${ }^{\mathrm{Cre}} \mathrm{x}$ Ai14 mouse was injected with AAV1:CAG:FLEX:Arch-eGFP AAV vector into 1420 the Astria, and in-vitro patch-clamp recordings of Arch - expressing neurons were performed 3-6

1421 weeks later. Example of light-induced currents evoked by $300 \mathrm{~ms}$ exposures with increasing light

$1422(530 \mathrm{~nm})$ intensities in an Adora + neuron expressing Arch. Maximal light intensity was 15

$1423 \mathrm{~mW} / \mathrm{mm}^{2}$; the holding potential was $-70 \mathrm{mV}$.

1424 (B) Quantification of the maximal plateau current measured at the end of the light pulse (grey

1425 dashed box in A) for D1R+ - $(\mathrm{n}=7)$ and Adora+ AStria neurons $(\mathrm{n}=13)$ expressing Arch.

1426 (C) Example traces recorded in current-clamp showing that light exposure ( $3 \mathrm{~s})$ was sufficient to

1427 block APs generated by a 1s current injection (no light, black trace; with light, red trace). This

1428 observation was made in all neurons recorded under current-clamp.

1429 (D-F) Repeated light exposures (300 ms pulses at $1 \mathrm{~Hz}, 30$ times) were applied to test for the

1430 efficiency of repeated hyperpolarizations, and for possible rebound APs after light offset.

1431 Hyperpolarization $(\mathrm{E})$ and rebound potentials $(\mathrm{F})$ were quantified for $\mathrm{D} 1 \mathrm{R}+(\mathrm{n}=6)$ and Adora +

1432 AStria neurons $(\mathrm{n}=13)$.

1433

1434 
1435

1436

1437

1438

1439

1440

1441

1442

1443

1444

1445

1446

1447

1448

1449

1450

1451

1452

1453

1454

1455

1456

1457

1458

1459

1460

\section{Figure 7, Figure Suppl. 1.}

Additional example images for transsynaptically retrogradely labelled neurons after injection of an AAV helper virus, and a rabies virus, into the AStria of a D1 $\mathrm{R}^{\mathrm{Cre}}$ mouse (A) and into the AStria of an Adora ${ }^{\text {Cre }}$ mouse (B). The images on the left sides illustrate a weak density of labelled neurons in the amygdalar region (left images, CeA, BLA, and LA, see also Figure $7 \mathrm{G}, \mathrm{H}$ for the quantifications). The images on the right sides illustrate labeling in a confined region of the PF (right images), which led to a notably high density of back-labelled neurons in the PF (see also Figure 7 G, H for the quantifications, and Figure 7, Figure Suppl. 1 - Table for the abbreviations of brain areas).

\section{Figure 7, Figure Suppl. 2.}

Analysis of the number of back-labelled neurons in $\mathrm{Adora}^{\mathrm{Cre}}$ mice relative to $\mathrm{D} 1 \mathrm{R}^{\mathrm{Cre}}$, according to the analysis of cell numbers shown in Figure 7G, H. The numbers were sorted according to relatively stronger back-labelling of brain areas observed in Adora ${ }^{\mathrm{Cre}}$ mice than in $\mathrm{D} 1 \mathrm{R}^{\mathrm{Cre}}$ (beginning on the left hand side). Note that Adora+ AStria neurons showed larger proportions of back-labelled presynaptic neurons in the lateral amygdala (LA), basolateral amygdala (BLA), central amygdala (CeA), temporal association cortex (TeA), and auditory cortex (AUD), as compared to D1R+ neurons; interestingly, these areas represent limbic - auditory areas with roles in associative learning (LeDoux, 2000; Weinberger, 2007; Sacco and Sacchetti, 2010; Dalmay et al., 2019). On the other hand, a higher proportion of neurons providing input to $\mathrm{D} 1 \mathrm{R}+$, as compared to Adora+ AStria neurons, was found in the S1, in the somatosensory thalamus (VPM), motor cortex (MO) and piriform cortex (PIR).

\section{Figure 7, Suppl. Table 1.}

Definition of brain area abbreviations, and correspondence of the names across the Allen Brain Atlas and the Mouse Brain Atlas of Franklin and Paxinos (2016). 


\section{Figure 8, Figure Suppl. 1}

1462 (A) Left panel, example traces of paired-pulse ratio measurements at $50 \mathrm{~ms}$ inter-stimulus interval.

1463 Traces are from a D1R ${ }^{\text {Cre }}$ and Adora ${ }^{\text {Cre }}$ mouse (green and red traces, respectively). Right,

1464 quantification of the paired-pulse ratio from all recorded cells $(\mathrm{n}=12 \mathrm{D} 1 \mathrm{R}+$ and $\mathrm{n}=18$ Adora +

1465 AStria neurons).

1466 (B) Excitation-inhibition (E/I) ratio was measured by recording optogenetically-evoked EPSCs at -

$146770 \mathrm{mV}$, and subsequently recording optogenetically-evoked IPSCs at the reversal potential for the

1468 EPSCs ( +5 to $+15 \mathrm{mV}$ across experiments). Left panel shows example traces, the quantification of

1469 E/I ratio (middle), and the quantification of latency between the start of the light pulse and the

1470 respective PSC (right, for $\mathrm{n}=12 \mathrm{D} 1 \mathrm{R}+$ and $\mathrm{n}=14$ Adora + AStria neurons). The statistical

1471 information for E/I ratios is given in the Results text. The delays for EPSCs were significantly

1472 shorter than the delays for IPSCs (D1R: $p=0.001$, paired t-test; Adora: $p<0.0001$, Wilcoxon

1473 matched-pairs signed-rank test). Data are shown as average \pm SEM.

1474

1475 Figure 8, Figure Suppl. 2

1476 EPSC traces illustrating the measurement of paired-pulse ratios in a D1R+ neuron from a mouse

1477 that had undergone the "CS only" protocol (left), and in a D1R+ neuron from a mouse that had

1478 undergone the "CS+US" protocol. Relates to the dataset shown in Figure 8G.

1479

1480 Figure 8, Figure Suppl. 3

1481 EPSC traces illustrating the measurement of AMPA/NMDA ratios in a Adora + neuron from a

1482 Adora $^{\mathrm{Cre}} \mathrm{x}$ Ai14 mouse that had undergone the "CS only" protocol (left), and in a Adora + neuron

1483 from a Adora ${ }^{\mathrm{Cre}} \mathrm{x}$ Ai14 mouse that had undergone the "CS+US" protocol. Relates to the dataset

1484 shown in Figure 8H. 
bioRxiv preprint doi: https://doi.org/10.1101/2021.12.09.471922; this version posted December 9,2021 . The copyright holder for this preprint (which was not certified by peer review) is the author/funder, who has granted bioRxiv a license to display the preprint in perpetuity. It is made available under aCC-BY-NC-ND 4.0 International license.

\section{Figure 8, Figure Suppl. 4}

1488 Anatomical evidence that D1R+ and Adora+ AStria neurons are analogous to striato-nigral, and

1489 striato-pallidal neurons of a direct, and indirect pathway, respectively. The images show slide

1490 scanner images of the fluorescence of eGFP, after bi-lateral injection of AAV1:CAG:FLEX:eGFP

1491 into the AStria of $\mathrm{D} 1 \mathrm{R}^{\mathrm{Cre}}$ - and Adora ${ }^{\mathrm{Cre}}$ mice $(\mathrm{B}, \mathrm{C}$, respectively). Note that eGFP expression in

$1492 \mathrm{D} 1 \mathrm{R}+$ neurons of the AStria leads to axonal labelling in the GPe which we interpret as axons of

1493 passage, and to labeling in the GPi and SNR which is confined to the lateral parts of these nuclei.

1494 On the other hand, eGFP expression in Adora+ neurons of the AStria leads to labeling in the GPe.

1495 The experiments were taken from the control data sets of in-vivo optogenetic experiments of

1496 Figures 5, 6. 
C

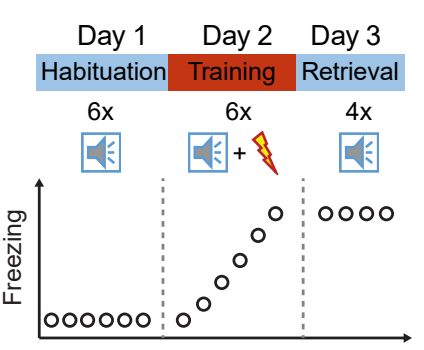

Day 2:

Training

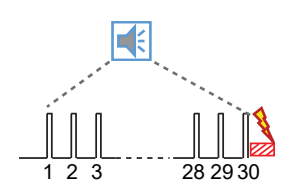

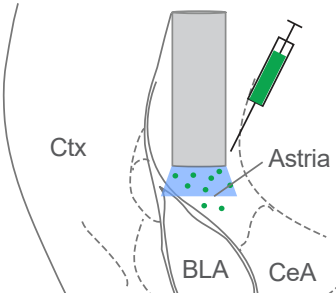

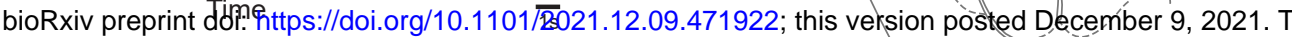
preprint (which was not certified by peer review) is the author/funder, who has granted bioRxiv a license

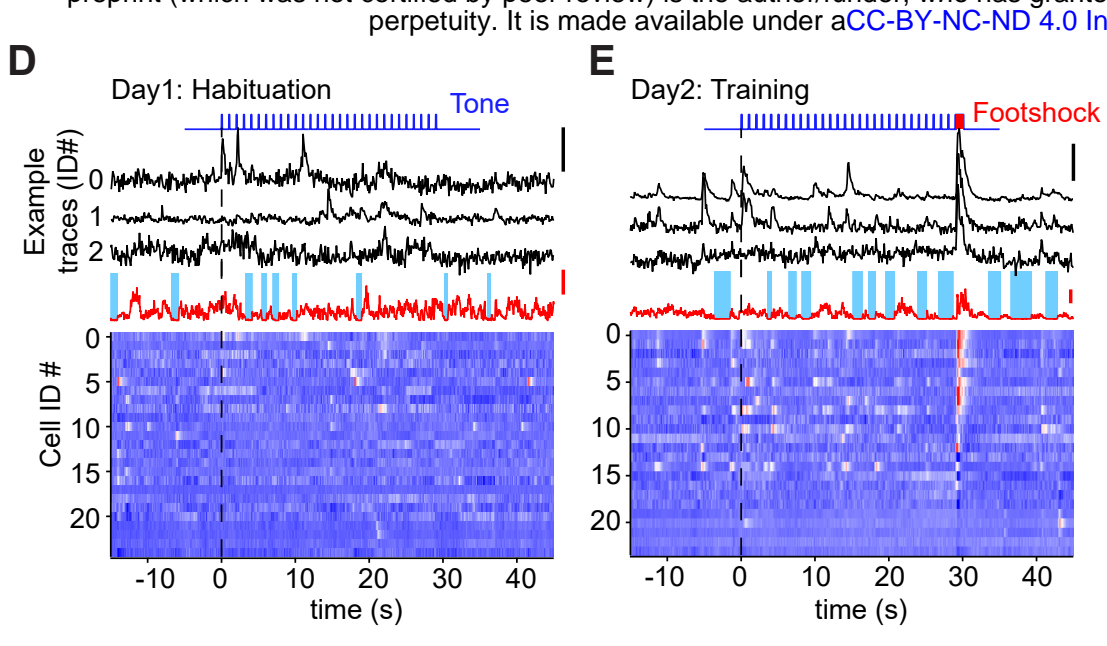

perpetuity. It is made

$$
F
$$

Day3: Retrieval
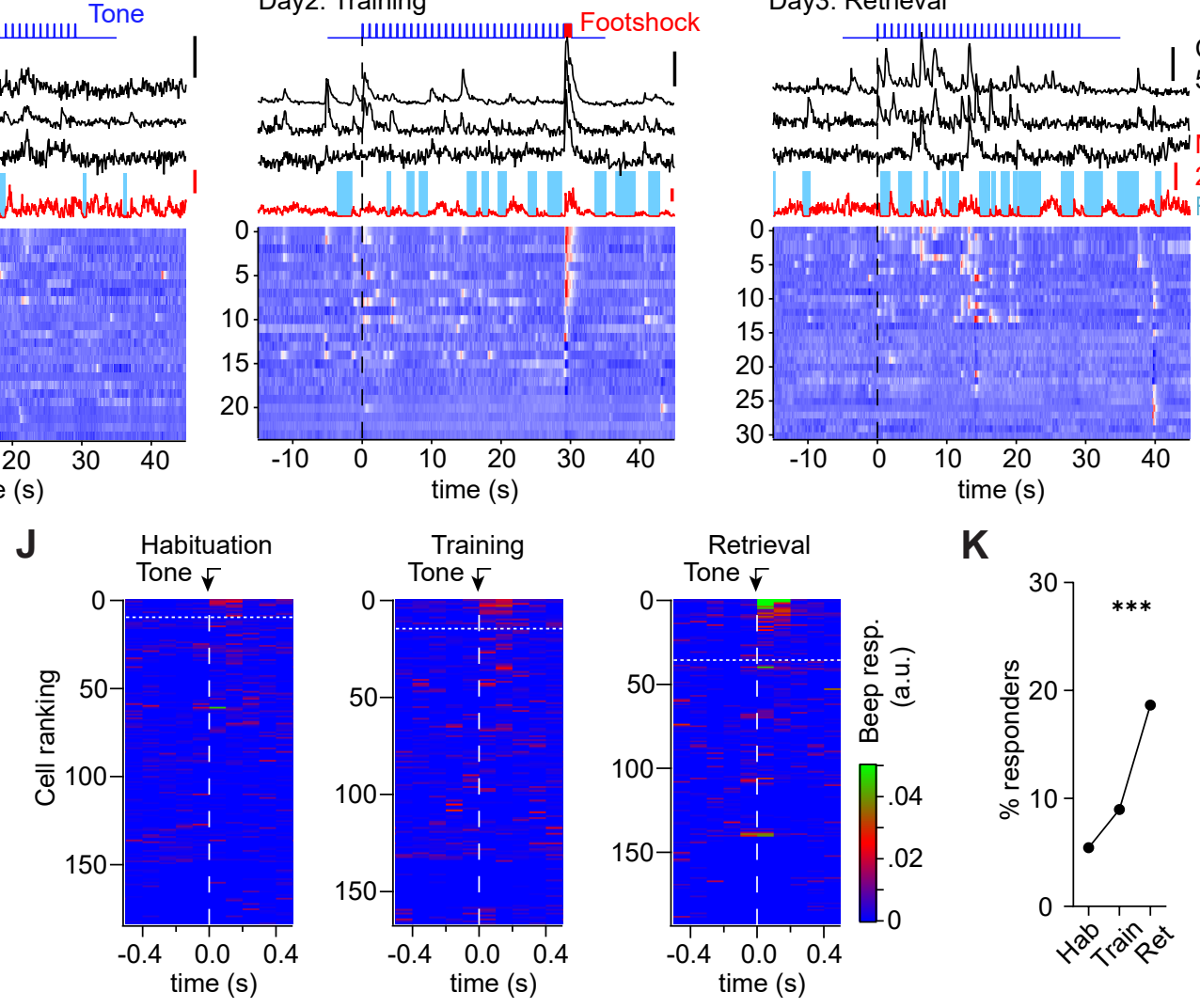

K

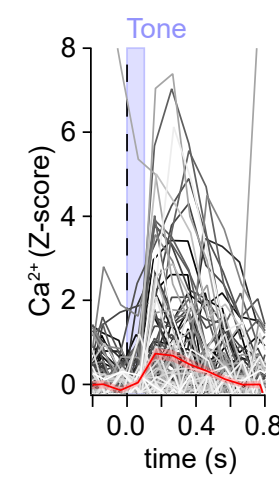

M
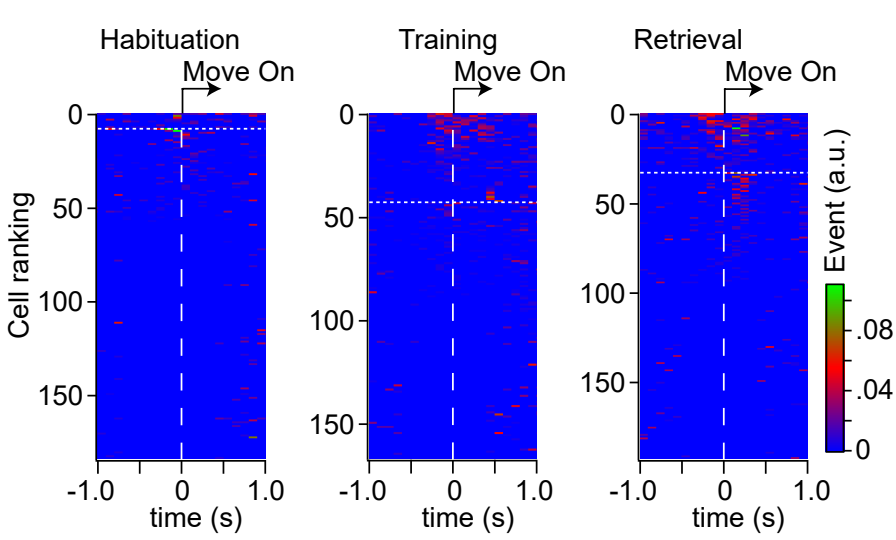

$\mathbf{N}$
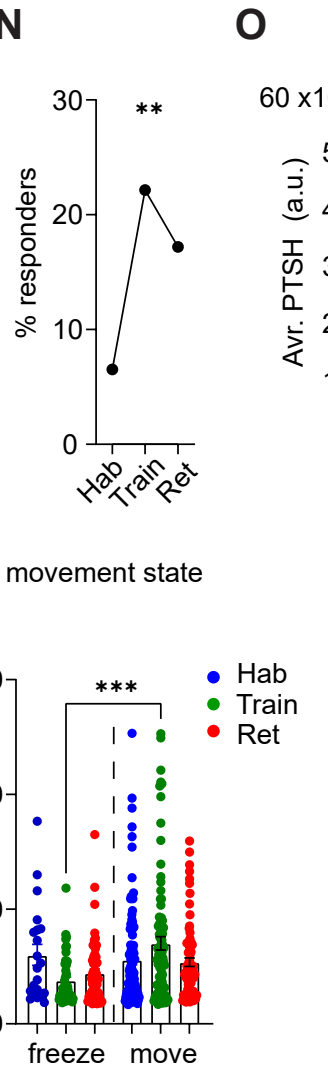

G
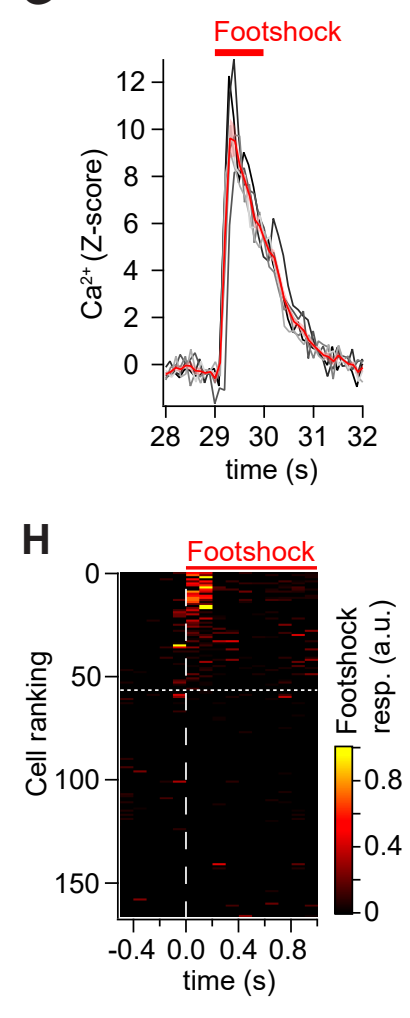

L

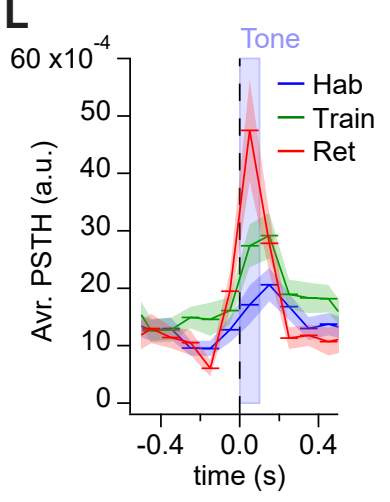

Z-Score

Movement reezing
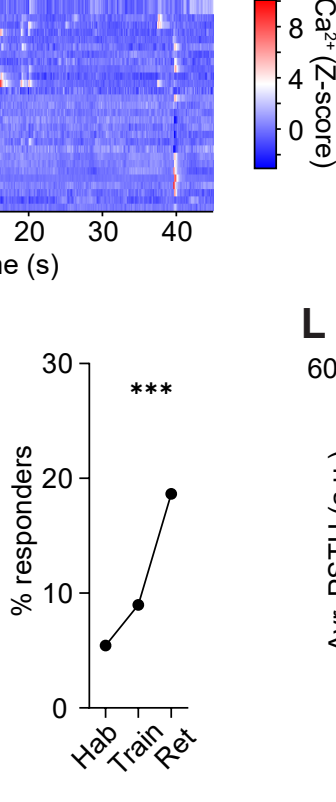

P

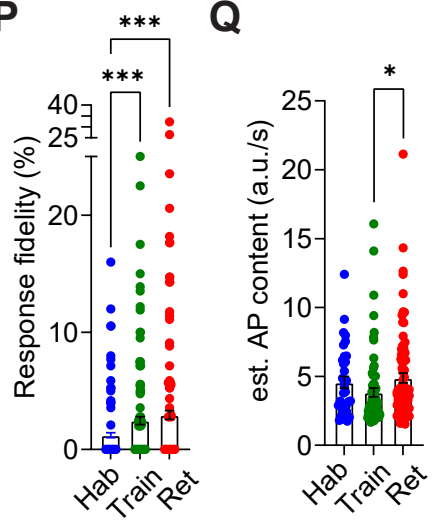

T
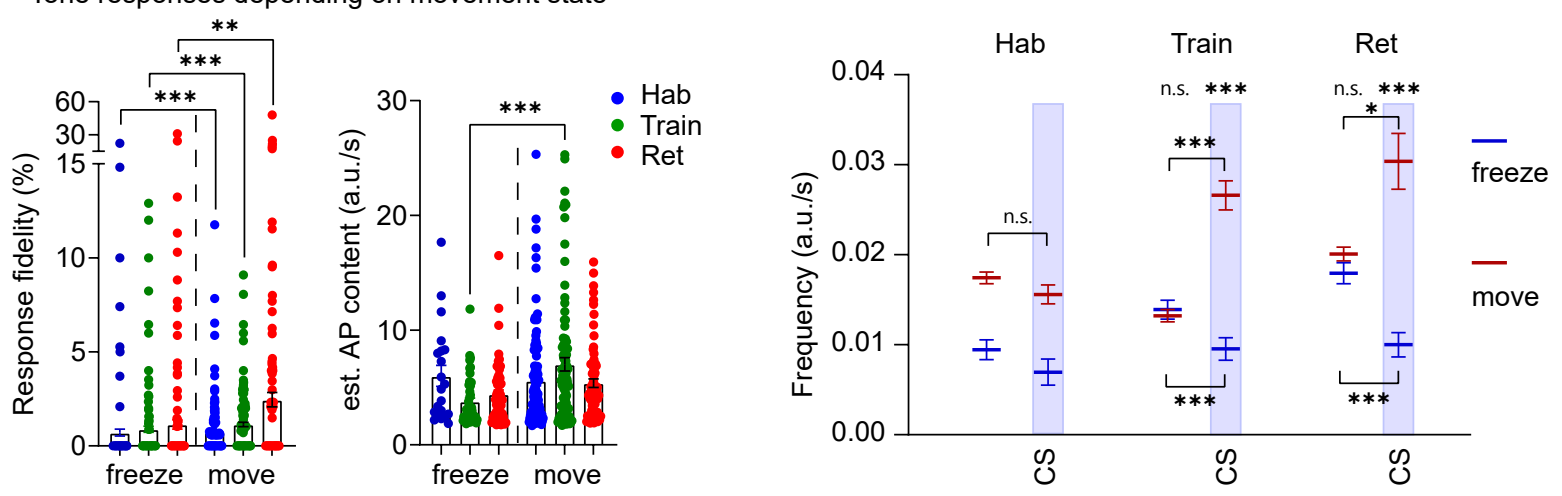
bioRxiv preprint doi: https://doi.org/10.1101/2021.12.09.471922; this version posted December 9, 2021. The copyright holder for this preprint (which was not certified by peer review) is the author/funder, who has granted bioRxiv a license to display the preprint in perpetuity. It is made available under aCC-BY-NC-ND 4.0 International license.

A

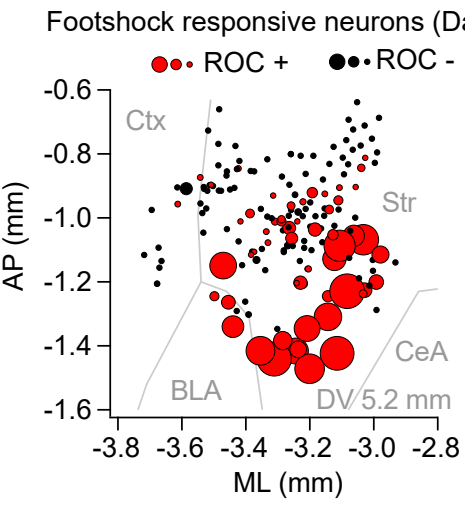

B

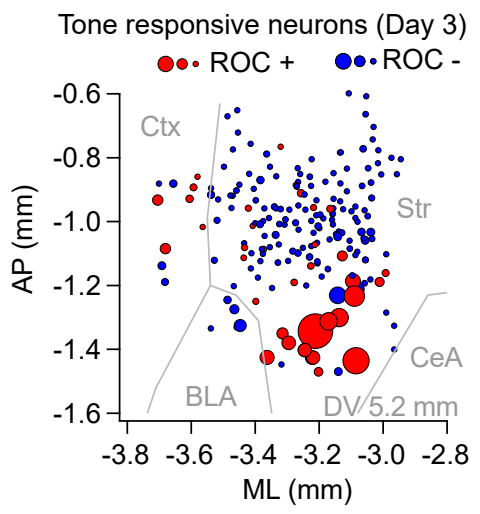

C

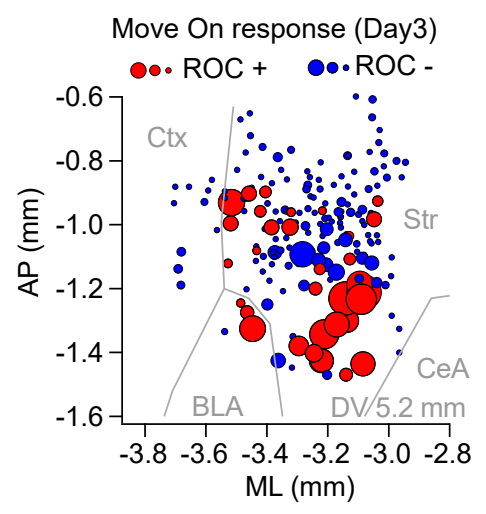

D

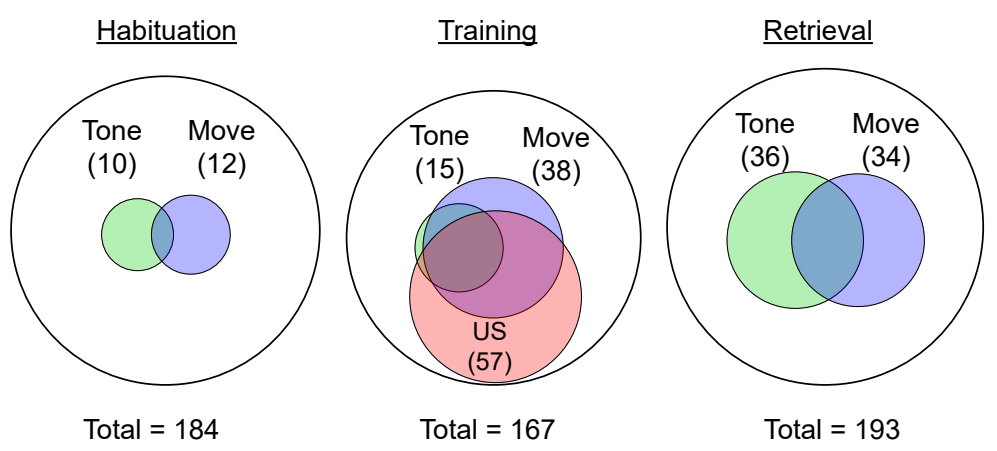


A

AAV1:hSyn:FLEX:GCaMP6m
B

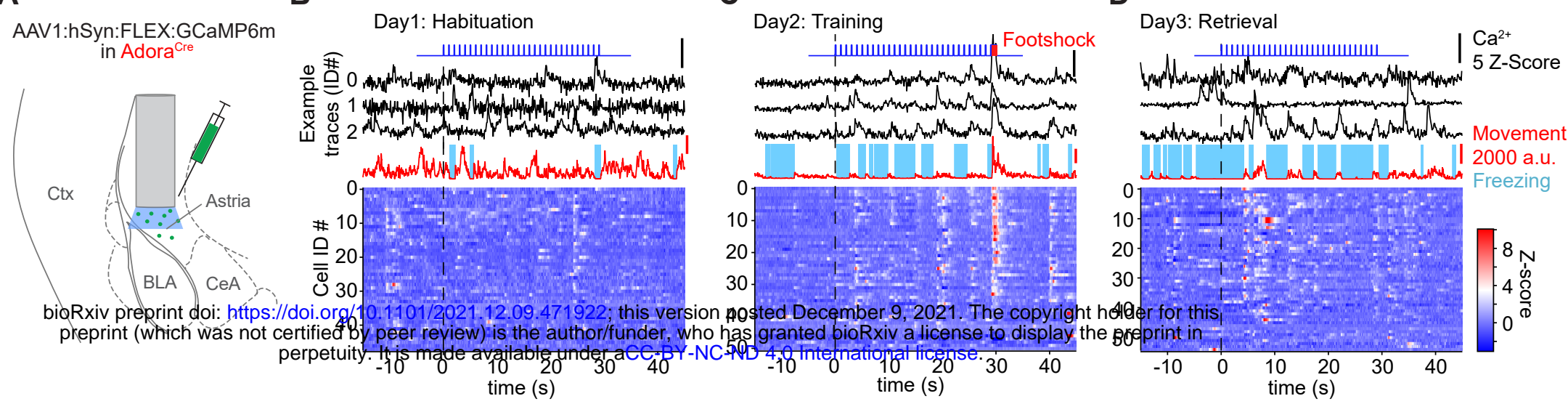

C

Day2: Training

D

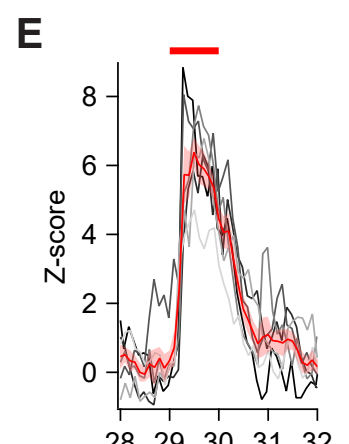

$\begin{array}{lllll}28 & 29 & 30 & 31 & 32\end{array}$ time (s)

L

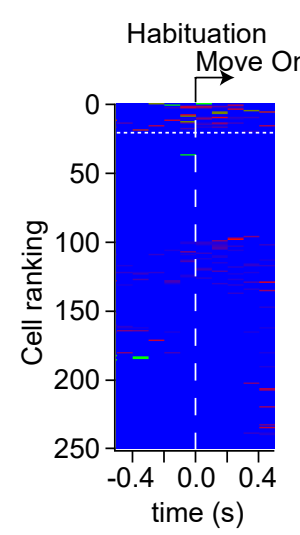

Q

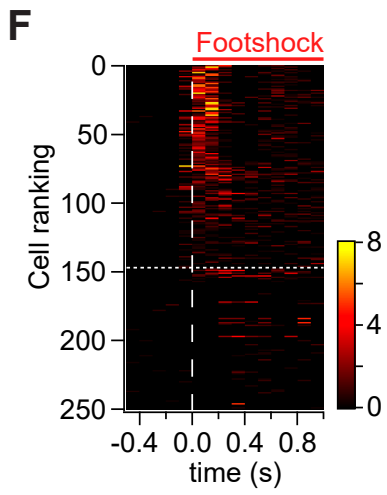

G
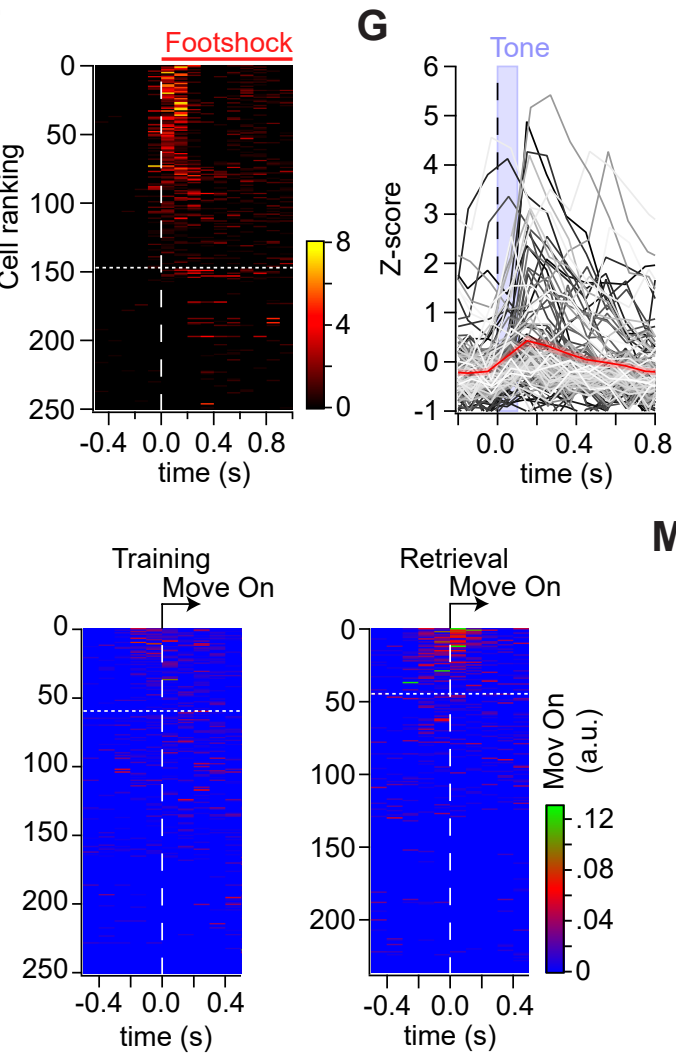

R

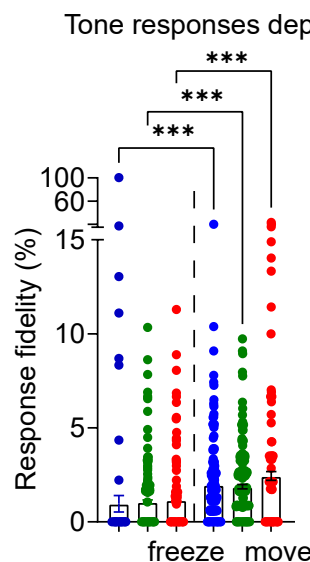

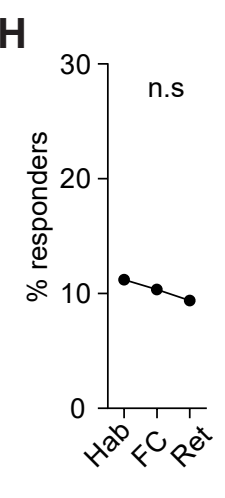

M

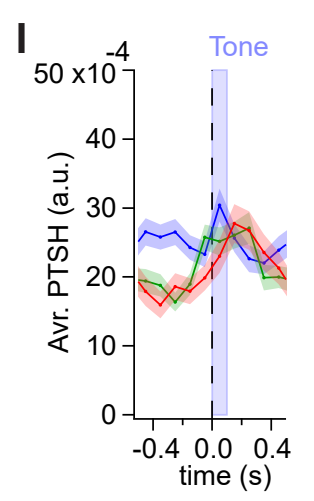

N
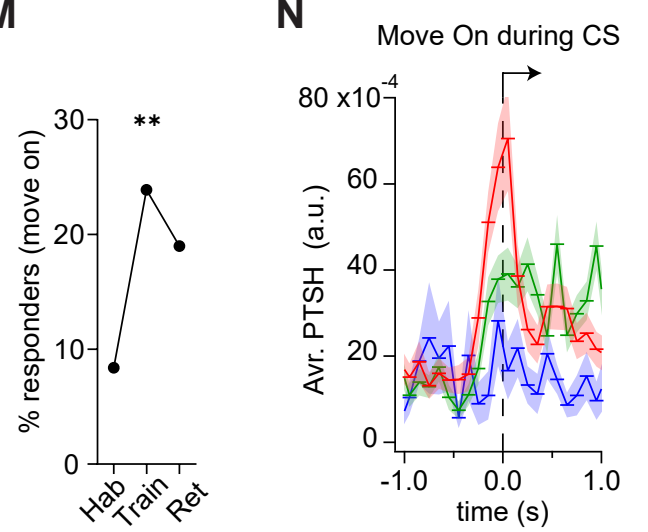

ing on movement state

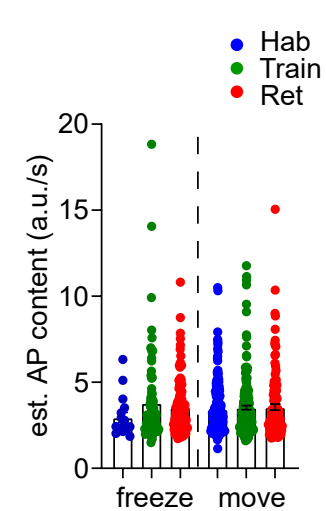

V

S

T

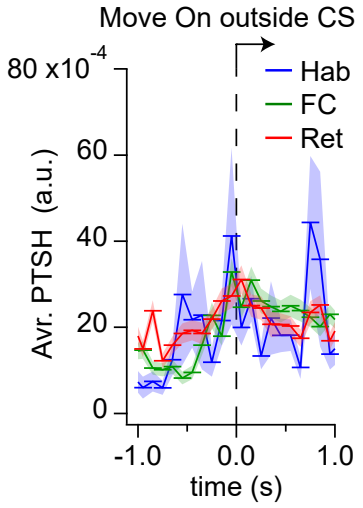

U
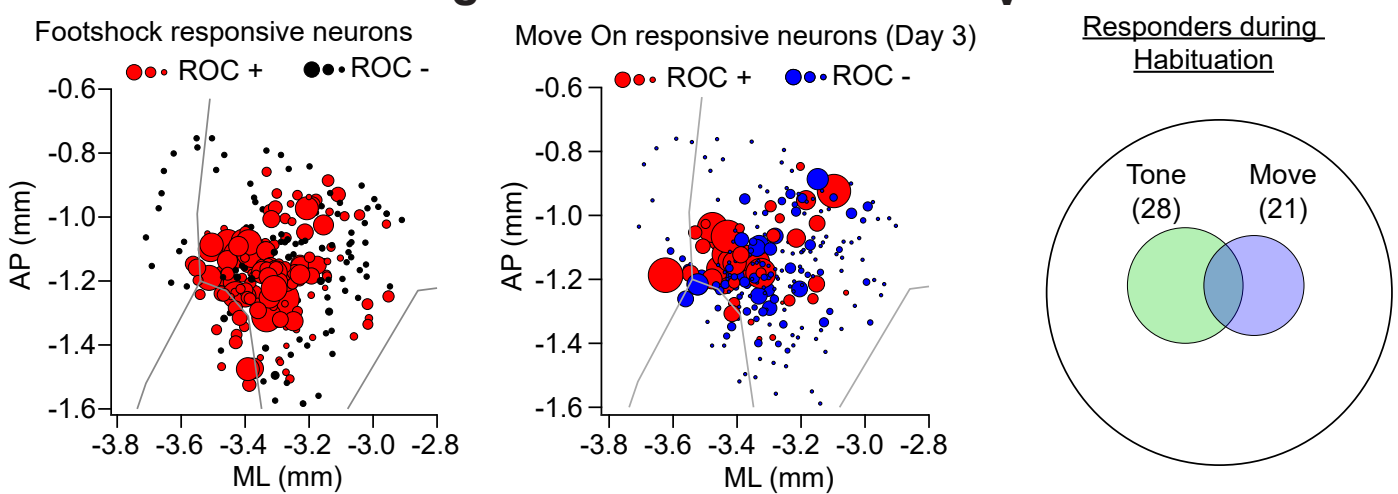

Total $=250$

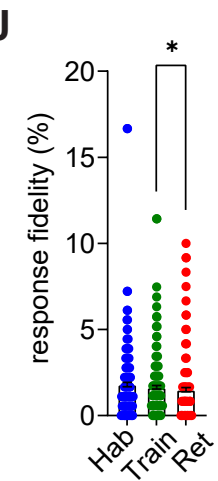

$\mathrm{K}$
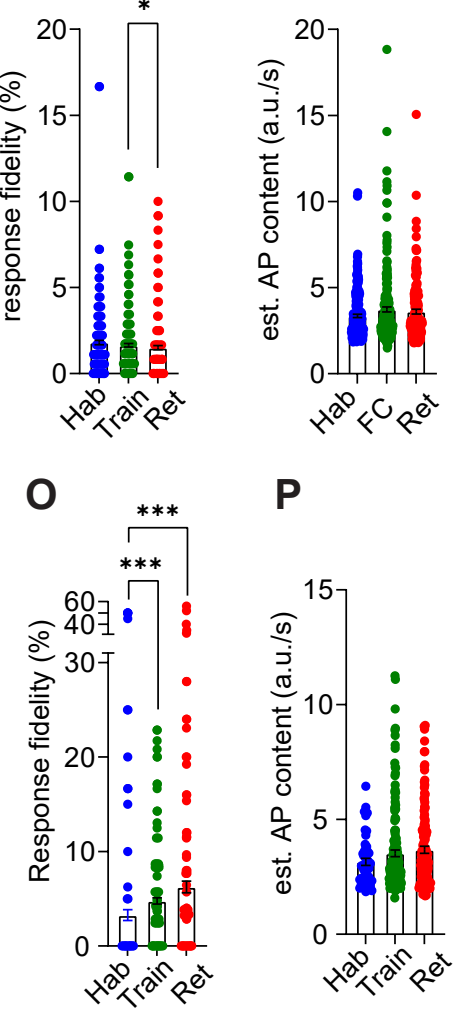

P
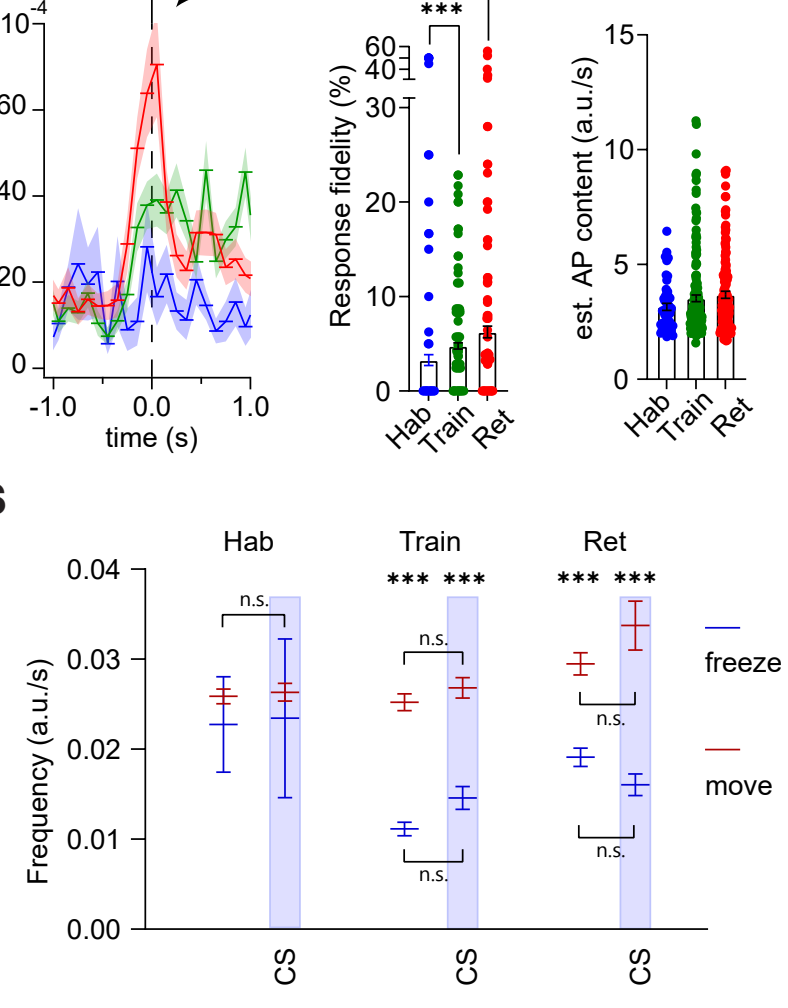

$\frac{\text { Responders during }}{\text { Training }}$

Responders during Retrieval
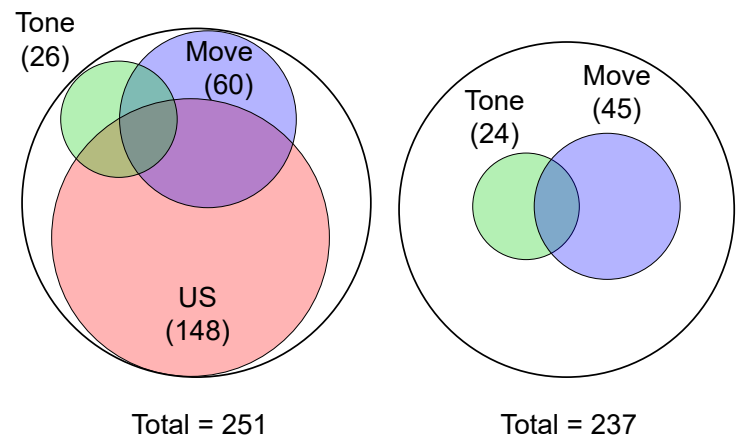
bioRxiv preprint doi: https://doi.org/10.1101/2021.12.09.471922; this version posted December 9, 2021. The copyright holder for this preprint (which was not certified by peer review) is the author/funder, who has granted bioRxiv a license to display the preprint in perpetuity. It is made available under aCC-BY-NC-ND 4.0 International license.

A

AAV1:hsyn:FLEX:Chronos-eGFP in $\mathrm{D} 1 \mathrm{R}^{\mathrm{Cre}}$ or Adora ${ }^{\mathrm{Cre}}$

injection site : ventral tail striatum
B

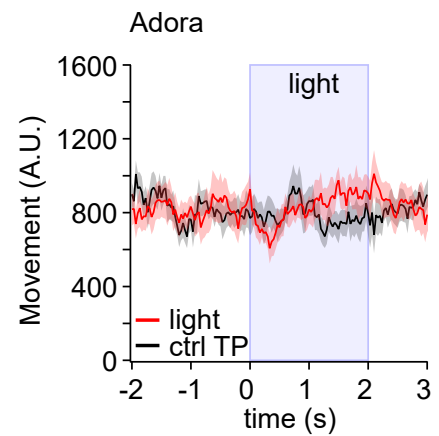

C

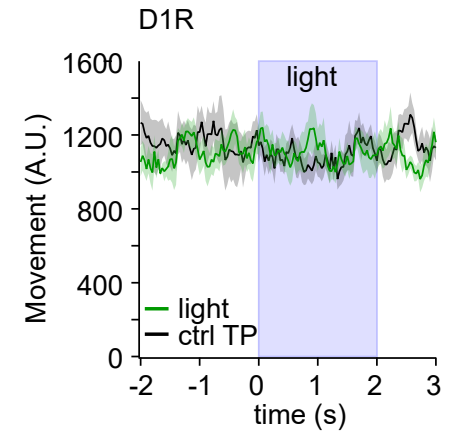


bioRxiv preprint doi: https://doi.org/10.1101/2021.12.09.471922; this version posted December 9, 2021. The copyright holder for this

preprint (which was not certified by peer review) is the author/funder, who has granted bioRxiv a license to display the preprint in perpetuity. It is made available under aCC-BY-NC-ND 4.0 International license.

A

AAV1:CAG:FLEX:Arch-eGFP in $\mathrm{D} 1 \mathrm{R}^{\mathrm{Cre}}$

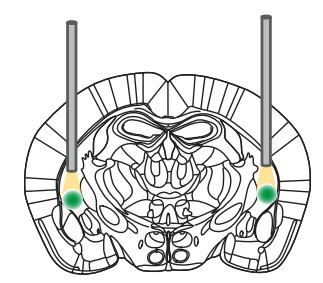

injection site : Astria
B

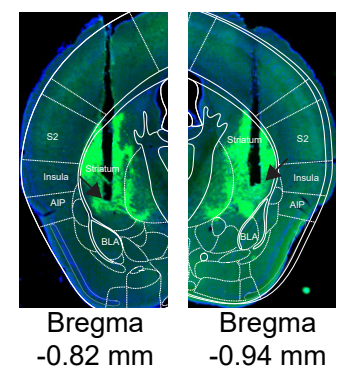

C

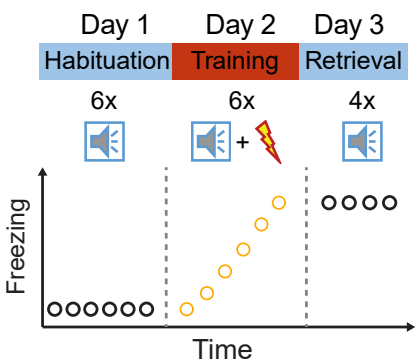

D

Day 2 :

Training

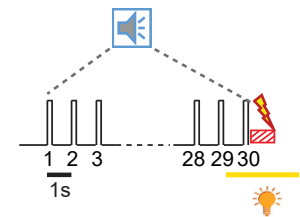

E Day1:

Habituation

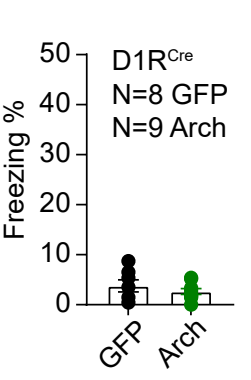

F Day2: Training

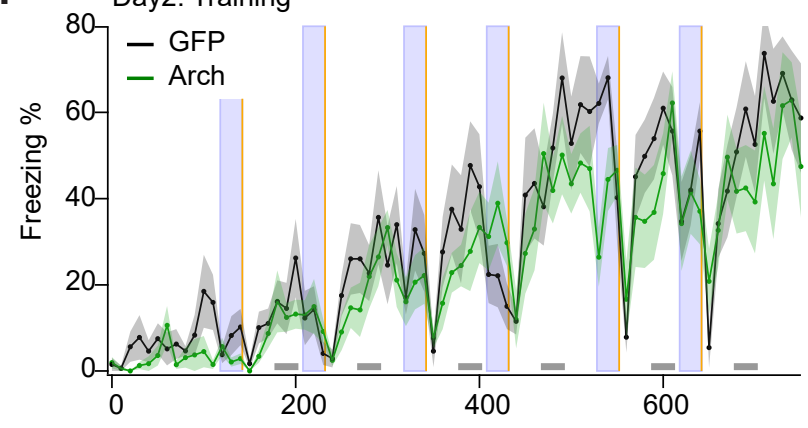

G

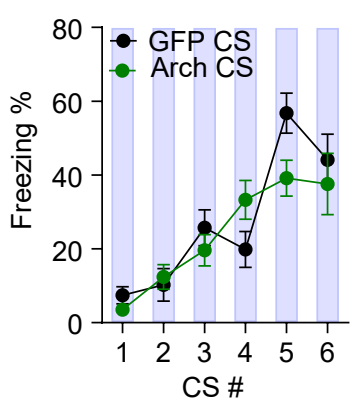
- GFP no CS
- Arch no CS

H

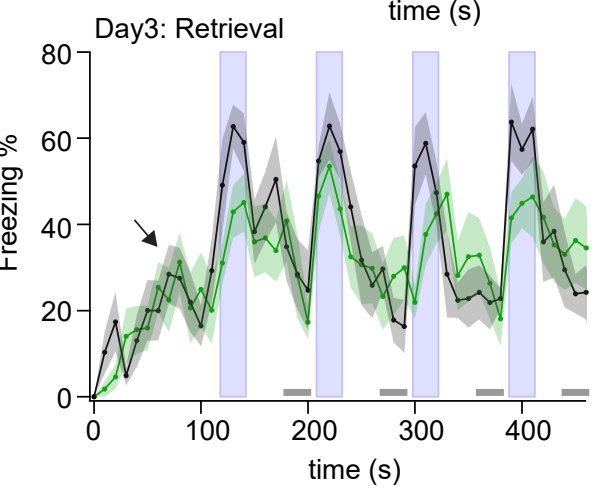

I
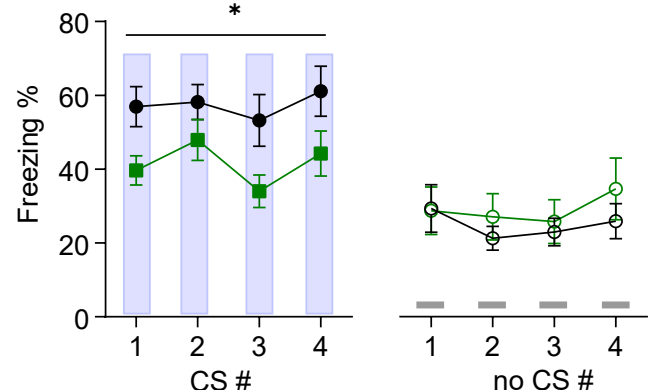

Figure 5 
bioRxiv preprint doi: https://doi.org/10.1101/2021.12.09.471922; this version posted December 9, 2021. The copyright holder for this preprint (which was not certified by peer review) is the author/funder, who has granted bioRxiv a license to display the preprint in perpetuity. It is made available under aCC-BY-NC-ND 4.0 International license.

A AAV1:CAG:FLEX:Arch-eGFP in Adoracre

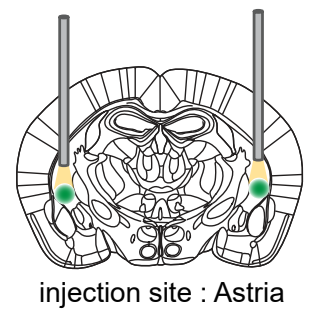

E

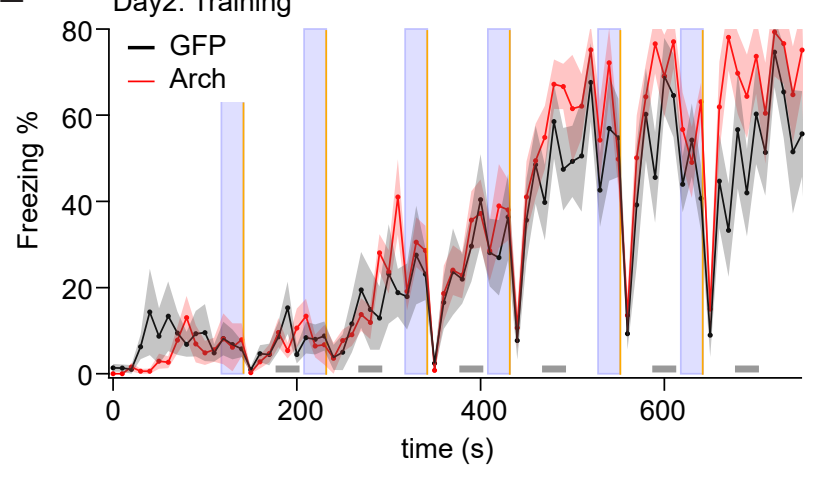

C

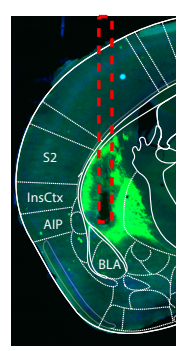

Bregma $-0.94 \mathrm{~mm}$

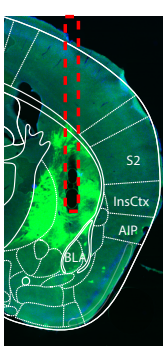

Bregma $-0.94 \mathrm{~mm}$
Day 2 :

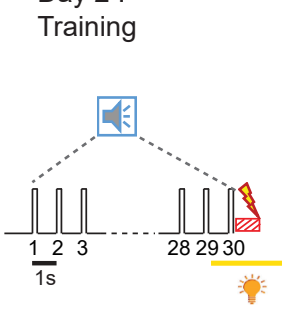

D Day1:

Habituation

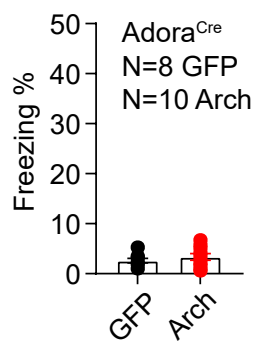

F

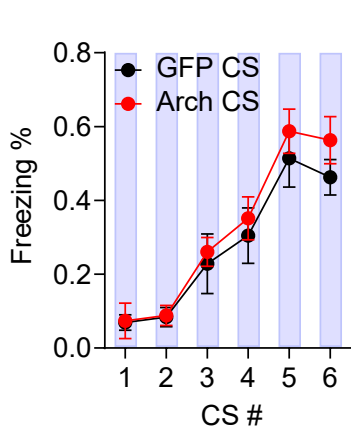

- Arch no CS

$\rightarrow$ GFP no CS
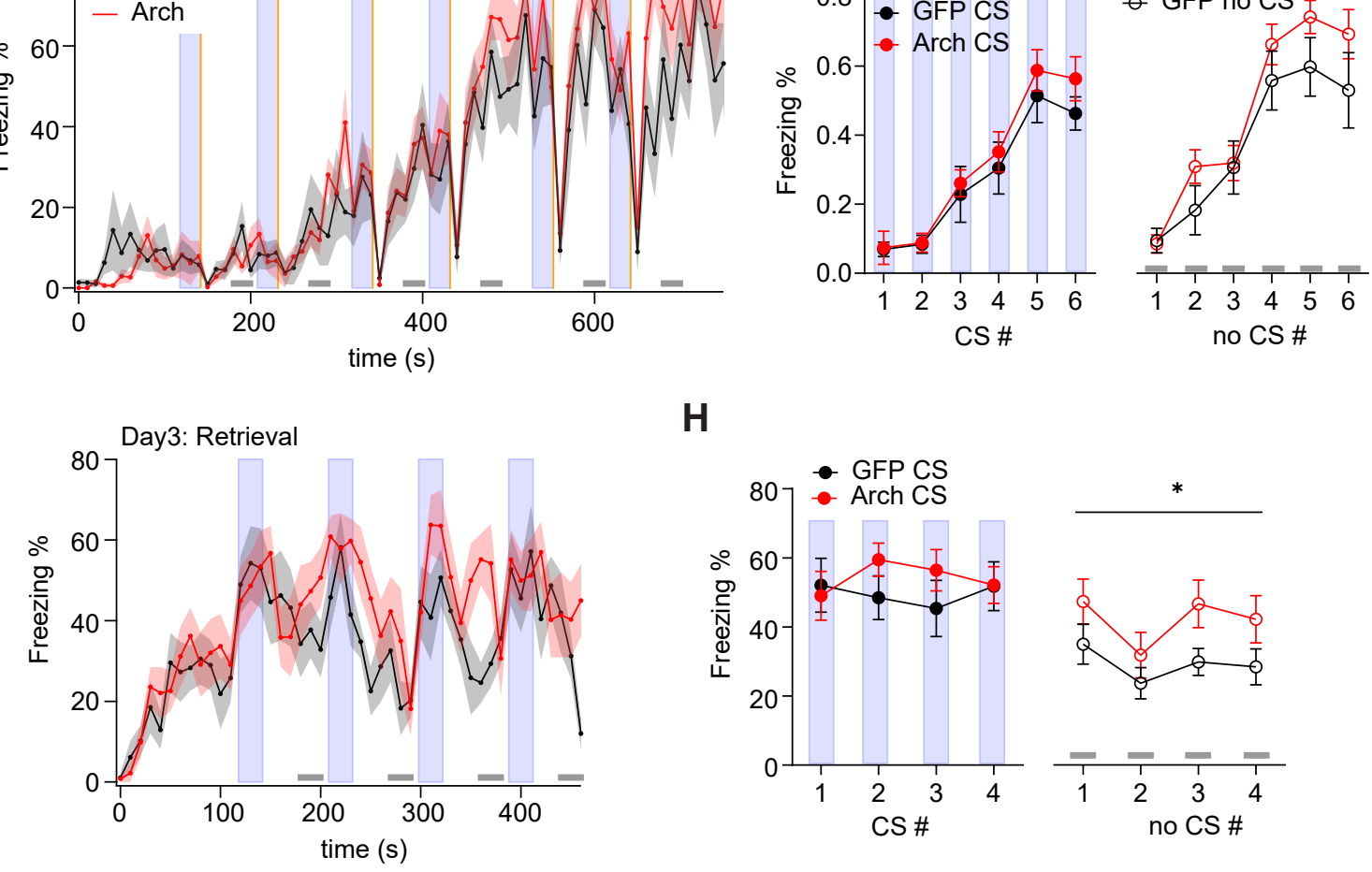

H

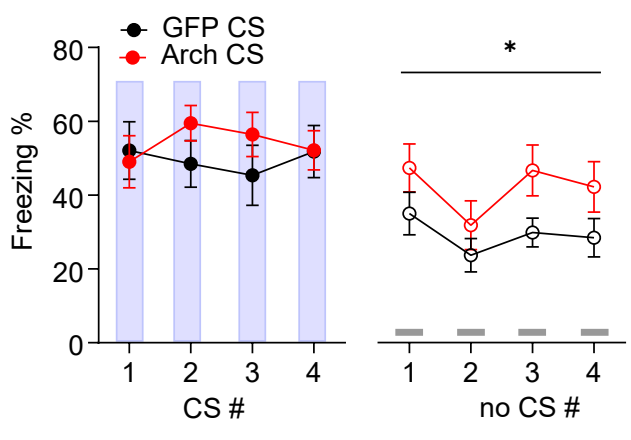


A

AAV8:hSyn:FLEX:TVA-2a-oG + AAV8:hSyn:FLEX:H2B-GFP-2a-oG

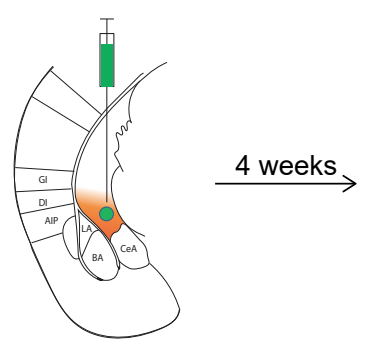

injection site : ventral tail striatum

C

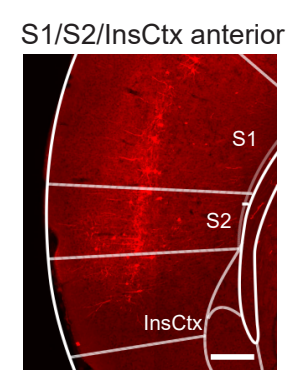

Bregma $0.98 \mathrm{~mm}$
D1R ${ }^{\text {Cre }}$

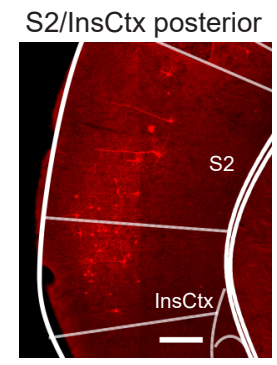

Bregma $-0.58 \mathrm{~mm}$
EnvA:deltaG-RV-dsRed

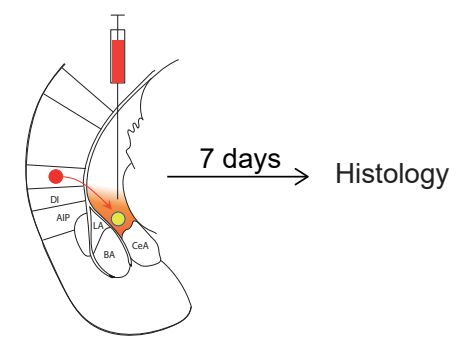

D
B

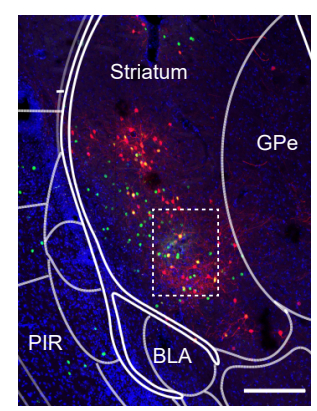

Bregma $-0.70 \mathrm{~mm}$

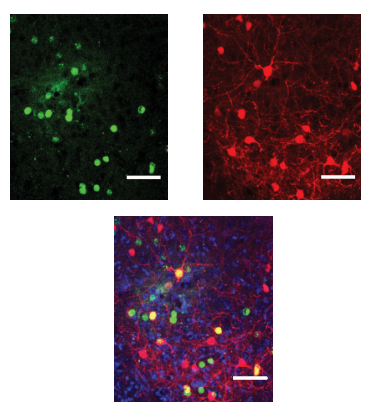

AdoraCre

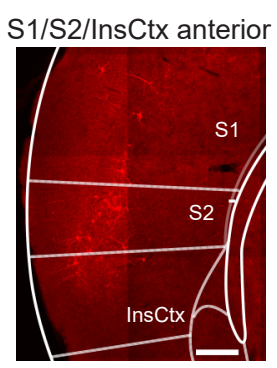

Bregma 0.98 mm

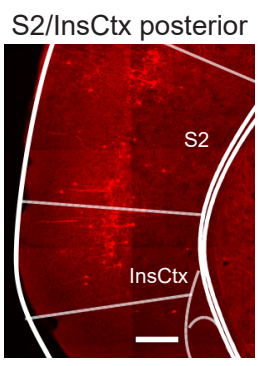

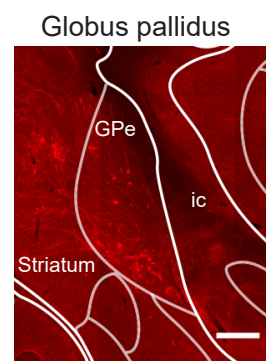

Bregma -1.06 mm

E

coronal

sagittal

horizontal
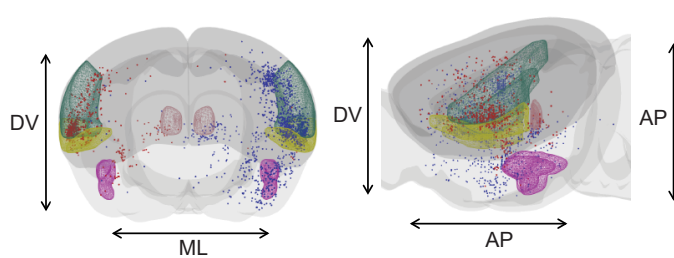

$\mathbf{G}$

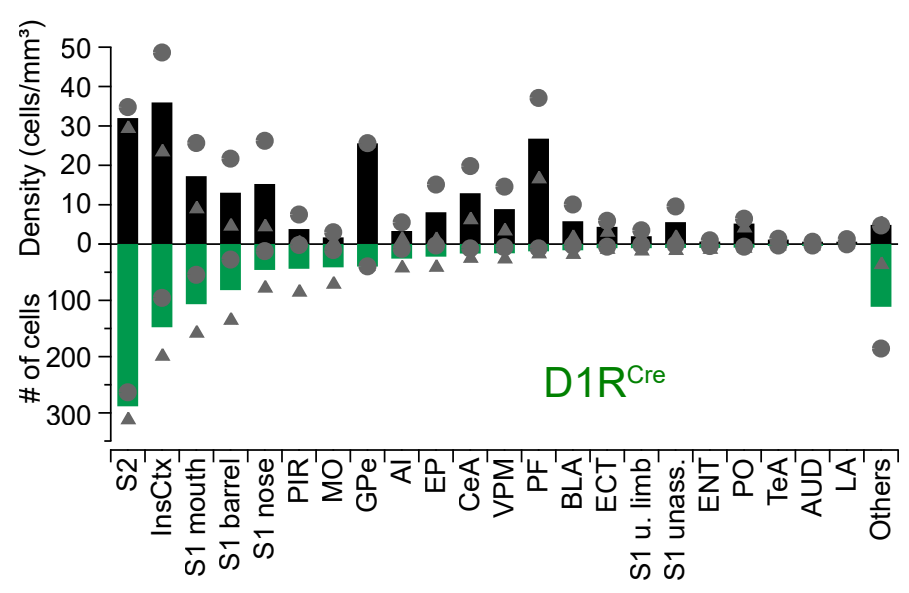

I

Insula

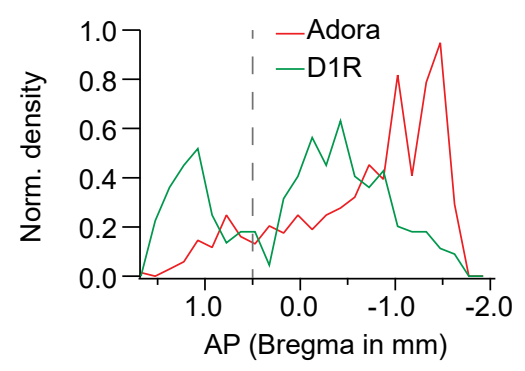

F

Bregma $-0.58 \mathrm{~mm}$

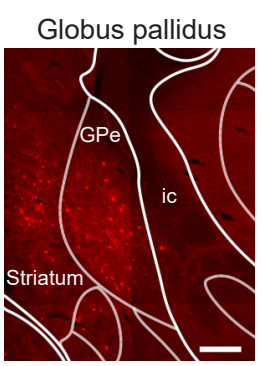

Bregma -1.06 mm coronal

sagittal

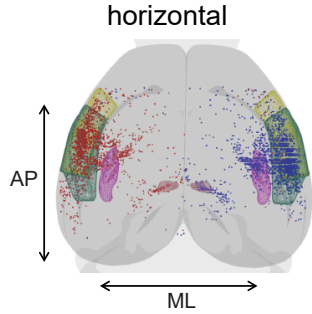

H

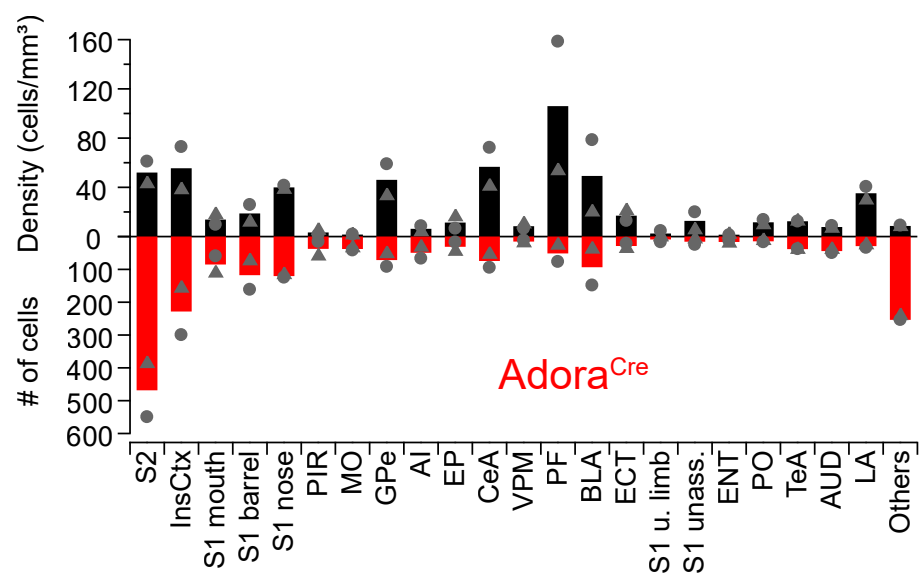

J

S2

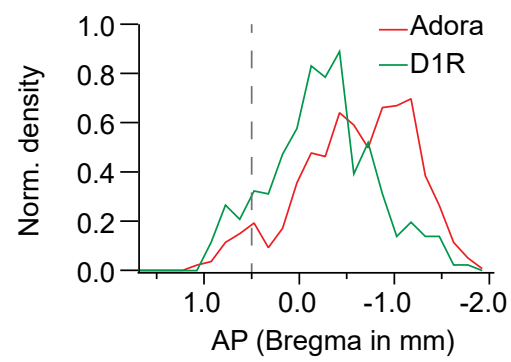


bioRxiv preprint doi: https://doi.org/10.1101/2021.12.09.471922; this version posted December 9, 2021. The copyright holder for this

preprint (which was not certified by peer review) is the author/funder, who has granted bioRxiv a license to display the preprint in perpetuity. It is made available under aCC-BY-NC-ND 4.0 International license.

A

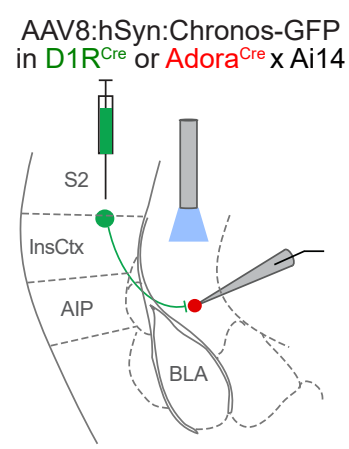

C

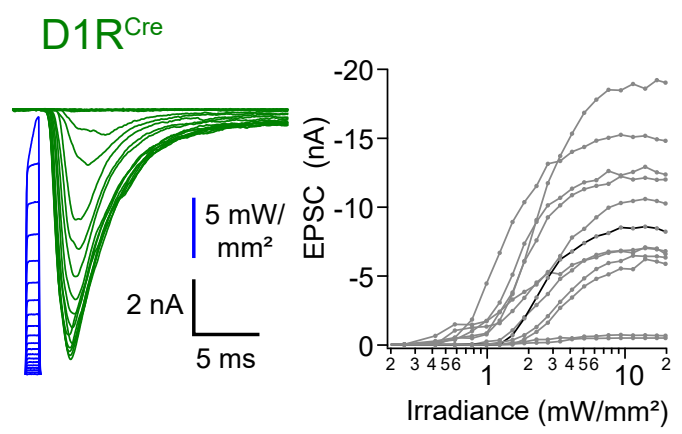

B
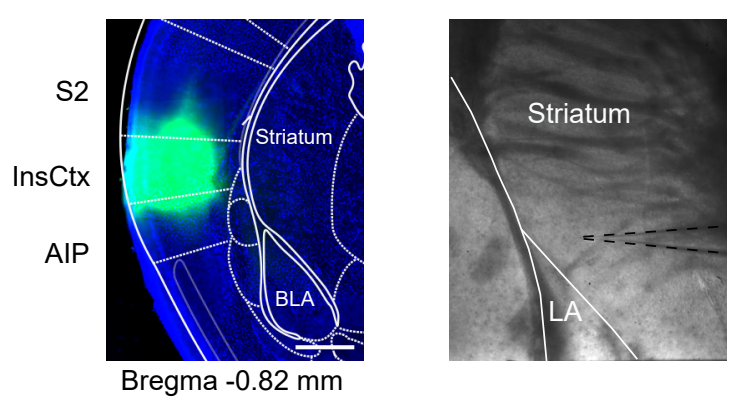

D

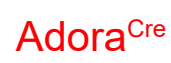

$\mathbf{F}$
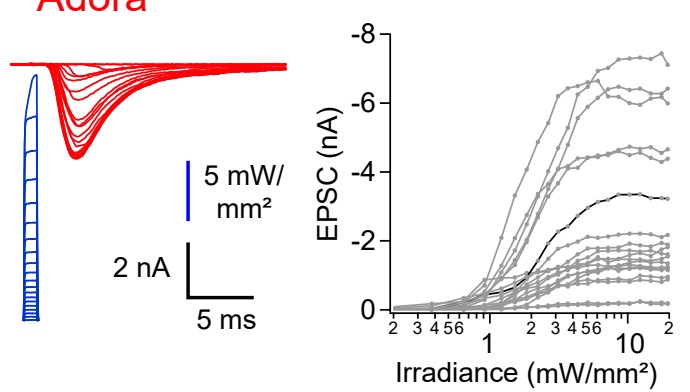

E

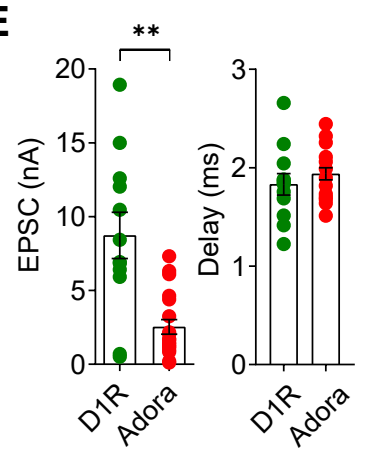

G $\quad D 1 R^{\mathrm{Cre}} \times \mathrm{Ai} 14$

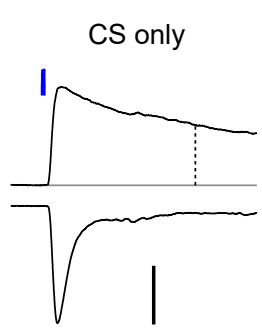

CS + US pairing

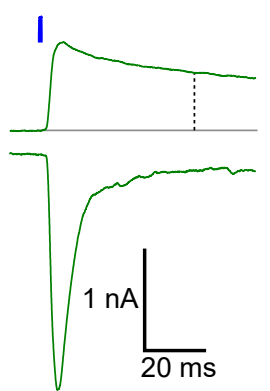

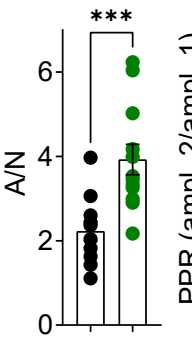

$a_{4} v_{2}$
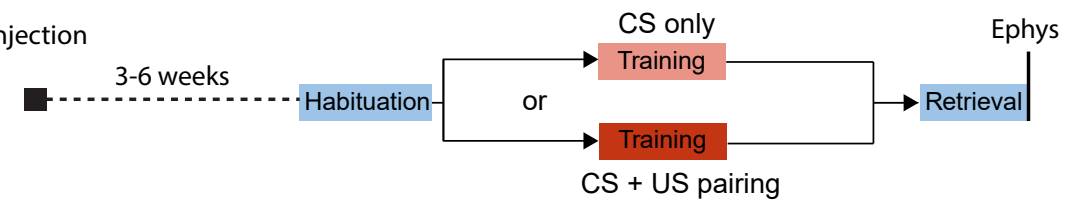

H $\quad$ AdoraCre $\times$ Ai 14

\section{CS only CS + US pairing}

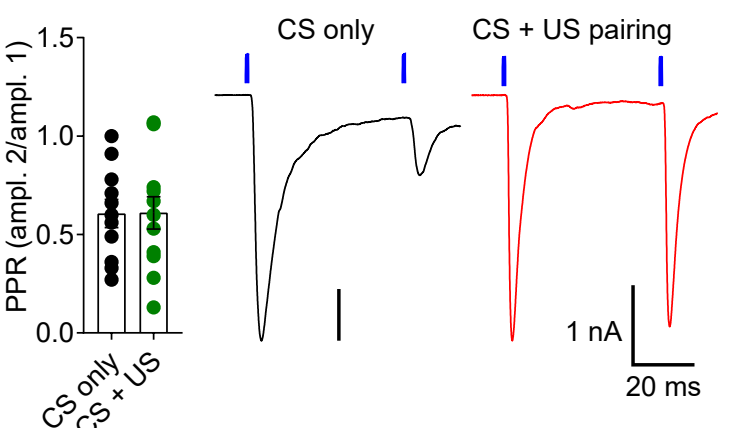

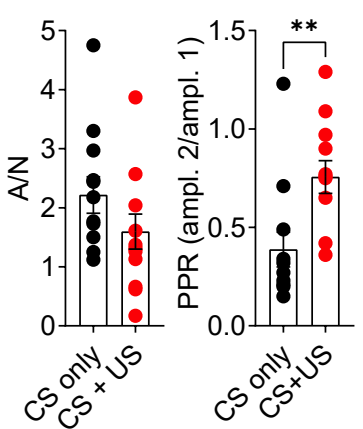


bioRxiv preprint doi: https://doi.org/10.1101/2021.12.09.471922; this version posted December $9,2021$. The copyright holder for this

preprint (which was not certified by peer review) is the author/funder, who has granted bioRxiv a license to display the preprint in perpetuity. It is made available under aCC-BY-NC-ND 4.0 International license.

A

Habituation (Day 1)

Training (Day 2)

Retrieval (Day 3)
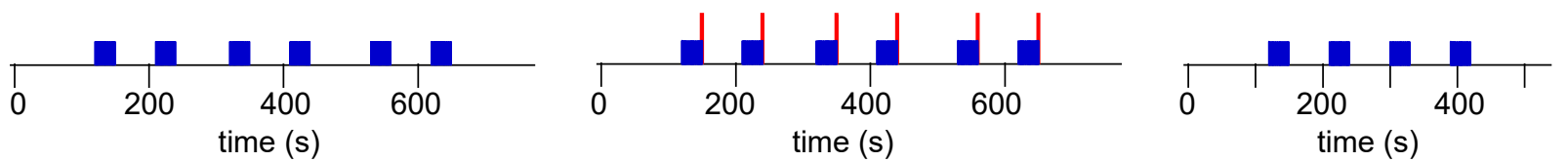

Tone block

Footshock

Figure 1, Figure suppl. 1

A no CS

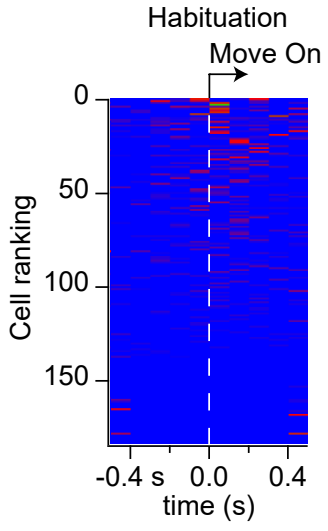

A During CS

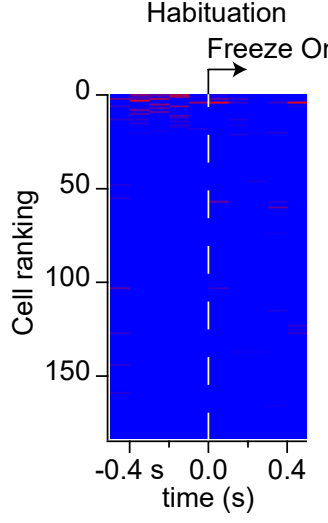

A no CS

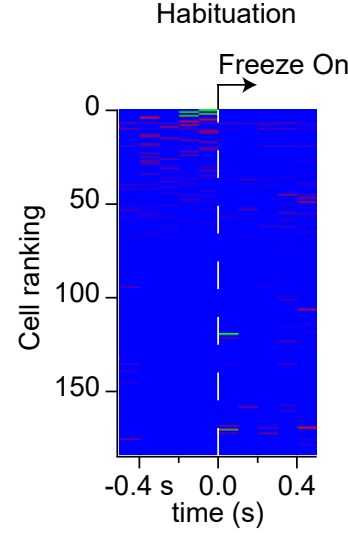

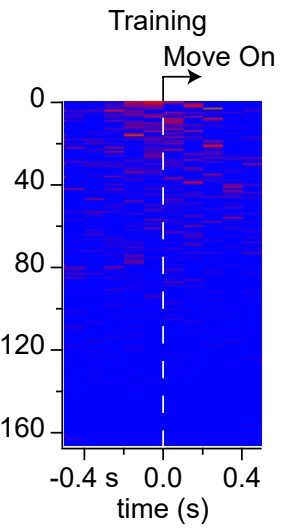

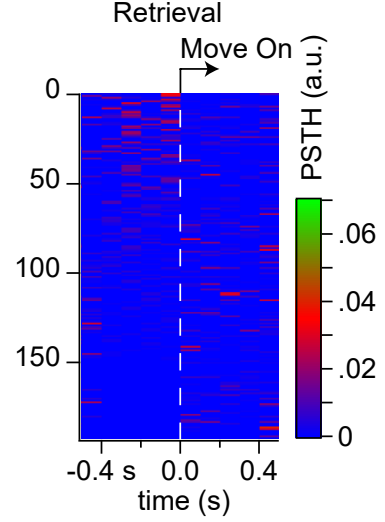

B
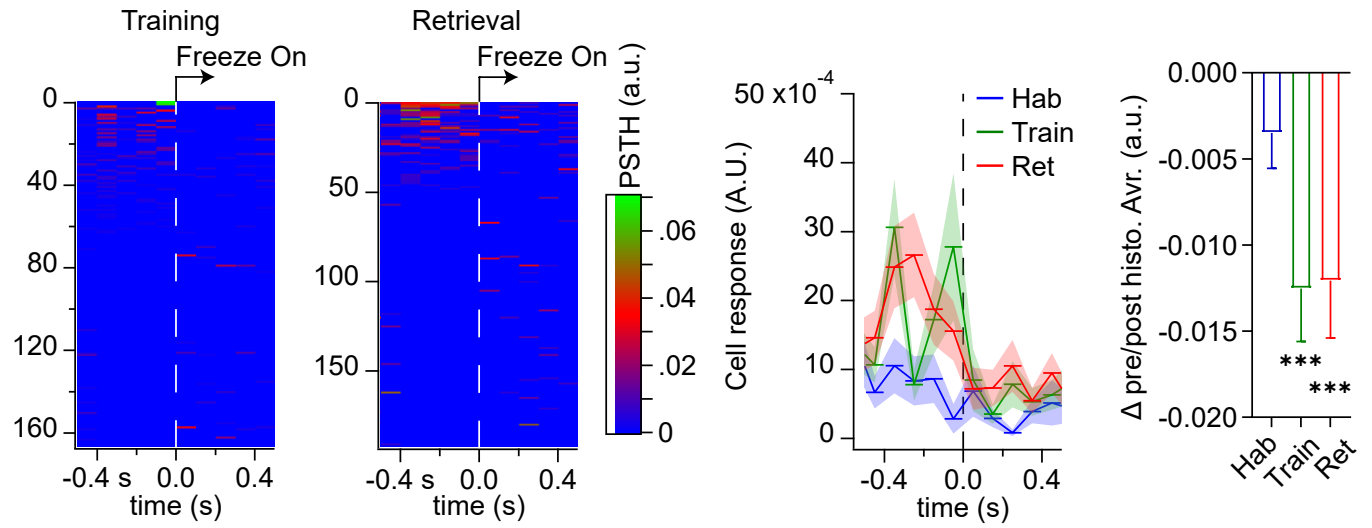

Figure 1, Figure suppl. 3

B

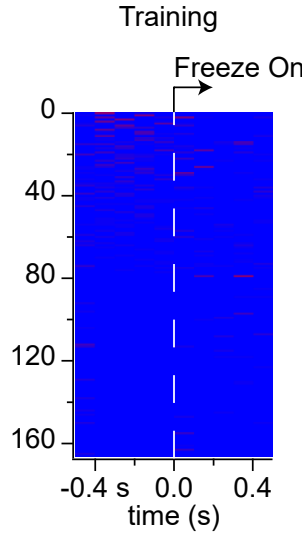

Retrieval
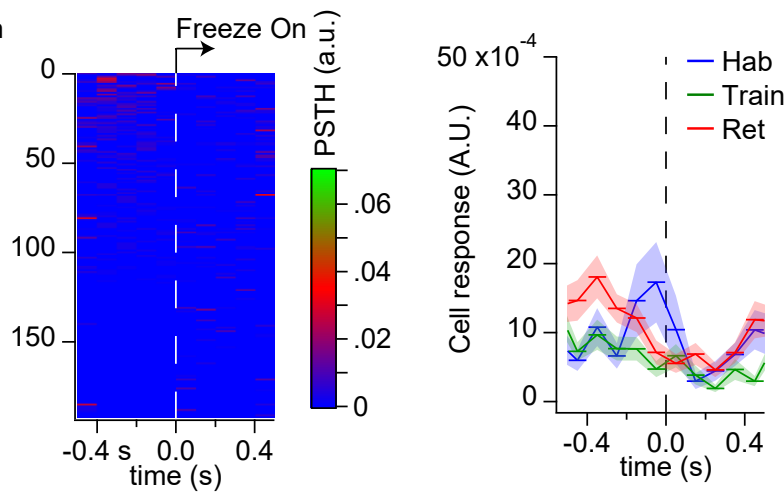

Figure 1, Figure suppl. 4 
bioRxiv preprint doi: https://doi.org/10.1101/2021.12.09.471922; this version posted December 9, 2021. The copyright holder for this

preprint (which was not certified by peer review) is the author/funder, who has granted bioRxiv a license to display the preprint in perpetuity. It is made available under aCC-BY-NC-ND 4.0 International license.

A
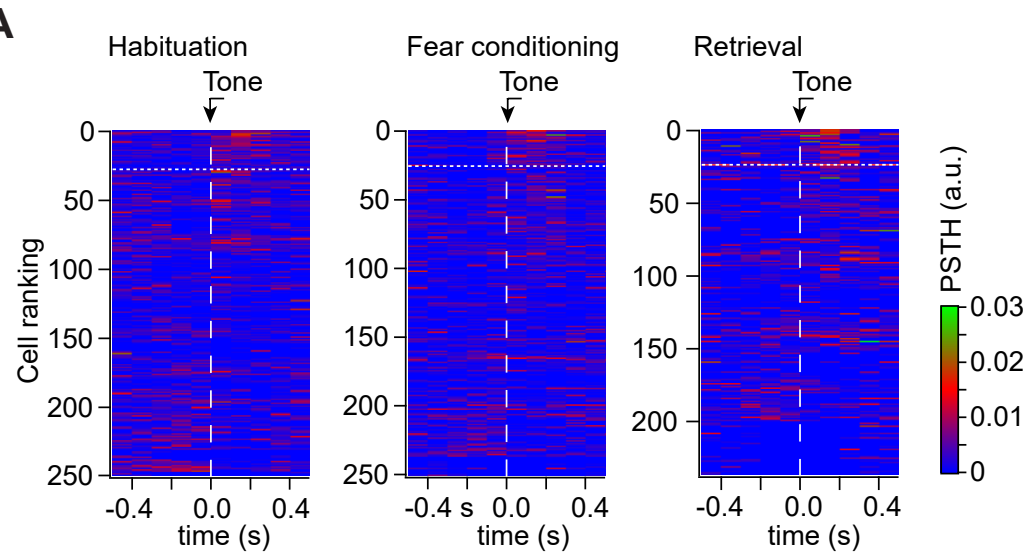

Figure 3, Figure suppl. 1

\section{A During CS}
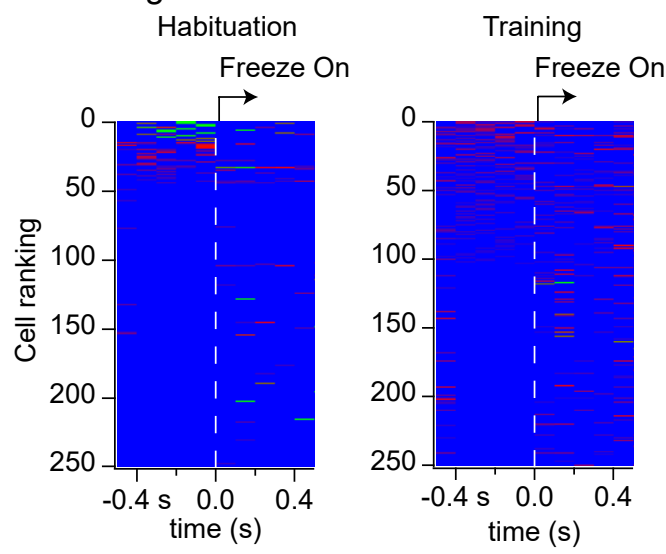

B

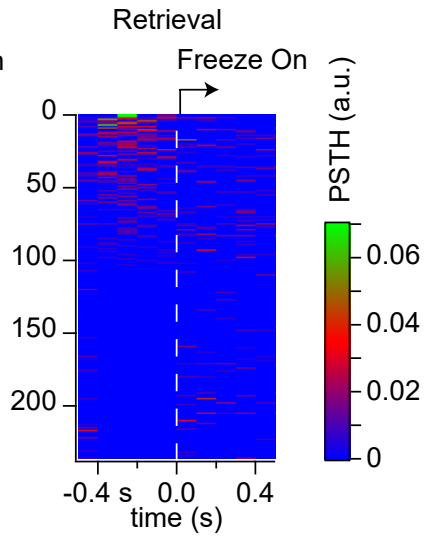

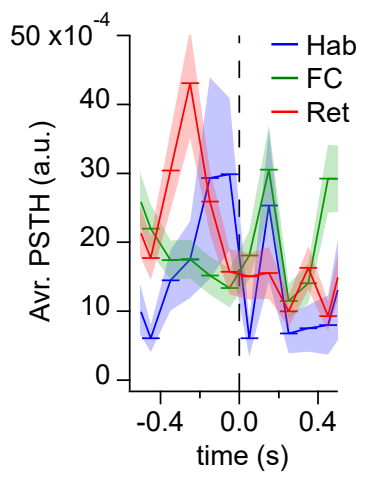

C

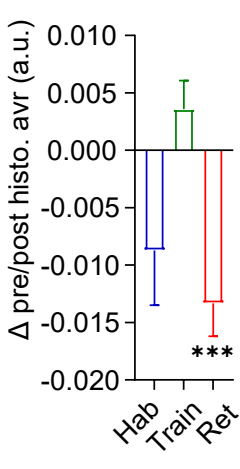

Figure 3, Figure suppl. 2 
A

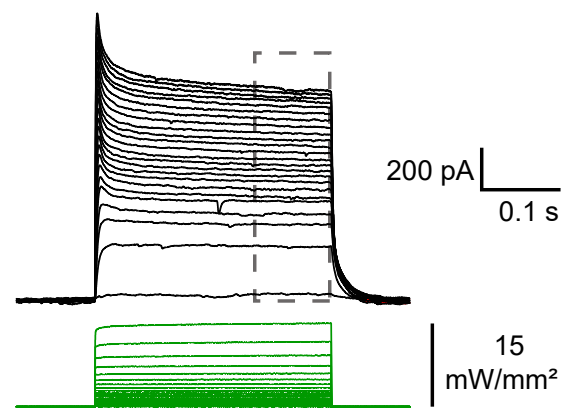

D

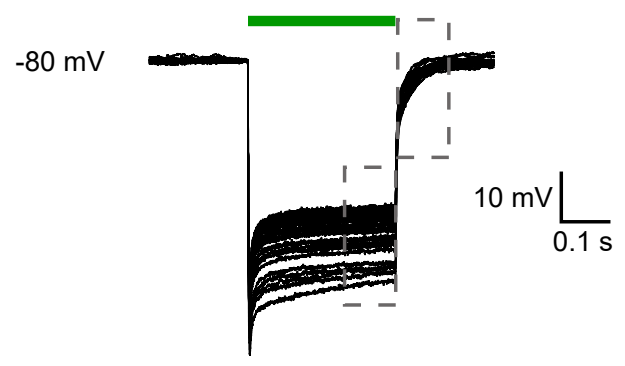

B

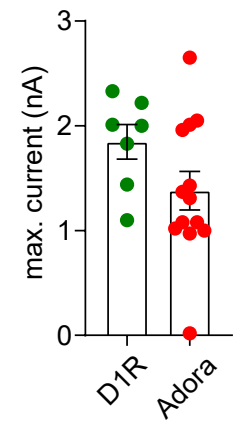

E

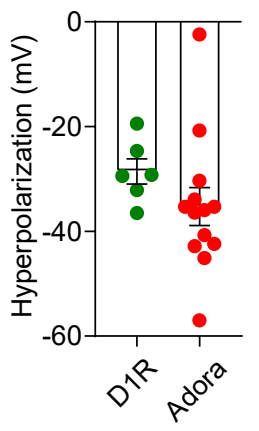

C

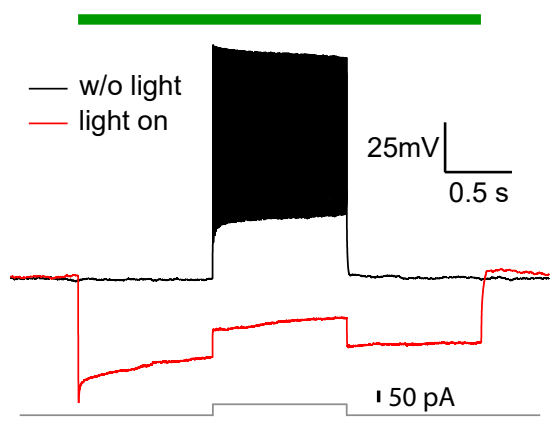

F

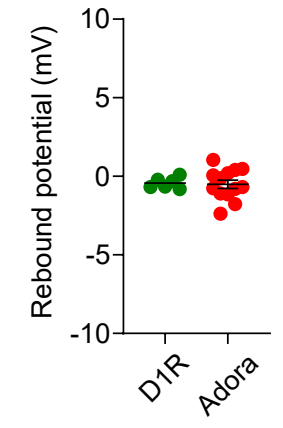

Figure 5, Figure suppl. 1 
bioRxiv preprint doi: https://doi.org/10.1101/2021.12.09.471922; this version posted December 9, 2021. The copyright holder for this

preprint (which was not certified by peer review) is the author/funder, who has granted bioRxiv a license to display the preprint in perpetuity. It is made available under aCC-BY-NC-ND 4.0 International license.

A

D1R $\mathrm{Rre}$

BLA

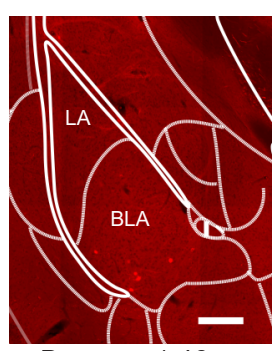

Bregma -1.46mm
PF

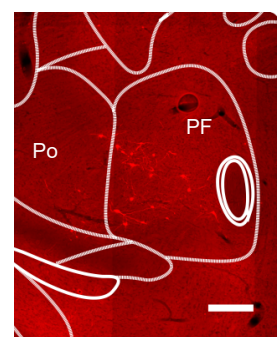

Bregma -2.30
B
Adora ${ }^{\text {Cre }}$

BLA

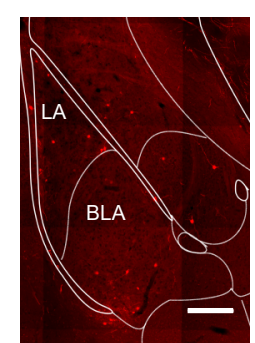

Bregma -1.58
PF

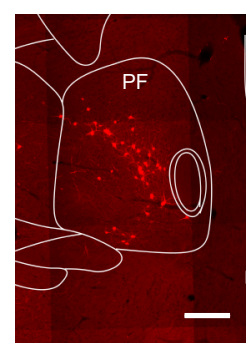

Bregma -2.30

Figure 7, Figure suppl. 1

A

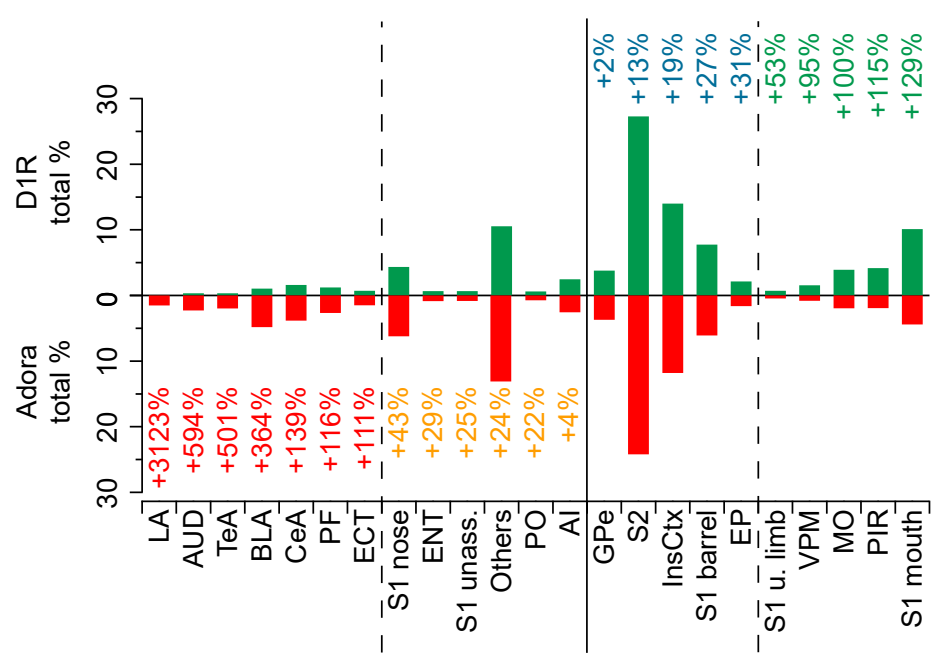

Figure 7, Figure suppl. 2 
A

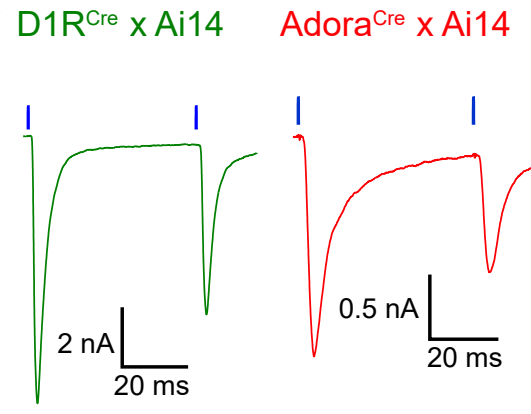

B

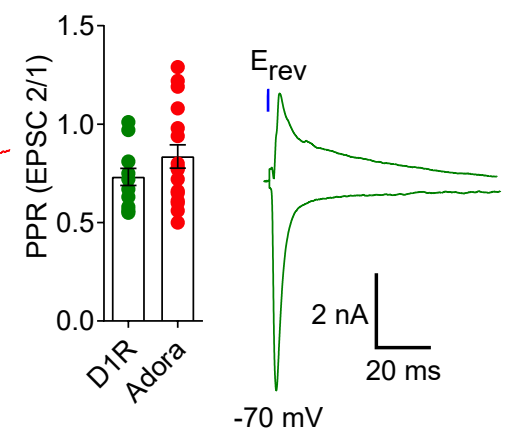

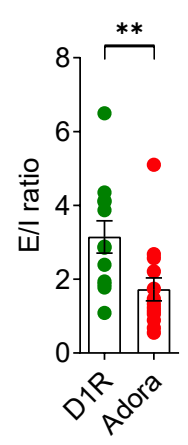

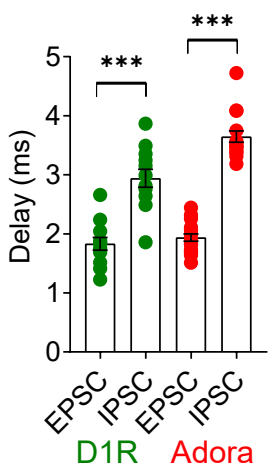

Figure 8, Figure Suppl. 1

A

D1R ${ }^{\text {Cre }} \times$ Ai14

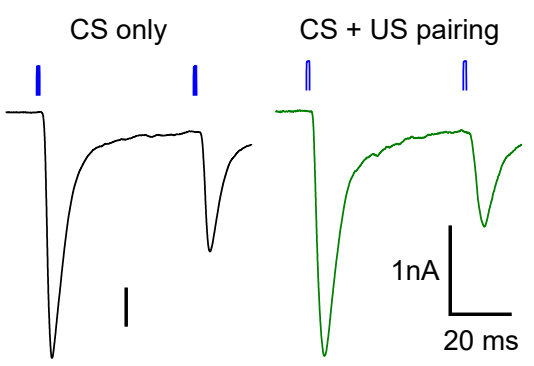

Figure 8, Figure Suppl. 2
A

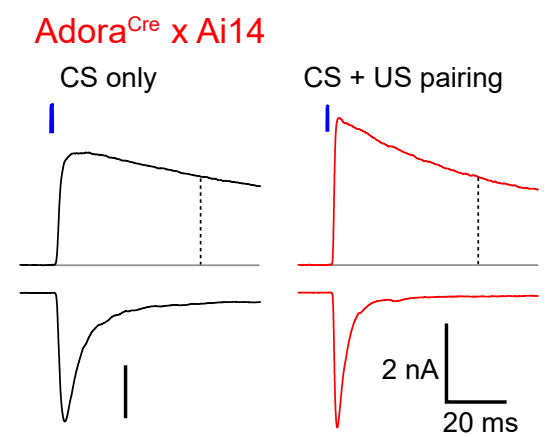

A

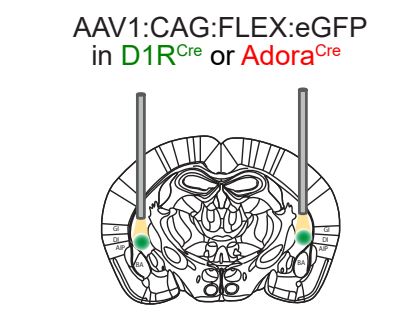

injection site : ventral tail striatum
B

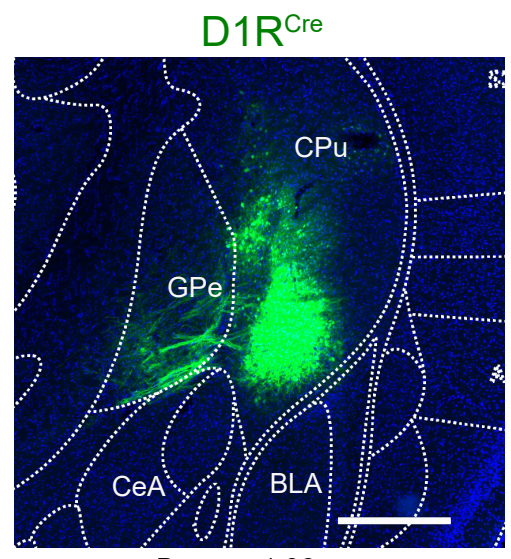

Bregma $1.06 \mathrm{~mm}$

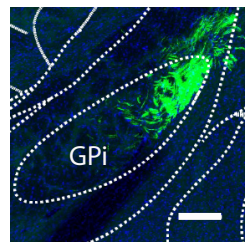

Bregma $-1.22 \mathrm{~mm}$

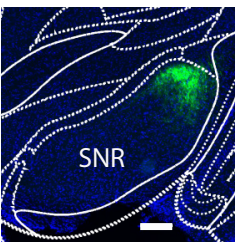

Bregma $-3.08 \mathrm{~mm}$
Figure 8, Figure Suppl. 3
C
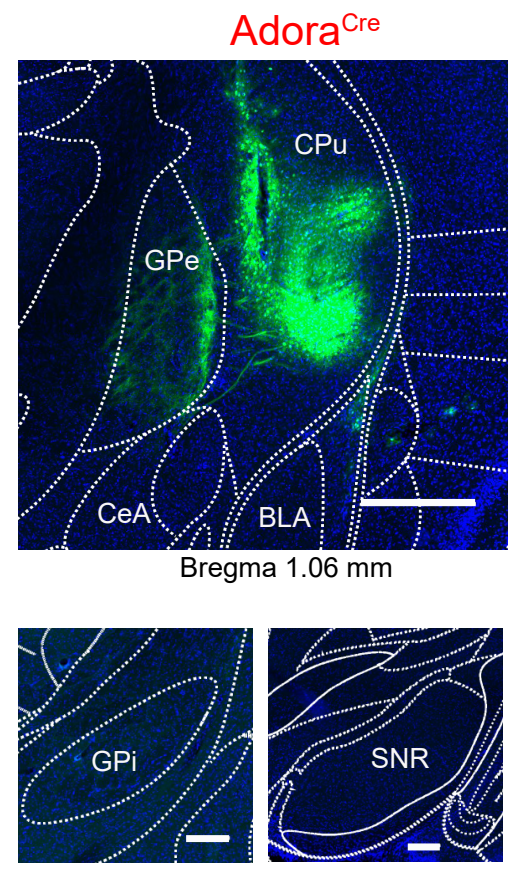

Bregma $-1.22 \mathrm{~mm}$ Bregma $-3.08 \mathrm{~mm}$ 
bioRxiv preprint doi: https://doi.org/10.1101/2021.12.09.471922; this version posted December $9,2021$. The copyright holder for this preprint (which was not certified by peer review) is the author/funder, who has granted bioRxiv a license to display the preprint in perpetuity. It is made available under aCC-BY-NC-ND 4.0 International license.

Figure 7, Suppl.Table 1

\begin{tabular}{|c|c|c|}
\hline Abbreviation & Allen Brain atlas & Franklin and Paxinos \\
\hline $\mathrm{Al}$ & Agranular insular area & $\begin{array}{l}\text { Agranular insular cortex (dorsal, ventral and } \\
\text { posterior) }\end{array}$ \\
\hline AUD & Auditory areas (dorsal and ventral) & Auditory cortex (dorsal, primary and ventral) \\
\hline BLA & $\begin{array}{l}\text { Basolateral amygdalar nucleus } \\
\text { (anterior, posterior and ventral) }\end{array}$ & $\begin{array}{l}\text { Basolateral amygdaloid nucleus (anterior, } \\
\text { posterior) }\end{array}$ \\
\hline $\mathrm{CeA}$ & $\begin{array}{l}\text { Central amygdalar nucleus } \\
\text { (capsular, medial and lateral) }\end{array}$ & $\begin{array}{l}\text { Central amygdaloid nucleus (capsular, } \\
\text { medial and lateral) }\end{array}$ \\
\hline Ect & Ectorhinal area & Ectorhinal cortex \\
\hline ENT & Entorhinal area & Entorhinal cortex \\
\hline EP & Endopiriform nucleus & Claustrum (dorsal, ventral and endopiriform) \\
\hline GPe & Globus pallidus, external segment & Globus pallidus \\
\hline GPi & Globus pallidus, internal segment & Entopenduncular nucleus \\
\hline InsCtx & Gustatory areas and Visceral area & Insular cortex (granular and dysgranular) \\
\hline LA & Lateral amygdalar nucleus & Lateral amygdaloid nucleus \\
\hline MO & Primary motor area & Primary motor cortex \\
\hline PF & Parafascicular nucleus & Parafascicular thalamic nucleus \\
\hline PIR & Piriform area & Piriform cortex \\
\hline $\mathrm{PO}$ & Posterior complex of the thalamus & Posterior thalamic nuclear group \\
\hline S1 barrel & $\begin{array}{l}\text { Primary somatosensory area, barrel } \\
\text { field }\end{array}$ & Primary somatosensory cortex, barrel field \\
\hline S1 mouth & $\begin{array}{l}\text { Primary somatosensory area, } \\
\text { mouth }\end{array}$ & $\begin{array}{l}\text { Primary somatosensory cortex, upper } \\
\text { lip/barrel field }\end{array}$ \\
\hline S1 nose & Primary somatosensory area, nose & Primary somatosensory cortex, upper lip \\
\hline S1 unassigned & $\begin{array}{l}\text { Primary somatosensory area, } \\
\text { unassigned }\end{array}$ & $\begin{array}{l}\text { Primary somatosensory cortex, dysgranular } \\
\text { zone }\end{array}$ \\
\hline S1 upper limb & $\begin{array}{l}\text { Primary somatosensory area, upper } \\
\text { limb }\end{array}$ & $\begin{array}{l}\text { Primary somatosensory cortex, shoulder } \\
\text { region }\end{array}$ \\
\hline S2 & Supplemental somatosensory area & Secondary somatosensory cortex \\
\hline SNR & Substantia nigra, reticular part & Substantia nigra, reticular part \\
\hline TeA & Temporal association areas & Temporal association cortex \\
\hline VPM & $\begin{array}{l}\text { Ventral posteromedial nucleus of } \\
\text { the thalamus }\end{array}$ & Ventral posteromedial thalamic nucleus \\
\hline
\end{tabular}

